\title{
Engender Persistent Organic Room-Temperature Phosphorescence by Trace Ingredient Incorporation
}

Bingbing Ding, Liangwei Ma, Zizhao Huang, Xiang Ma* and He Tian

Key Laboratory for Advanced Materials and Feringa Nobel Prize Scientist Joint Research Center, Frontiers Science Center for Materiobiology and Dynamic Chemistry, School of Chemistry and Molecular Engineering, East China University of Science and Technology, Shanghai 200237, P. R. China.

*Correspondence to: maxiang@ecust.edu.cn

\begin{abstract}
Pure organic persistent room-temperature phosphorescence (RTP) has shown great potential in information encryption, optoelectronic devices, and bio-applications. However, trace impurities would be generated in synthesis, causing unpredictable effects on the luminescence properties. Herein, a magical impurity is isolated from a pure organic RTP system and structural characterized, which could light up the unusual ultralong RTP in matrix even at $0.01 \mathrm{~mol} \%$ content. Inspired by this effect, a series of compounds are screened out to form the bicomponent RTP system by the trace-ingredient-incorporation method. The RTP quantum yields reach as high as $74.2 \%$, and the lifetimes reach up to $430 \mathrm{~ms}$. Flexible application of trace ingredients to construct RTP materials has become an eye-catching strategy with high efficiency, economy, easy preparation and application potentials.
\end{abstract}

\section{Introduction}

With unique luminescent properties and low cost, pure organic room-temperature phosphorescence (RTP) materials have received broad attention (1-4). In the last century, researchers believed that it was difficult to use pure organic materials to emit phosphorescence at room temperature due to the difficulty of intersystem crossing (ISC) between singlet and triplet, and fast non-radiative transition (5). Recently, pure organic RTP with long lifetime and high efficiency have been realized by several methods, such as crystal or co-crystal packing (69), polymer and host-guest supramolecular system (10-13), and bimolecular charge separation state (14). However, it is still an urgent need for more convenient strategies to construct RTP as 
well as a reliable mechanism for afterglow luminescence.

There are reports on the existence of impurities and its impact on some organic RTP system $(15,16)$, though the chemical structure and impact mechanism of impurities were not specified due to the difficulties in separation, purification, and structuring characterization. Literature shows that Liu and colleagues have recently reported the ultralong RTP of a series of carbazole derivative caused by $1 H$-benzo[f]indole, an isomer of carbazole, participating in the synthesis process (17). Due to the low content of $1 H$-benzo[f]indole in carbazole, its existence has been overlooked in previous reports $(18,19)$. Since trace impurities may impact the luminescence of materials, organic compounds always need to be carefully purified, despite that few reports focused on impurity research in the RTP system.

In this research, an unusual yellow-green persistent luminescence of 1-(4-bromophenyl)-1Himidazole (1BBI) powder was observed at room temperature. A trace impurity was observed to play important roles in generating RTP. Importantly, the impurity was then successfully isolated and identified to be 6-(1H-imidazol-1-yl)- $N, N$-dimethyl isoquinolin-1-amine (DMIQI). Further studies demonstrated the great influence of trace impurities on RTP emission. The existence of impurities and their impacts on RTP inspired us with a novel strategy to design a pure organic trace-ingredient-mediated bicomponent RTP system. A series of artificially added active ingredients were screened out, working as impurities to engender pure organic RTP. The matrix 1BBI was also extended to a halogen-free imidazole derivative. Bicomponent RTP systems achieved an extra high quantum yield (QY) up to 74.2\% and their lifetimes varied from 2 to $430 \mathrm{~ms}$. Considering the low content of ingredient $(<0.1 \%)$ achieving bright RTP, the traceingredient-mediated bicomponent systems could work as an efficient, economical and convenient strategy in realizing pure organic RTP of high QY and extra-long lifetime. Additionally, the achieved white-light emission showed its excellent application potentials as well.

\section{Impurity in room-temperature phosphorescence organism}

The compound 1BBI was synthesized through the substitution reaction of imidazole and 4bromofluorobenzene followed by purification by flash column chromatography on silica gel. A bright yellow-green afterglow luminescence was observed lasting for more than two seconds. With one more flash column chromatography purification and re-crystallization from methanol 
for several times, the afterglow still existed. However, the emission intensity decreased with more purification, while the emission wavelength and lifetime kept unchanged (Fig. 1, A and B). Finally, 1BBI was purified to almost no photoluminescence after flash column chromatography for twice on silica gel and one time reversed-phase chromatography on $\mathrm{C}_{18-}$ bonded silica gel (Fig. 1D, Movie S1). These facts indicated that the RTP in 1BBI was caused by the impurities.
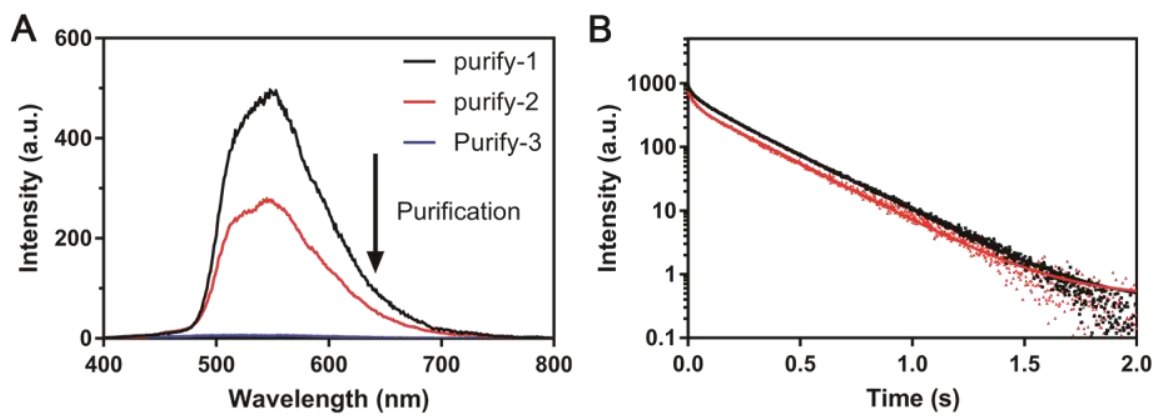

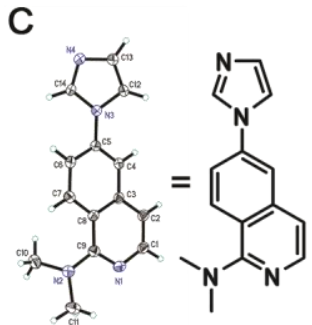

DMIQI

E

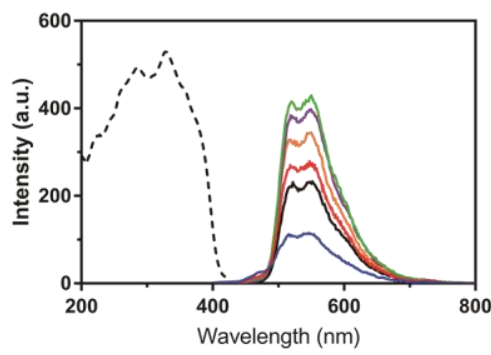

D

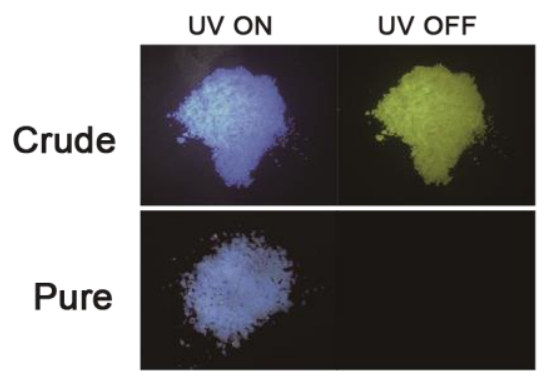

$1 \mathrm{BBI}$

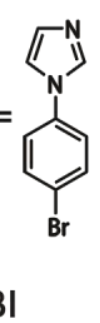

$\mathrm{F}$

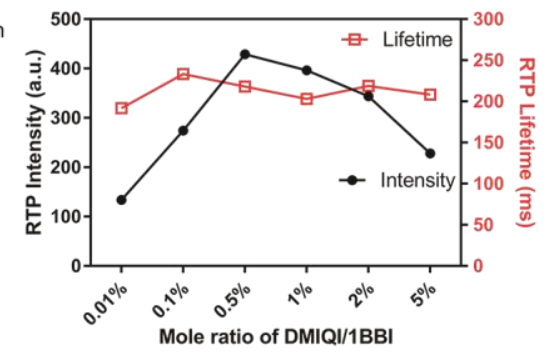

Fig. 1. Phenomena of impurity induced RTP. (A) RTP spectra of 1BBI with different purification. Excitation: $365 \mathrm{~nm}$; Slit width: $10 \mathrm{~nm}$; Voltage: $700 \mathrm{~V}$. (B) RTP decay curve of 1BBI with different purification. (C) Structure of DMIQI and 1BBI identified by single-crystal X-ray diffraction. (D) The different luminescent performance between crude and extra-pure 1BBI under $365 \mathrm{~nm}$ irradiation. (E) RTP spectra of 1BBI mixed with various contents of DMIQI. Excitation: $365 \mathrm{~nm}$; Slit width: $10 \mathrm{~nm}$; Voltage: $650 \mathrm{~V}$. (F) Changes of phosphorescence intensity (value at $550 \mathrm{~nm}$ ) and lifetime with different molar ratios. 
The abnormal RTP could be elucidated only after the structure of the impurity is resolved. About $70 \mathrm{mg}$ impurity was successfully isolated from more than $200 \mathrm{~g}$ crude 1BBI products. The Nuclear Magnetic Resonance (NMR) spectra $\left({ }^{1} \mathrm{H},{ }^{13} \mathrm{C},{ }^{1} \mathrm{H}-{ }^{1} \mathrm{H}\right.$ COSY, HMBC, and HMQC) and High-Resolution Mass (HRMS) spectra helped to infer the structure to be 6-(1H-imidazol1-yl)- $N, N$-dimethyl isoquinolin-1-amine (DMIQI). To confirm that structure, DMIQI was synthesized by a different route starting from 6-bromoisoquinolin-1(2H)-one (Scheme S4). The NMR and HRMS spectra of synthetic DMIQI agreed with that of isolated DMIQI. The structure of DMIQI was further determined by single crystal X-ray diffraction and structure analysis (Fig. 1C). To explore the origin of the impurity DMIQI, imidazole, 4-bromofluorobenzene and 1BBI was placed respectively in the same reaction condition (with $\mathrm{NaH}$ in DMF while heating). The result showed that no DMIQI was produced, indicating that the impurity was not from the decomposition of reagents or products. It was then found that the synthesis of 1BBI using the sublimated purified imidazole could avoid the impurity DMIQI, while the purification of 4bromofluorobenzene or DMF by vacuum distillation did not affect the harvest of DMIQI. Additionally, an intermediate, 4-(1H-imidazol-1-yl)- $N, N$-dimethylbenzamide, was successfully identified through HPLC-HRMS (Fig. S2). In view of this, we proposed that impurities like aminoacetaldehyde in imidazole reacted with the intermediate to produce the new impurity DMIQI (Fig. S1).

To demonstrate the influence of trace impurities on RTP emission, a bicomponent RTP system of DMIQI/1BBI mixture was constructed by the solvent evaporation method. Different proportions (0.01-5 mol\%) of DMIQI in 1BBI were completely dissolved in methanol. Then the solvent was evaporated under reduced pressure to result in a white crystalline solid. The time-resolved luminescence spectra showed a double-peak emission at $520 \mathrm{~nm}$ and $550 \mathrm{~nm}$ (Fig. 1E). With the increase of impurity ratio, the RTP intensity first increased to the highest at $0.5 \mathrm{~mol} \%$ and then decreased (Fig. 1F). While the RTP lifetime kept almost unchanged. Remarkably, RTP intensity remained about $30 \%$ of the highest even the proportion dropped to $0.01 \mathrm{~mol} \%$. Extra low level of impurity may also lead to high RTP benefits. All the luminescence decay curves followed the exponential decay. The calculated lifetime of all proportions was $212 \pm 14 \mathrm{~ms}$ (Fig. S26). The pure DMIQI showed a maximum fluorescence emission at $427 \mathrm{~nm}$ and undetectable phosphorescence at room temperature. This means the unusual phosphorescence was generated through the interaction of impurities and matrixes. 


\section{Design of trace-ingredient-mediated bicomponent RTP system}

The impurity DMIQI was found by coincidence, but the case of RTP caused by impurities was not uncommon. The 1BBI also showed a strong RTP signal even synthesized by a completely different route from 4-bromoaniline. The emission spectra and lifetime differed from that of DMIQI/1BBI system (Fig. S3). It seemed a feasible strategy to engender effective pure organic RTP through the interaction of trace ingredients and matrixes.

It was time-consuming and inefficient to separate and identify impurities from synthetic matrix. As an alternative, it was more efficient to find active ingredients to substitute for the impurities to light up RTP in matrix. A total number of six active ingredients (Fig. 2A) were screened out to engender RTP after adding 1BBI. The isomers of matrix were first tested. The 2-(4-bromophenyl)-1H-imidazole (2BBI) and 4-(4-bromophenyl)-1H-imidazole (4BBI) showed bright cyan RTP under $254 \mathrm{~nm}$ irradiation when mixed with 1BBI. The RTP quantum yield of $4 \mathrm{BBI} / 1 \mathrm{BBI}$ reached as high as $74.2 \%$ without deaeration. Another type of active ingredient was $N$-substituted aminobenzaldehyde derivatives, 4-(dimethylamino)benzaldehyde (DMBA), 4-(pyrrolidin-1-yl)benzaldehyde (PBA), and 9-julolidine carboxaldehyde (JCA). Being added to 1BBI, they could also show obvious cyan RTP peak at $465 \mathrm{~nm}, 480 \mathrm{~nm}$ and 495 $\mathrm{nm}$ under excitation at $365 \mathrm{~nm}$, respectively. Surprisingly, the emission could last for more than a second after removing the irradiation light (Fig. 2C). The measured lifetimes were $122 \mathrm{ms,}$ $113 \mathrm{~ms}$ and $143 \mathrm{~ms}$, respectively (Fig. 2B). An analogue of DMIQI, 2-(1H-imidazol-1-yl)- $N, N$ dimethyl quinolin-6-amine (DMQI) was also synthesized to achieve the longest RTP lifetime ( $\tau=262 \mathrm{~ms}$ ) of our designed trace-ingredient-mediated bicomponent RTP systems, and the RTP emission could reach the yellow region (peak at $560 \mathrm{~nm}$ ). In general, seven compounds were able to engender RTP in 1BBI matrix. The maximum RTP wavelength ranged from $465 \mathrm{~nm}$ to $560 \mathrm{~nm}$ with lifetime ranging from $6.8 \mathrm{~ms}$ to $263 \mathrm{~ms}$. None of these purified ingredients or matrix showed any detectable phosphorescence at room temperature, and their fluorescence has significant differences in terms of wavelength and intensity (Fig. S4 to S12). 


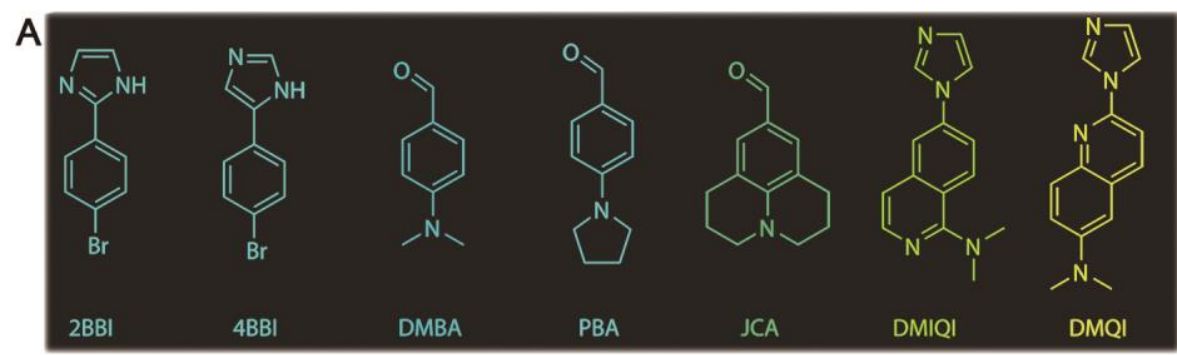

B

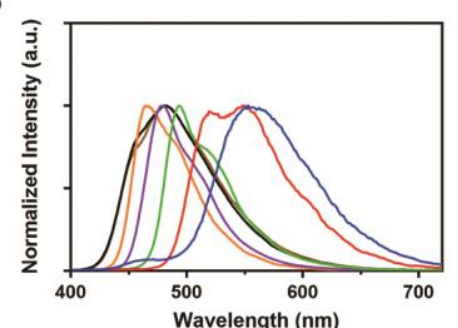

- 2BBI/1BBI - DMBA/1BBI - DMIQI/1BBI

- 4BBI/1BBI - JCA/1BBI - DMQI/1BBI - PBA/1BB

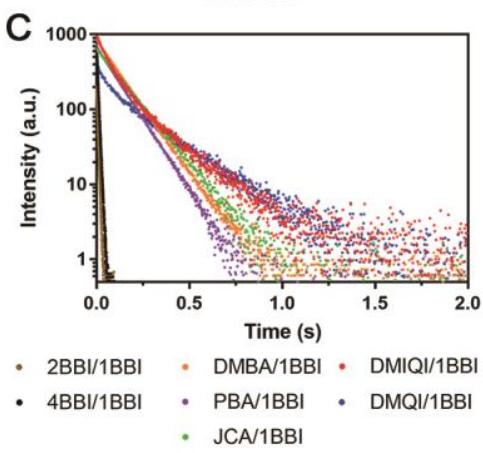

D

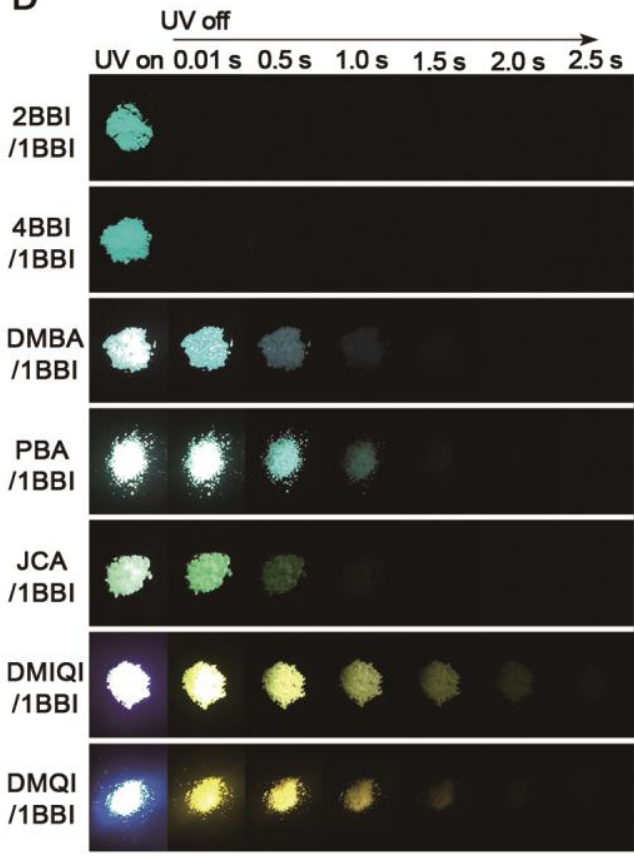

Fig. 2. Optical characteristics of trace-ingredient-mediated bicomponent RTP systems. (A) Chemical structures of seven selected ingredients. (B) Normalized RTP spectra of traceingredient-mediated bicomponent RTP systems. (C) RTP decay curve of trace-ingredientmediated bicomponent RTP systems. (D) After-glow images of trace-ingredient-mediated bicomponent RTP systems. The spectra and images of 2BBI/1BBI and 4BBI/1BBI were measured under $254 \mathrm{~nm}$ excitation and others under $365 \mathrm{~nm}$.

To explore the structural commonality of active ingredients, a series of compounds with similar structures were tested for RTP after being mixed with the matrix. However, even compounds with similar structures may not generate the same effect, such as 4-(1H-Imidazol1-yl)- $N, N$-dimethylbenzenamine. Fig. S24 provides part of compounds that were tested inactive with 1BBI, which indicated that the matrix material has strong selectivity for active ingredients. Further research is needed to explore the unusual RTP emission in bicomponent system. 
The low-temperature phosphorescence was used to investigate the attribution of RTP. The phosphorescence lifetimes of DMBA/1BBI, PBA/1BBI and JCA/1BBI were $179 \mathrm{~ms}, 149 \mathrm{~ms}$ and $278 \mathrm{~ms}$ at $77 \mathrm{~K}$, respectively, compared with $124 \mathrm{~ms}, 109 \mathrm{~ms}$ and $143 \mathrm{~ms}$ at room temperature (Fig. S14). The increase of lifetime at $77 \mathrm{~K}$ verified the luminescence to be phosphorescence. The phosphorescence spectra of pure 1BBI at 77K showed an emission peak at around $425 \mathrm{~nm}$, which highlighted a big difference with the bicomponent system (Fig. S15). The phosphorescence spectra of pure DMBA, PBA and JCA showed phosphorescence in $\mathrm{MeOH}$ solution at $77 \mathrm{~K}$, which were much closer to their RTP than 1BBI (Fig. S16). Their lifetimes were in an order of magnitude with that of RTP in bicomponent system. The lowtemperature phosphorescence spectra and lifetime illustrated that the RTP in trace-ingredientmediated bicomponent system might emit from the triplet of active ingredients rather than from the matrixes.

All the tested X-ray powder diffractometer (XRD) patterns indicated the ingredient/ matrix systems were crystal materials (Fig. S17). Compared with the matrix, the XRD patterns were similar to that of pure $1 \mathrm{BBI}$. When taking DMBA/1BBI into further research, three distinct peaks (black arrow) were found differing from the pure DMBA or 1BBI (Fig. 3A). After grinding the sample for one hour, these characteristic peaks remained but decreased in intensity. Similarly, the RTP also decreased but remained (Fig. 3B). The melting point of the DMBA/1BBI mixture was significantly lower than that of the pure components by differential scanning calorimetry (DSC) test (Fig. 3C). This revealed that a co-crystal or solid solution may be formed and play roles in the generation of RTP. 

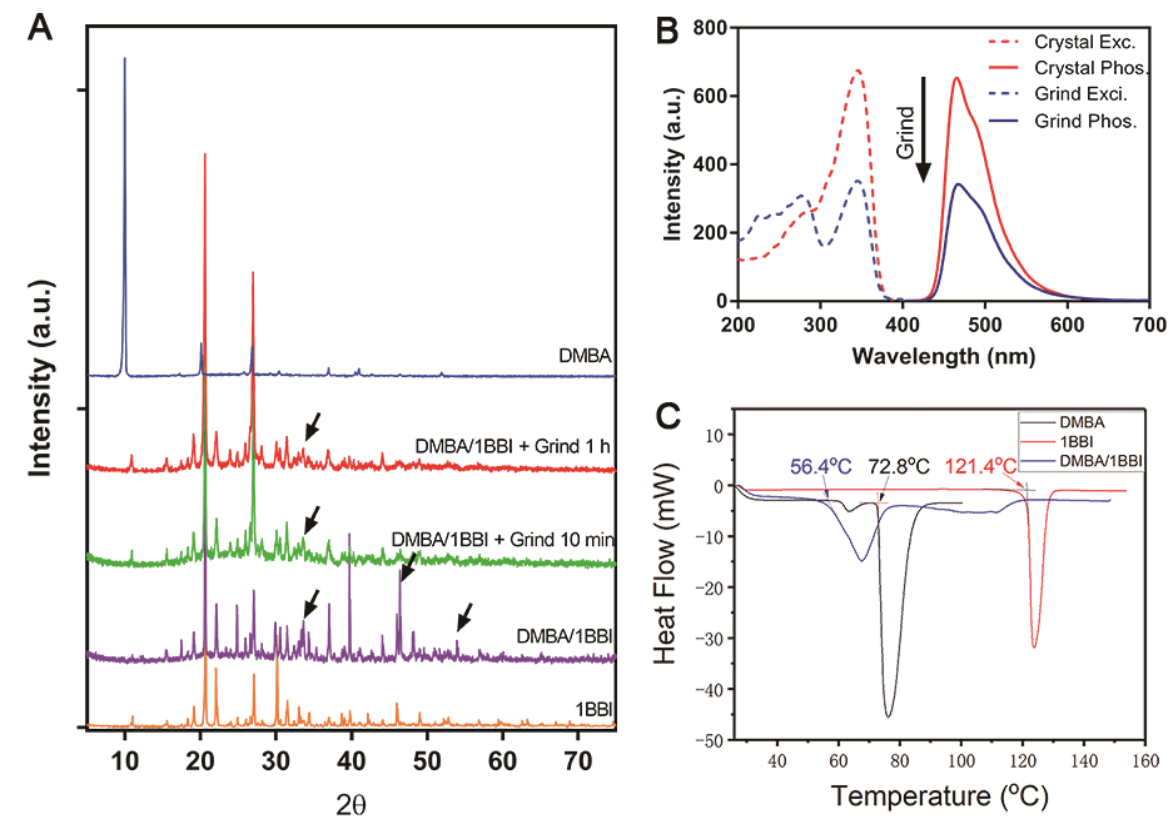

Fig. 3. Crystal analysis of DMBA/1BBI solid. (A) XRD pattern of DMBA/1BBI before and after grinding. (B) RTP intensity change of DMBA/1BBI before (red line) and after (blue line) grinding. (C) melting points of the DMBA/1BBI mixture compared with single components.

\section{Halogen-free bicomponent RTP system}

The 1BBI is not the only matrix that can conduct the bicomponent RTP. The compound 1-(4(4H-imidazol-4-yl)phenyl)-1H-imidazole (DIB) was synthesized for the purpose of removing the halogen atom in 1BBI. The carefully purified DIB showed no RTP even in crystal states. Then, the DMQI and DMIQI was selected to mix with DIB to form the halogen-free bicomponent RTP system. As seen from Fig. 4A, the RTP emission spectra of DMQI/DIB and DMIQI/DIB were similar to that of DMQI/1BBI and DMIQI/1BBI, respectively. It reveals that the RTP may come from the triplet ingredients rather than from the matrix. The QYs dropped from 7.6\% (DMQI/1BBI) and 8.0\% (DMIQI/1BBI) to $6.4 \%$ (DMQI/DIB) and $1.4 \%$ (DMIQI/DIB) due to the loss of heavy atom effect. The RTP lifetime of DMQI/DIB was increased to $\tau=430 \mathrm{~ms}$ compared with $\tau=263 \mathrm{~ms}$ of DMQI/1BBI. When applied to other active ingredients, all the QYs and lifetimes were decreased at a reasonable level (Table 1, Fig. 4B).

Table 1. RTP emission peaks, lifetimes and QYs of Trace-Ingredient-mediated RTP systems. 


\begin{tabular}{lllll}
\hline \multicolumn{2}{c}{$\begin{array}{l}\text { Two-compound } \\
\text { system }\end{array}$} & & & \\
\cline { 1 - 2 } Matrix & Ingredie & $\lambda_{\mathrm{p}}{ }^{\mathrm{max}}(\mathrm{nm})$ & $\tau_{\mathrm{p}}(\mathrm{ms})$ & $\mathrm{QY}$ \\
& $\mathrm{nt}$ & & & \\
\hline \multirow{6}{*}{ 1BBI } & 2BBI & 482 & 6.8 & $8.3 \%$ \\
& 4BBI & 482 & 8.0 & $74.2 \%$ \\
& DMBA & 465 & 122 & $14.8 \%$ \\
& PBA & 480 & 113 & $19.6 \%$ \\
& JCA & 495 & 143 & $2.6 \%$ \\
& DMIQI & 520,550 & 233 & $6.0 \%$ \\
& DMQI & 556 & 262 & $7.6 \%$ \\
\hline \multirow{5}{*}{ DIB } & 2BBI & 492 & 4.4 & $7.3 \%$ \\
& 4BBI & 492 & 2.7 & $6.1 \%$ \\
& DMBA & 467 & 72 & $4.1 \%$ \\
& PBA & 470 & 84 & $6.4 \%$ \\
& JCA & 510 & 66 & $3.7 \%$ \\
& DMIQI & 550 & 186 & $1.4 \%$ \\
& DMQI & 564 & 430 & $6.4 \%$ \\
\hline
\end{tabular}

A

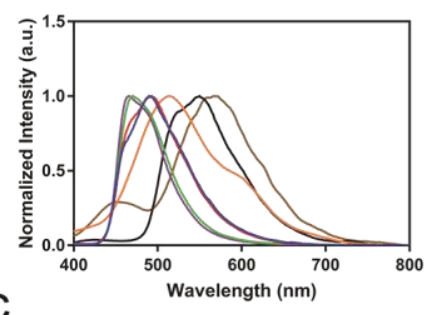

C

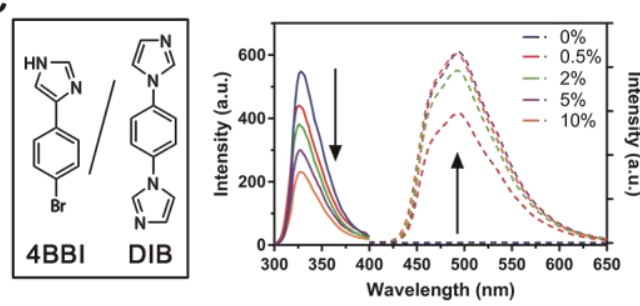

E

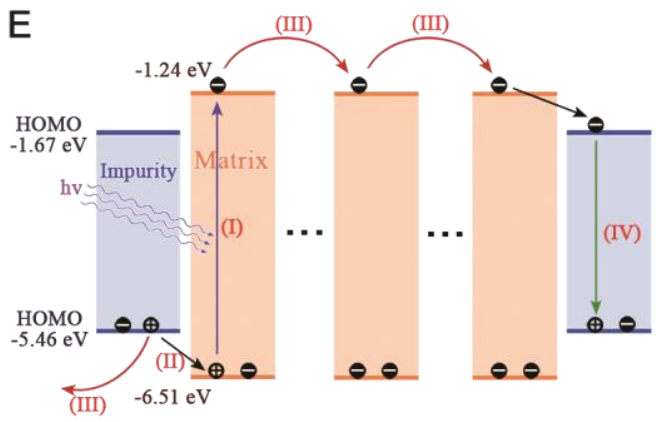

(I) Photo-excitation

(II) Charge transfer

(III) Charge separation

(IV) Charge recombinaton

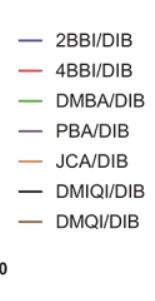

B
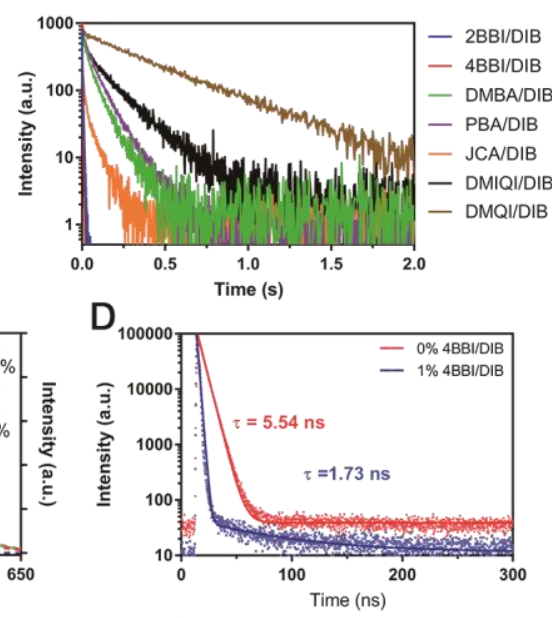

F

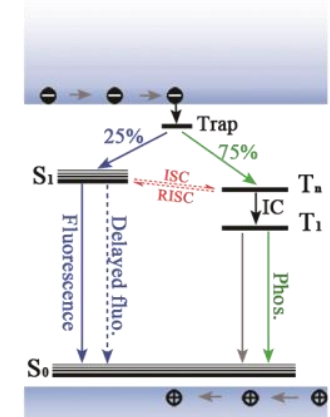

Defect-induced charge recombination 
Fig. 4. Optical characteristics of trace-ingredients-mediated bicomponent system using DIB matrix and corresponding mechanism. (A) Normalized RTP spectra of traceingredients-mediated bicomponent system using DIB matrix at $1 \mathrm{~mol} \%$ contents. (B) RTP intensity decay curve of race-ingredients-mediated bicomponent system using DIB matrix at 1 mol\% contents. (C) Fluorescence spectra (solid line and left Y-axis, excitation: 254 nm; slit width: $5 \mathrm{~nm}$; voltage: $400 \mathrm{~V}$ ) and RTP spectra (dash line and right Y-axis, excitation: $254 \mathrm{~nm}$; slit width: $5 \mathrm{~nm}$; voltage: $600 \mathrm{~V}$ ) of 4BBI/DIB at various proportions. (D) Fluorescence decay of DIB before and after being mixed with 4BBI. (E) Electron and hole motion after photoexcitation. Upon photo-excitation, electrons were transported from HOMO to LUMO of the matrix (I). Then electrons from HOMO of impurities were transferred to the HOMO of the excited matrix to generate the charge-transfer state (II). The resulting electrons and holes diffused in different directions to form free charge carriers (III). Finally, non-geminate radiative recombination of free charge carriers generated luminescence (IV). (F) Defect-induced charge recombination. The impurities worked as defects or energy traps and enhanced the charge recombination process.

The matrix DIB emits fluorescence peak at $328 \mathrm{~nm}$ in solid state. The absolute fluorescence QY was measured as $16.6 \%$. Taking 4BBI/DIB as a model, the fluorescence intensities and QYs of DIB decreased significantly as the content of 4BBI increased (Fig. 4C, Table S1). The fluorescence lifetime of 1\% 4BBI/DIB was reduced to 1.73 ns from 5.54 ns of pure DIB (Fig. 4d). Meanwhile, the absolute fluorescence QY dropped to 9.4\%. All the fluorescence changes of the matrix were consistent with the donor characteristic in the energy transfer system. However, the singlet-singlet energy transfer did not contribute to the formation of triplet states, and the singlet-triplet energy transfer was spin forbidden (20). One probable process was that the donor matrix absorbed firstly a photon to generate an electron-hole pair. Then, a charge transfer (CT) state was formed through electron transfer. The charge transfer state generated triplet excitons through the process of charge separation and charge recombination $(14,15)$.

\section{Mechanism of trace-ingredient-mediated bicomponent RTP}

Recently, a great number of pure organic RTP system was achieved based on certain strategies (21). Strategy-based mechanisms have also been proposed to explain the generation of RTP. In the traditional photoluminescence process, RTP is generated by the radiative transition of triplet 
state which is generated from excited singlet state through intersystem crossing (ISC). Crystal packing (22), polymerization (23) and host-guest interaction (24-26) are analyzed to suppress the molecular vibration and oxygen quenching which competed with the radiative transition. However, vibration restraint and avoiding quenching were not the sole factors for RTP, since not all materials could emit RTP in crystal state in vacuum (27). Other mechanisms for enhancing ISC were proposed by increasing heavy atom effect, reducing the energy gap between singlet and triplet $\left(\Delta \mathrm{E}_{\mathrm{ST}}\right)$, and being subjected to the El-Sayed rule $(28,29)$.

For a multi-component system, the phosphorescence mechanism would be unusual and more complex. Although the crystallization suppresses the molecular vibration and oxygen quenching, the above mechanism cannot elucidate the RTP of the trace-ingredient-mediated bicomponent system. Co-crystallization of two compounds with similar crystal structure could achieve direct heavy atom effect to enhance the $\operatorname{RTP}(30,31)$. But the difference between traceingredient-mediated bicomponent RTP system is that the single component alone from cocrystalline system can still emit RTP. External heavy atom effect (32) and intermolecular halogen bond (33) are effective strategies to obtain RTP, which may explain partly the mechanism of trace-ingredient-mediated bicomponent RTP. However, RTP can still be obtained in a halogen-free trace-ingredient-mediated bicomponent system. Recently, a dopant system was reported to generate charge-separated states and emit RTP through the following charge recombination progress $(14,15)$.

Here are details of the possible mechanism of trace-ingredient-mediated bicomponent RTP system. The matrixes and impurities (or active ingredients) in the crystal formed charge-transfer states upon photo excitation. From the excitation spectra of $2 \mathrm{BBI} / 1 \mathrm{BBI}$ and $4 \mathrm{BBI} / 1 \mathrm{BBI}$ we can see a weak excitation peak at $\sim 350 \mathrm{~nm}$ (Fig, S19 and S20), which did not match any absorption spectra of the single component. The fluorescence of DMIQI/1BBI system was red shifted as the ratio increased (Fig. S21). The change of excitation and emission spectra may reveal the formation of charge-transfer state. Taking DMIQI/1BBI system as an example, the electron of 1BBI (or DMIQI) jumped from HOMO to LUMO and generated an electron-hole pair after absorbing a photon (Fig. 4E). The generated excitons then diffused to the surface of DMIQI and 1BBI, generating the charge transfer state. Subsequently, the electron-hole pair was separated into free charge carriers before relaxing to the ground state. Finally, the radiative recombination of free charge carriers or electron-hole pair generated fluorescence and 
phosphorescence (34). Recombination of free charge carriers generated from different photon has a $25 \%$ probability of producing singlet state and $75 \%$ triplet state according to spinstatistics (35). The impurity DMIQI worked as defects in crystals and promoted defect-induced charge recombination (Fig. 4F) (36). This mechanism provided an efficient way to obtain triplet state by bypassing intersystem crossing.

\section{White-light emission by bicomponent RTP system}

Trace-ingredient-mediated bicomponent RTP system exhibited a variety of luminescence colors, which makes it highly feasible for white-light emission design (37). The DMQI/1BBI ( $1 \mathrm{~mol} \%$ ) couple presented blue fluorescence peak at $460 \mathrm{~nm}$ and yellow RTP peak at $560 \mathrm{~nm}$. Under $280 \mathrm{~nm}$ excitation, the blue and yellow emissions achieved a balance to form white-light emission (Fig. 5, A and B). The calculated Commission Internationale de L'Eclairage (CIE) chromaticity coordinate $(0.30,0.33)$ was located at white region of CIE 1931 chromaticity diagram (Fig. 5C). A series of proportion between 0.2-5 mol\% DMQI/1BBI were prepared to optimize the white-light emission. They all exhibited near white-light emission under $280 \mathrm{~nm}$ excitation and yellow afterglow after removing the excitation light (Fig. S22). The $1 \mathrm{~mol} \%$ DMQI/1BBI showed the brightest white-light emission among all the tested samples of different proportions.
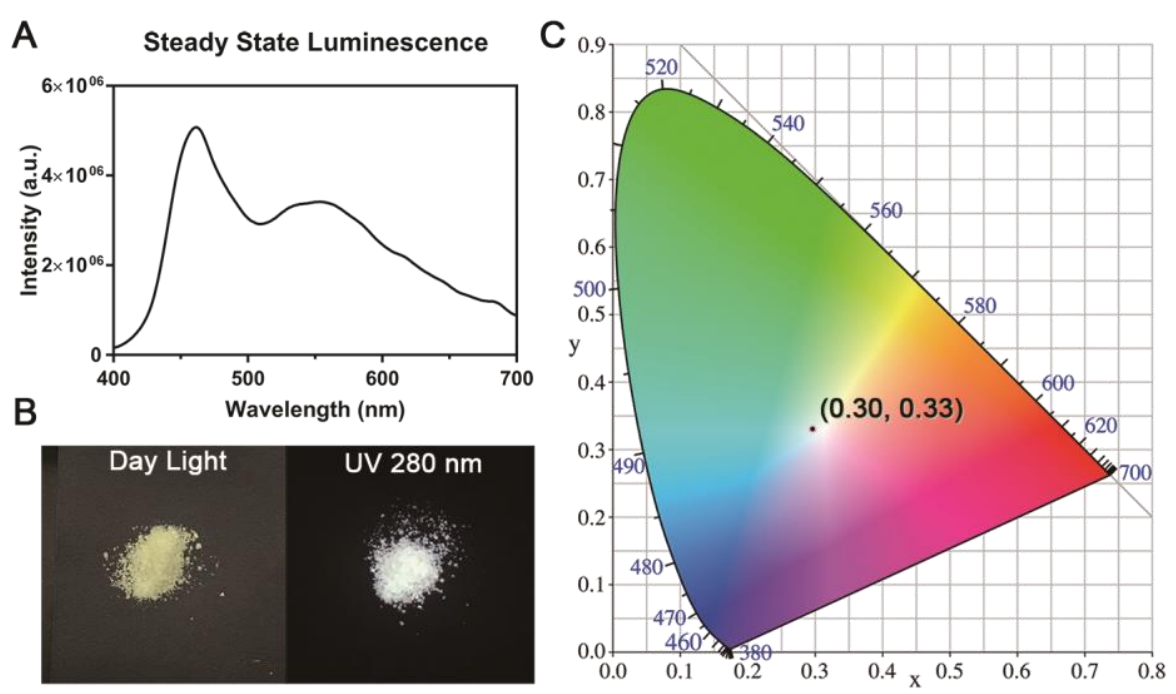

Fig. 5. White-Light Emission System. (A) Steady state luminescence of 1\% DMQI/1BBI under $280 \mathrm{~nm}$ excitation. (B) Images of 1\% DMQI/1BBI under day light or $280 \mathrm{~nm}$ excitation. (C) CIE coordinate of $1 \% \mathrm{DMQI} / 1 \mathrm{BBI}$ luminescence. 


\section{Conclusion}

In summary, a trace-ingredient-mediated bicomponent strategy for pure organic persistent RTP was introduced in this paper inspired by trace impurity DMIQI engendering unusual RTP in organic compound 1BBI. By simply mixing the matrix with a trace amount of screened active ingredients, a series of trace-ingredient-mediated bicomponent RTP systems of high phosphorescence QY (up to 74.2\%) and/or ultra-long phosphorescence lifetime (up to $430 \mathrm{~ms}$ ) were achieved with tunable colors. The low-temperature phosphorescence properties, fluorescence lifetime of matrix, and XRD analysis illustrated the corresponding mechanism of this bicomponent RTP involved charge transfer, charge separation and trap assisted charge recombination process. This work concerning the great impact of trace impurity or ingredients on RTP will lead to a new understanding of persistent organic RTP. The trace-ingredientmediated strategy will be a facile way to design RTP materials for its high efficiency, colortunable, low cost and easy to prepare properties.

\section{Supplementary Information}

Synthetic route, structural identification and supplementary figures/tables are available in Supplementary Information.

\section{Acknowledgments:}

This study was financially supported by the National Natural Science Foundation of China (21788102, 22020102006, 21722603 and 21871083), Program of Shanghai Academic/Technology Research Leader (20XD1421300), the Innovation Program of Shanghai Municipal Education Commission (2017-01-07-00-02-E00010), 'Shu Guang' project supported by Shanghai Municipal Education Commission and Shanghai Education Development Foundation (19SG26), Shanghai Municipal Science and Technology Major Project (Grant No. 2018SHZDZX03), and the Fundamental Research Funds for the Central Universities. We acknowledge Yifeng Cheng for constructive discussions.

\section{Competing interests}

The authors declare no competing interests.

References and Notes: 
[1] L. Gu, H. Wu, H. Ma, W. Ye, W. Jia, H. Wang, H. Chen, N. Zhang, D. Wang, C. Qian, Z. An, W. Huang, Y. Zhao, Color-tunable ultralong organic room temperature phosphorescence from a multicomponent copolymer. Nat. Commun. 11, 944 (2020).

[2] S. Kuila, S. J. George, Phosphorescence energy transfer: Ambient afterglow fluorescence from water-processable and purely organic dyes via delayed sensitization. Angew. Chem. Int. Ed. 59, 9393-9397 (2020).

[3] T. Wang, X. Su, X. Zhang, X. Nie, L. Huang, X. Zhang, X. Sun, Y. Luo, G. Zhang, Aggregation-Induced Dual-Phosphorescence from Organic Molecules for Nondoped Light-Emitting Diodes. Adv. Mater. 31, 1904273 (2019).

[4] S. M. A. Fateminia, Z. Mao, S. Xu, Z. Yang, Z. Chi, B. Liu, Organic nanocrystals with bright red persistent room-temperature phosphorescence for biological applications. Angew. Chem. Int. Ed. 56, 12160-12164 (2017).

[5] H. Ma, A. Lv, L. Fu, S. Wang, Z. An, H. Shi, W. Huang, Room-temperature phosphorescence in metal-free organic materials. Ann. Phys.(Berlin) 531, 1800482 (2019).

[6] L. Gu, H. Shi, L. Bian, M. Gu, K. Ling, X. Wang, H. Ma, S. Cai, W. Ning, L. Fu, H. Wang, S. Wang, Y. Gao, W. Yao, F. Huo, Y. Tao, Z. An, X. Liu, W. Huang, Colour-tunable ultralong organic phosphorescence of a single-component molecular crystal. Nat. Photonics 13, 406-411 (2019).

[7] L. Huang, L. Liu, X. Li, H. Hu, M. Chen, Q. Yang, Z. Ma, X. Jia, Crystal-state photochromism and dual-mode mechanochromism of an organic molecule with fluorescence, room-temperature phosphorescence, and delayed fluorescence. Angew. Chem. Int. Ed. 58, 16445-16450 (2019).

[8] J. Wang, Y. Fang, C. Li, L. Niu, W. Fang, G. Cui, Q. Yang, Time-Dependent Afterglow Color in a Single-Component Organic Molecular Crystal. Angew. Chem. Int. Ed. 59, 10032-10036 (2020).

[9] X. Wang, W. Guo, H. Xiao, Q. Yang, B. Chen, Y. Chen, C. Tung, L. Wu, Pure organic room temperature phosphorescence from unique micelle-assisted assembly of nanocrystals in water. Adv. Funct. Mater. 30, 1907282 (2020).

[10]Z. Huang, X. Ma, Tailoring tunable luminescence via supramolecular assembly strategies. Cell Rep. 1, 100167 (2020).

[11] S. Kuila, K. V. Rao, S. Garain, P. K. Samanta, S. Das, S. K. Pati, M. Eswaramoorthy, S. J. George, Aqueous phase phosphorescence: Ambient triplet harvesting of purely organic phosphors via supramolecular scaffolding. Angew. Chem. Int. Ed. 57, 17115-17119 (2018).

[12] M. S. Kwon, Y. Yu, C. Coburn, A. W. Phillips, K. Chung, A. Shanker, J. Jung, G. Kim, K. Pipe, S. R. Forrest, J. H. Youk, J. Gierschner, J. Kim, Suppressing molecular motions for enhanced room-temperature phosphorescence of metal-free organic materials. Nat. Commun. 6, 8947 (2015).

[13] M. Louis, H. Thomas, M. Gmelch, A. Haft, F. Fries, S. Reineke, Blue-light-absorbing thin films showing ultralong room-temperature phosphorescence. Adv. Mater. 31, 1807887 (2019).

[14] R. Kabe, C. Adachi, Organic long persistent luminescence. Nature 550, 384-387 (2017).

[15]C. S. Bilen, N. Harrison, D. J. Morantz, Unusual room temperature afterglow in some crystalline organic compounds. Nature 271, 235-237 (1978).

[16]D. B. Clapp, The phosphorescence of tetraphenylmethane and certain related substances. J. Am. Chem. Soc. 61, 523-524 (1939).

[17] C. Chen, Z. Chi, K. C. Chong, A. S. Batsanov, Z. Yang, Z. Mao, Z. Yang, B. Liu, Carbazole 
isomers induce ultralong organic phosphorescence. Nat. Mater. doi:10.1038/s4156341020-40797-41562 (2020).

[18]Z. An, C. Zheng, Y. Tao, R. Chen, H. Shi, T. Chen, Z. Wang, H. Li, R. Deng, X. Liu, W. Huang, Stabilizing triplet excited states for ultralong organic phosphorescence. Nat. Mater. 14, 685-690 (2015).

[19] Y. Gong, G. Chen, Q. Peng, W. Z. Yuan, Y. Xie, S. Li, Y. Zhang, B. Z. Tang, Achieving persistent room temperature phosphorescence and remarkable mechanochromism from pure organic luminogens. Adv. Mater. 27, 6195-6201 (2015).

[20] M. A. Baldo, D. F. O'Brien, M. E. Thompson, S. R. Forrest, Excitonic singlet-triplet ratio in a semiconducting organic thin film. Phys. Rev. B 60, 14422-14428 (1999).

[21]G. Qu, Y. Zhang, X. Ma, Recent progress on pure organic room temperature phosphorescence materials based on host-guest interactions. Chin. Chem. Lett. 30, 18091814 (2019).

[22]Z. Yang, C. Xu, W. Li, Z. Mao, X. Ge, Q. Huang, H. Deng, J. Zhao, F. L. Gu, Y. Zhang, Z. Chi, Boosting the Quantum Efficiency of Ultralong Organic Phosphorescence up to $52 \%$ via Intramolecular Halogen Bonding. Angew. Chem. Int. Ed. 59, 17451-17455 (2020).

[23] X. Ma, C. Xu, J. Wang, H. Tian, Amorphous pure organic polymers for heavy-atom-free efficient room-temperature phosphorescence emission. Angew. Chem. Int. Ed. 57, 1085410858 (2018).

[24]Z. Zhang, Y. Chen, Y. Liu, Efficient room-temperature phosphorescence of a solid-state supramolecule enhanced by cucurbit[6]uril. Angew. Chem. Int. Ed. 58, 6028-6032 (2019).

[25]J. Wang, Z. Huang, X. Ma, H. Tian, Visible-light-excited room-temperature phosphorescence in water by cucurbit[8]uril-mediated supramolecular assembly. Angew. Chem. Int. Ed. 59, 9928-9933 (2020).

[26] T. Jiang, X. Wang, J. Wang, G. Hu, X. Ma, Humidity- and temperature-tunable multicolor luminescence of cucurbit[8]uril-based supramolecular assembly. ACS Appl. Mater. Interfaces 11, 14399-14407 (2019).

[27]H. Yuasa, S. Kuno, Intersystem crossing mechanisms in the room temperature phosphorescence of crystalline organic compounds. Bull. Chem. Soc. Jpn. 91, 223-229 (2018).

[28] J. Yang, X. Gao, Z. Xie, Y. Gong, M. Fang, Q. Peng, Z. Chi, Z. Li, Elucidating the excited state of mechanoluminescence in organic luminogens with room-temperature phosphorescence. Angew. Chem. Int. Ed. 56, 15299-15303 (2017).

[29] C. Chen, R. Huang, A. S. Batsanov, P. Pander, Y.-T. Hsu, Z. Chi, F. B. Dias, M. R. Bryce, Intramolecular Charge Transfer Controls Switching Between Room Temperature Phosphorescence and Thermally Activated Delayed Fluorescence. Angew. Chem. Int. Ed. 57, 16407-16411 (2018).

[30] Kenry, C. Chen, B. Liu, Enhancing the performance of pure organic room-temperature phosphorescent luminophores. Nat. Commun. 10, 2111 (2019).

[31] O. Bolton, K. Lee, H.-J. Kim, K. Y. Lin, J. Kim, Activating efficient phosphorescence from purely organic materials by crystal design. Nat. Chem. 3, 205-210 (2011).

[32] J. Wang, X. Gu, H. Ma, Q. Peng, X. Huang, X. Zheng, S. H. P. Sung, G. Shan, J. W. Y. Lam, Z. Shuai, B. Z. Tang, A facile strategy for realizing room temperature phosphorescence and single molecule white light emission. Nat. Commun. 9, 2963 (2018).

[33] W. Wang, Y. Zhang, W. J. Jin, Halogen bonding in room-temperature phosphorescent materials. Coord. Chem. Rev. 404, 213107 (2020). 
[34]C. M. Proctor, M. Kuik, T.-Q. Nguyen, Charge carrier recombination in organic solar cells. Prog. Polym. Sci. 38, 1941-1960 (2013).

[35] Y. Liu, C. Li, Z. Ren, S. Yan, M. R. Bryce, All-organic thermally activated delayed fluorescence materials for organic light-emitting diodes. Nat. Rev. Mater. 3, 18020 (2018).

[36]B. Chen, P. N. Rudd, S. Yang, Y. Yuan, J. Huang, Imperfections and their passivation in halide perovskite solar cells. Chem. Soc. Rev. 48, 3842-3867 (2019).

[37]Z. He, W. Zhao, J. W. Y. Lam, Q. Peng, H. Ma, G. Liang, Z. Shuai, B. Z. Tang, White light emission from a single organic molecule with dual phosphorescence at room temperature. Nat. Commun. 8, 416 (2017). 


\section{Supplementary Information}

\section{Engender Persistent Organic Room-Temperature Phosphorescence by Trace Ingredient Incorporation}

Bingbing Ding, Liangwei Ma, Zizhao Huang, Xiang Ma* and He Tian

Key Laboratory for Advanced Materials and Feringa Nobel Prize Scientist Joint Research Center, Frontiers Science Center for Materiobiology and Dynamic Chemistry, School of Chemistry and Molecular Engineering, East China University of Science and Technology, Shanghai 200237, P. R. China

E-mail: maxiang@ecust.edu.cn

\section{Table of contents}

General Information Page S2

Chemistry Page S2-6

Supplementary Tables and Figures

Supplementary Table 1 Fluorescence quantum yield 4BBI/DIB Page S6

Supplementary Figure 1-S2 Impurity generation process Page S6-7

Supplementary Figure 3-S16 Optical spectra Page S7-12

Supplementary Figure 17 XRD pattern Page S13

Supplementary Figure 18 HOMO and LUMO Page S13

Supplementary Figure 19-S20 Excitation and solid-state absorbance Page S14

Supplementary Figure 21 Fluorescence of DMIQI/1BBI Page S14

Supplementary Figure 22 White-light emission Page S15

Supplementary Figure 23 Steady state luminescence spectra Page S15

Supplementary Figure 24 A list of unworked compounds Page S16

Supplementary Table 2 Singlet and triplet transition configurations - Page S17-S18 Supplementary Figure $25 \&$ Supplementary Table 3 X-Ray Single Crystal Data --Page S19-S20 


\section{General Information}

The UV-Vis absorption spectra of solid sample were obtained on a PerkinElmer Lambda 950 spectrophotometer. The UV-Vis absorption spectra of solution state were obtained on an Agilent Cary 60 spectrophotometer. The steady state photoluminescence spectra at room temperature were measured in air using a Horiba FluoroMax-4 spectrofluorometer. The time-resolved photoluminescence spectra and lifetime at room temperature were recorded in air on an Agilent Cary Eclipse spectrophotometer. The photoluminescence quantum yields were measured using a HAMAMATSU absolute PL quantum yield spectrometer (C11347). Nuclear Magnetic Resonance (NMR) spectra were measured on a Bruker AV-400 spectrometer and processing on MestReNova (Mestralab Research, version: 9.0.1) software. The high-performance liquid chromatography coupled with high resolution mass spectra were tested on a Thermo Scientific ${ }^{\mathrm{TM}} \mathrm{Q}$ Exactive Plus ${ }^{\mathrm{TM}}$ spectrometer system. The electron impact (EI) high-resolution mass spectra were tested on a Waters GCT Premier spectrometer. X-ray diffraction experiments were carried out on Bruker D8 Venture diffractometer with a PHOTON 100 CMOS area detector, using Mo-K radiation from an Incoatec $\mathrm{I} \mu \mathrm{S}$ micro source with focusing mirrors. Reversed phase chromatography was performed on SepaBean ${ }^{\mathrm{TM}}$ machine (Santai Technology Inc., China) equipped with C18-bonded Sepaflash ${ }^{\circledR}$ columns.

\section{Chemistry}

Synthesis of 1-(4-bromophenyl)-1H-imidazole.

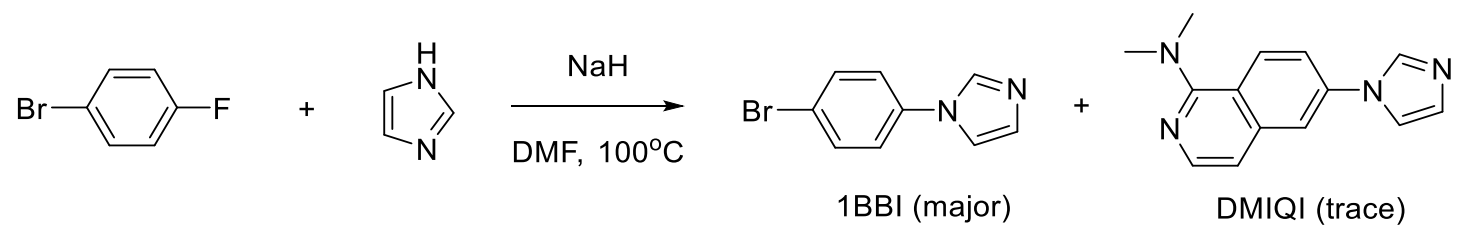

Supplementary Scheme 1. Synthesis of 1-(4-bromophenyl)-1H-imidazole from 4bromofluorobenzene.

To a solution of imidazole $(68 \mathrm{~g}, 1.0 \mathrm{~mol})$ in dry DMF $(0.5 \mathrm{~L})$ was added $\mathrm{NaH}(80 \mathrm{~g}, 2.0 \mathrm{~mol})$ in portions at $0^{\circ} \mathrm{C}$. After stirred for $1 \mathrm{~h}$ at $0^{\circ} \mathrm{C}$, the reaction was added 4-bromofluorobenzene $(109 \mathrm{~mL}$, $1 \mathrm{~mol}$ ) followed by heating at $100^{\circ} \mathrm{C}$ for $12 \mathrm{~h}$. Then the reaction was poured into cold water $(5.0 \mathrm{~L})$. A large amount of white solid was precipitated out. After filtration and purification by the flash column chromatography on silica gel with petroleum ether/EA=2/1 as eluent, 1-(4-bromophenyl)$1 H$-imidazole (1BBI, $140 \mathrm{~g}$, Yield $=63 \%)$ was obtained as white crystalline solid. Then the eluent was changed to $\mathrm{DCM} / \mathrm{MeOH}=30 / 1$. About $100 \mathrm{mg}$ crude 6 -(1H-imidazol-1-yl)- $N, N$ dimethylisoquinolin-1-amine (DMIQI, Yield $<0.1 \%$ ) was achieved.

The 1BBI was further applied purification by flash column chromatography on silica gel and reversed phase chromatography on C18-bonded silica gel before using. Purified DMIQI was obtained by further preparative thin layer chromatography.

1BBI: ${ }^{1} \mathrm{H}$ NMR (400 MHz, $\left.\mathrm{CDCl}_{3}\right) \delta=7.83$ (s, 1H, ArH), $7.61(\mathrm{~d}, J=8.7 \mathrm{~Hz}, 2 \mathrm{H}, \mathrm{ArH}), 7.28$ (d, $J=8.8 \mathrm{~Hz}, 2 \mathrm{H}, \mathrm{ArH}), 7.25(\mathrm{~s}, 1 \mathrm{H}, \mathrm{ArH}), 7.21(\mathrm{~s}, 1 \mathrm{H}, \mathrm{ArH})$; HRMS(ESI+): $m / z$ calcd for $\mathrm{C}_{9} \mathrm{H}_{8} \mathrm{BrN}_{2}+\mathrm{H}^{+}: 222.9871$; found: 222.9890 .

DMIQI: $\mathrm{R}_{\mathrm{f}}=0.62(\mathrm{DCM} / \mathrm{MeOH}=10 / 1) ;{ }^{1} \mathrm{H} \mathrm{NMR}\left(400 \mathrm{MHz}, \mathrm{CDCl}_{3}\right) \delta=8.23(\mathrm{~d}, J=9.0 \mathrm{~Hz}$, $1 \mathrm{H}, \operatorname{ArH}), 8.14$ (d, $J=5.8 \mathrm{~Hz}, 1 \mathrm{H}, \mathrm{ArH}), 8.00(\mathrm{t}, J=1.1 \mathrm{~Hz}, 1 \mathrm{H}, \operatorname{ArH}), 7.68(\mathrm{~d}, J=2.3 \mathrm{~Hz}, 1 \mathrm{H}$, ArH), 7.51 (dd, $J=9.0,2.3 \mathrm{~Hz}, 1 \mathrm{H}, \mathrm{ArH}), 7.41$ (t, $J=1.4 \mathrm{~Hz}, 1 \mathrm{H}, \mathrm{ArH}), 7.25$ (s, 1H, ArH), 7.16 (d, 
$J=5.7 \mathrm{~Hz}, 1 \mathrm{H}, \mathrm{ArH}), 3.13\left(\mathrm{~s}, 6 \mathrm{H}, \mathrm{NCH}_{3}\right) ;{ }^{13} \mathrm{C} \mathrm{NMR}\left(101 \mathrm{MHz}, \mathrm{CDCl}_{3}\right) \delta=161.9,142.2,139.4$, 137.7, 135.7, 131.0, 128.9, 119.8, 119.1, 118.1, 117.5, 114.1, 43.2; HRMS(ESI+): $m / z$ calcd for $\mathrm{C}_{14} \mathrm{H}_{14} \mathrm{~N}_{4}+\mathrm{H}^{+}: 239.1297$; found: 239.1293 ; HRMS(EI+): $m / z(\%): 238.1216(62)[M]^{+}, 237.1140(53)$ $[M-\mathrm{H}]^{+}, \quad 223.0986(38) \quad\left[\mathrm{M}-\mathrm{CH}_{3}\right]^{+}, \quad 209.0959(100) \quad\left[M-\mathrm{NCH}_{3}\right]^{+}, \quad 195.0794(31) \quad\left[M-\mathrm{NC}_{2} \mathrm{H}_{5}\right]^{+}$, $194.0716(24)\left[M-\mathrm{NC}_{2} \mathrm{H}_{6}\right]^{+}$.

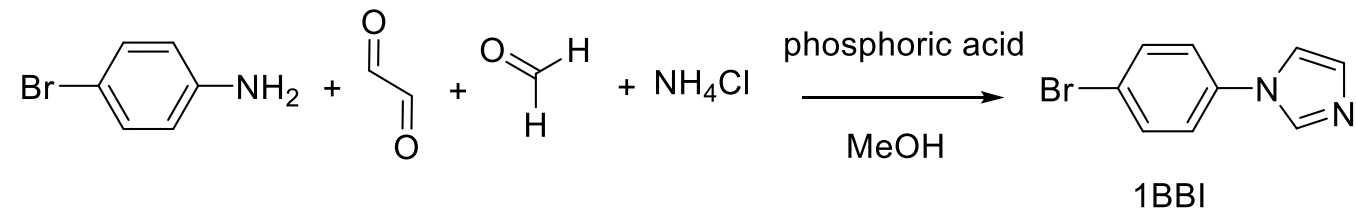

Supplementary Scheme 2. Synthesis of 1-(4-bromophenyl)-1 $H$-imidazole from 4-bromoaniline. To a solution of 4-bromoaniline $(17.2 \mathrm{~g}, 100 \mathrm{mmol})$ in methanol $(70 \mathrm{~mL})$, glyoxal $(14.5 \mathrm{~mL}, 100$ mmol) is added and the mixture is stirred at room temperature for $16 \mathrm{~h}$. After formation of a yellow solid, formaldehyde (17 mL, $210 \mathrm{mmol})$, ammonium chloride (10.7 mg, $200 \mathrm{mmol})$ and methanol $(35 \mathrm{~mL})$ were added and the reaction mixture is heated to $65^{\circ} \mathrm{C}$ for $1 \mathrm{~h}$. Then phosphoric acid $(0.7$ $\mathrm{mL}$ ) was added and the reaction mixture is refluxed for two days. The solvent is distilled off and then dissolved in DCM $(200 \mathrm{~mL})$. The organic phase was extracted with water three times $(3 \times 100$ $\mathrm{mL}$ ). The combined aqueous phase was washed with DCM. The solution was adjusted to $\mathrm{pH}=9$ 10 using aqueous $\mathrm{KOH}$. The precipitate was collected by filtration and followed by the flash column chromatography on silica gel with petroleum ether/EA=2/1 as eluent. An amount of $9.2 \mathrm{~g}$ 1BBI $($ Yield $=41 \%)$ was got as light-yellow solid. ${ }^{1} \mathrm{H}$ NMR $\left(400 \mathrm{MHz}, \mathrm{CDCl}_{3}\right) \delta=7.83(\mathrm{~s}, 1 \mathrm{H}, \mathrm{ArH})$, $7.61(\mathrm{~d}, J=8.7 \mathrm{~Hz}, 2 \mathrm{H}, \mathrm{ArH}), 7.28$ (d, $J=8.8 \mathrm{~Hz}, 2 \mathrm{H}, \mathrm{ArH}), 7.25$ (s, 1H, ArH), 7.22 (s, 1H, ArH).

Synthesis of 1-(4-(4H-imidazol-4-yl)phenyl)-1H-imidazole.

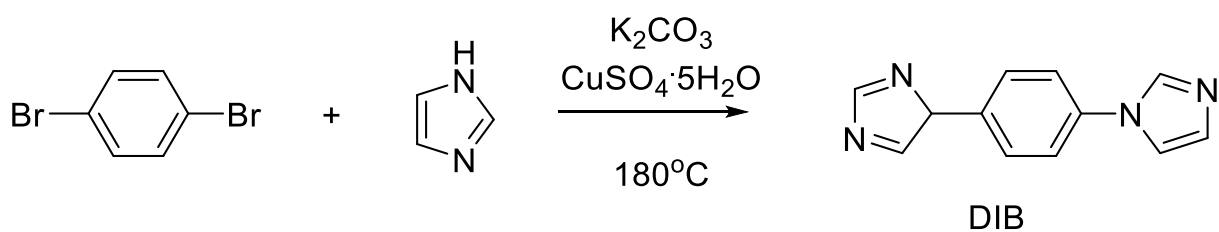

Supplementary Scheme 3. Synthesis of 1-(4-(4H-imidazol-4-yl)phenyl)- $1 H$-imidazole.

A mixture of 1,4-dibromobenzene ( $2.4 \mathrm{~g}, 10 \mathrm{mmol})$, imidazole ( $2.86 \mathrm{~g}, 42 \mathrm{mmol}), \mathrm{K}_{2} \mathrm{CO}_{3}(4.4 \mathrm{~g}$, $32 \mathrm{mmol})$ and $\mathrm{CuSO}_{4} \cdot 5 \mathrm{H}_{2} \mathrm{O}(50 \mathrm{mg}, 0.2 \mathrm{mmol})$ were heated to $180^{\circ} \mathrm{C}$ for 24 hours in a sealed tube. Then the reaction was cool down and diluted with water $(100 \mathrm{~mL})$. The precipitate was collected by filtration and followed by flash column chromatography on silica gel. The 1-(4-(4H-imidazol-4yl)phenyl)- $1 H$-imidazole (DIB, $1.9 \mathrm{~g}$, Yield $=90 \%$ ) was obtained as white solid. ${ }^{1} \mathrm{H}$ NMR (400 $\left.\mathrm{MHz}, \mathrm{CDCl}_{3}\right) \delta=7.88$ (s, 2H, ArH), 7.52 (s, 4H, ArH), 7.31 (s, 2H, ArH), 7.24 (s, 2H, ArH); HRMS(ESI+): $m / z$ calcd for $\mathrm{C}_{12} \mathrm{H}_{10} \mathrm{~N}_{4}+\mathrm{H}^{+}: 211.0984$; found: 211.0973 .

Synthetic route of 6-(1H-imidazol-1-yl)- $N, N$-dimethylisoquinolin-1-amine. 


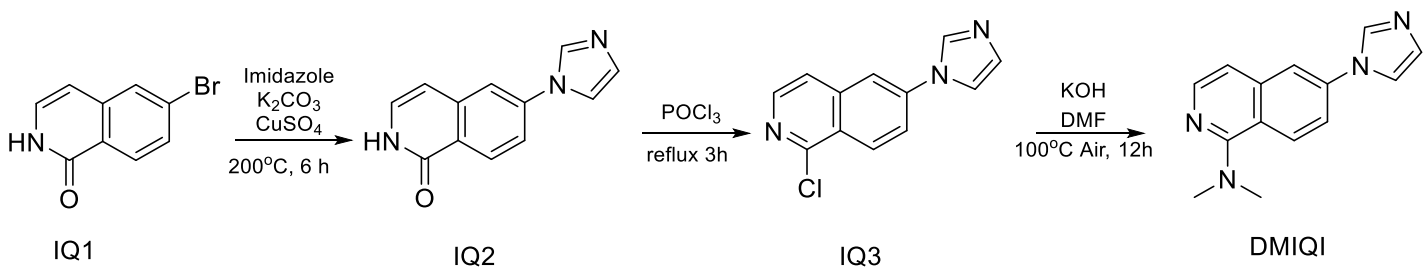

Supplementary Scheme 4. Synthesis of 6-(1H-imidazol-1-yl)- $N, N$-dimethylisoquinolin-1-amine. Imidazole (1.36 g, $20 \mathrm{mmol}$ ), 6-bromoisoquinolin-1(2H)-one (1.12 g, $5 \mathrm{mmol}), \mathrm{K}_{2} \mathrm{CO}_{3}(1.04 \mathrm{~g}, 7.5$ mmol) and a catalytic amount of $\mathrm{CuSO}_{4} \cdot 5 \mathrm{H}_{2} \mathrm{O}(12 \mathrm{mg})$ were stirred in a sealed tube at $200^{\circ} \mathrm{C}$ for 6 h. After cooling to room temperature, the mixture was extracted with dichloromethane/MeOH (10:1) The combined organic phase was filtered and evaporated to dryness. The crude product was suspended in $5 \mathrm{~mL}$ EA, filtered and dried to achieve 6-(1H-imidazol-1-yl)isoquinolin-1(2H)-one (IQ2, $798 \mathrm{mg}$, Yield $=76 \%)$ as white solid. ${ }^{1} \mathrm{H}$ NMR (400 MHz, DMSO- $\left.d_{6}\right) \delta=11.31$ (br s, $1 \mathrm{H}$, NH), 8.39 (t, $J=1.1 \mathrm{~Hz}, 1 \mathrm{H}, \mathrm{ArH}), 8.22$ (d, $J=8.7 \mathrm{~Hz}, 1 \mathrm{H}, \operatorname{ArH}), 7.93$ (d, $J=2.3 \mathrm{~Hz}, 1 \mathrm{H}, \operatorname{ArH})$, 7.85 (s, 1H, ArH), 7.74 (dd, $J=8.7,2.3 \mathrm{~Hz}, 1 \mathrm{H}, \mathrm{ArH}), 7.20$ (d, $J=7.1 \mathrm{~Hz}, 1 \mathrm{H}, \mathrm{ArH}), 7.12$ (t, $J=$ $1.1 \mathrm{~Hz}, 1 \mathrm{H}, \mathrm{ArH}), 6.51(\mathrm{~d}, J=7.1 \mathrm{~Hz}, 1 \mathrm{H}, \mathrm{ArH}) ;{ }^{13} \mathrm{C}$ NMR $\left(101 \mathrm{MHz}, \mathrm{DMSO}-d_{6}\right) \delta=161.3,139.6$, $139.4,135.8,135.2,130.5,128.9,124.2,118.4,117.9,116.1,104.4$.

IQ2 (422 mg, $2 \mathrm{mmol}$ ) was suspended in $\mathrm{POCl}_{3}(5 \mathrm{~mL})$ and reflux overnight. After cooling down, the mixture was poured onto ice $(30 \mathrm{~g})$. Aqueous $\mathrm{Na}_{2} \mathrm{CO}_{3}(10 \%, \mathrm{w} / \mathrm{w})$ was added to adjust $\mathrm{pH}$ to $8-$ 9. Then the solution was extraced by DCM. The combined organic phase was evaporated. The solid crude product was suspended in $2 \mathrm{~mL}$ EA. After filtered and dried, 1-chloro-6-(1H-imidazol-1yl)isoquinoline $\left(I Q 3,278 \mathrm{mg}\right.$, Yield $=60 \%$ ) was achieved as white solid. ${ }^{1} \mathrm{H}$ NMR (400 MHz, $\left.\mathrm{CDCl}_{3}\right) \delta=8.48(\mathrm{~d}, J=9.0 \mathrm{~Hz}, 1 \mathrm{H}, \mathrm{ArH}), 8.34(\mathrm{~d}, J=5.7 \mathrm{~Hz}, 1 \mathrm{H}, \mathrm{ArH}), 8.05(\mathrm{t}, J=1.1 \mathrm{~Hz}, 1 \mathrm{H}$, ArH), $7.83(\mathrm{~d}, J=2.2 \mathrm{~Hz}, 1 \mathrm{H}, \mathrm{ArH}), 7.75(\mathrm{dd}, J=9.0,2.2 \mathrm{~Hz}, 1 \mathrm{H}, \mathrm{ArH}), 7.64$ (dd, $J=5.7,0.8 \mathrm{~Hz}$, 1H, ArH), 7.45 (t, $J=1.4 \mathrm{~Hz}, 1 \mathrm{H}, \mathrm{ArH}), 7.29$ (t, $J=1.1 \mathrm{~Hz}, 1 \mathrm{H}, \mathrm{ArH}) ;{ }^{13} \mathrm{C} \mathrm{NMR}\left(101 \mathrm{MHz}, \mathrm{CDCl}_{3}\right)$ $\delta=151.8,143.1,139.1,138.6,135.7,131.5,129.4,125.6,122.3,120.6,118.0,117.2$.

A solution of IQ3 (115 mg, $0.5 \mathrm{mmol})$ and $\mathrm{KOH}(70 \mathrm{mg}, 1.25 \mathrm{mmol})$ in DMF (0.271 mL, 3.5 mmol) were stirred in a sealed tube under an atmosphere of air at $100^{\circ} \mathrm{C}$ for $8 \mathrm{~h}$. After cooled to room temperature, the reaction mixture was pour into water $(10 \mathrm{~mL})$ and extracted with ethyl acetate $(3 \times 10 \mathrm{~mL})$. The combined organic phase was washed with brine and dried over anhydrous $\mathrm{Na}_{2} \mathrm{SO} 4$. The solvent was evaporated under vacuum and the crude product was purified by preparative thinlayer chromatography (TLC) on silica gel with ethyl acetate to achieve the pure DMIQI (86 mg, Yield $=72 \%$ ) as colorless to yellowish oil. The pure oily product slowly turned to white crystalline solid at $-20^{\circ} \mathrm{C} .{ }^{1} \mathrm{H}$ NMR $\left(400 \mathrm{MHz}, \mathrm{CDCl}_{3}\right) \delta=8.22(\mathrm{~d}, J=9.0 \mathrm{~Hz}, 1 \mathrm{H}, \mathrm{ArH}), 8.14(\mathrm{~d}, J=5.8 \mathrm{~Hz}$, 1H, ArH), 8.00 (t, $J=1.1 \mathrm{~Hz}, 1 \mathrm{H}, \mathrm{ArH}), 7.67$ (d, $J=2.3 \mathrm{~Hz}, 1 \mathrm{H}, \mathrm{ArH}), 7.50$ (dd, $J=9.0,2.3 \mathrm{~Hz}$, 1H, ArH), 7.41 (t, J=1.4 Hz, 1H, ArH), 7.25 (s, 1H, ArH), 7.16 (d, J=5.8 Hz, 1H, ArH), 3.13 (s, $\left.6 \mathrm{H}, \mathrm{NCH}_{3}\right) ;{ }^{13} \mathrm{C} \mathrm{NMR}\left(101 \mathrm{MHz}, \mathrm{CDCl}_{3}\right) \delta=161.9,142.2,139.4,137.7,135.7,131.0,128.9,119.8$, 119.1, 118.1, 117.5, 114.1, 43.2; HRMS(EI+): $m / z(\%): 238.1215(62)[M]^{+}, 237.1140(51)[M-\mathrm{H}]^{+}$, $223.0980(34)\left[\mathrm{M}-\mathrm{CH}_{3}\right]^{+}, 209.0951(100)\left[M-\mathrm{NCH}_{3}\right]^{+}, 195.0791(30)\left[M-\mathrm{NC}_{2} \mathrm{H}_{5}\right]^{+}, 194.0718(23)[M-$ $\left.\mathrm{NC}_{2} \mathrm{H}_{6}\right]^{+}$.

\section{Synthetic route of 2-(1H-imidazol-1-yl)- $N$, $N$-dimethylquinolin-6-amine.}



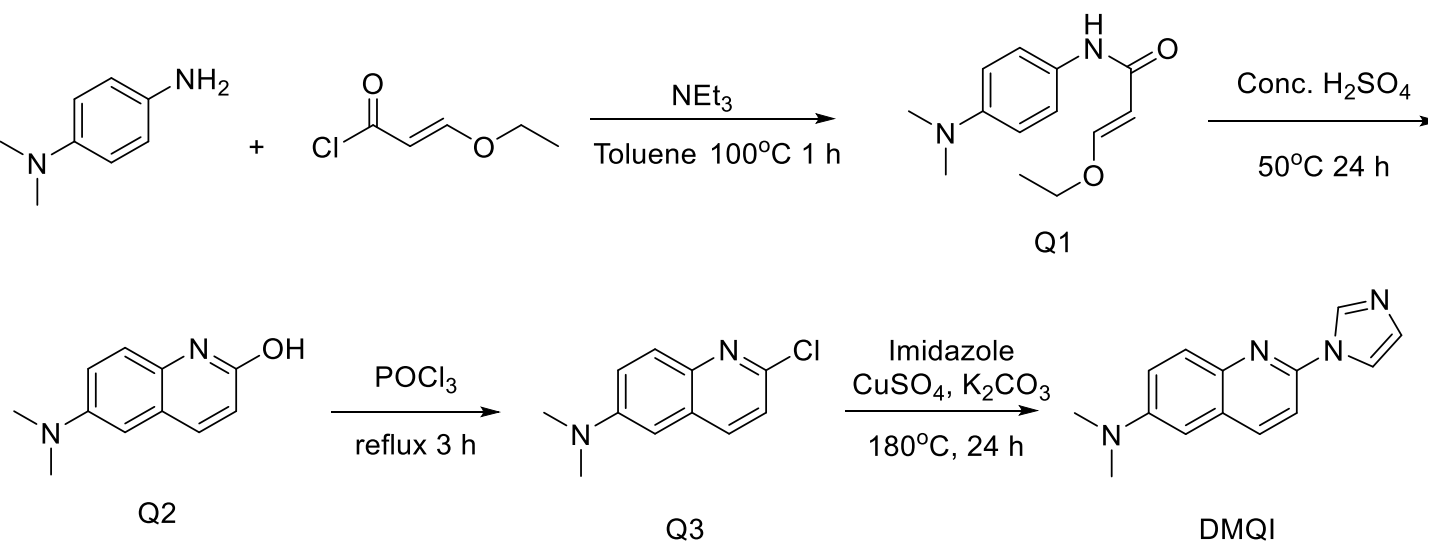

Supplementary Scheme 5. Synthesis of 2-(1H-imidazol-1-yl)- $N, N$-dimethylquinolin-6-amine.

$\mathrm{Et}_{3} \mathrm{~N}(2.5 \mathrm{~mL}, 1.89 \mathrm{~g}, 18.7 \mathrm{mmol})$ and $p$-( $N, N$-dimethylamino $)$ aniline $(2.00 \mathrm{~g}, 14.7 \mathrm{mmol})$ was dissolved in anhydrous toluene $(50 \mathrm{~mL})$. After the mixture was heated to $100^{\circ} \mathrm{C}$, a solution of 3ethoxyacryloyl chloride $(1.96 \mathrm{~g}, 14.6 \mathrm{mmol})$ in anhydrous toluene $(10 \mathrm{~mL})$ was added dropwise over $10 \mathrm{~min}$. The mixture was refluxed for $1 \mathrm{~h}$ before the solvent was removed in vacuum. The remaining solid was extracted with $\mathrm{EA}(100 \mathrm{~mL})$ and the $\mathrm{Et}_{3} \mathrm{~N} \times \mathrm{HCl}$ solid was filtered off. Solvent was collected and washed with brine, evaporated to dryness. $N$-(4-(dimethylamino)phenyl)-3ethoxyacrylamide $(\mathrm{Q} 1,2.2 \mathrm{~g}$, yield $=64 \%)$ was obtained through recrystallization from $\mathrm{CHCl}_{3}$ as light-yellow crystals. ${ }^{1} \mathrm{H}$ NMR $\left(400 \mathrm{MHz}, \mathrm{CDCl}_{3}\right) \delta=7.59(\mathrm{~d}, J=12.0 \mathrm{~Hz}, 1 \mathrm{H},=\mathrm{CH}-), 7.41-7.32$ (br m, 2H, ArH), 6.95 (br s, 1H, CONH), 6.69 (d, $J=8.9 \mathrm{~Hz}, 2 \mathrm{H}, \mathrm{ArH}), 5.30$ (d, $J=12.0 \mathrm{~Hz}, 1 \mathrm{H}$ $=\mathrm{CH}-$ ), 3.90 (br m, 2H, $\left.-\mathrm{CH}_{2}-\right), 2.91\left(\mathrm{~s}, 6 \mathrm{H}, \mathrm{NCH}_{3}\right), 1.32\left(\mathrm{t}, J=7.0 \mathrm{~Hz}, 3 \mathrm{H}, \mathrm{CCH}_{3}\right)$.

Q1 $(1.17 \mathrm{~g}, 5 \mathrm{mmol})$ was added to concentrated $\mathrm{H}_{2} \mathrm{SO}_{4}(8 \mathrm{~mL})$ in small portions on an ice-salt bath. After reagent was completed dissolved, the reaction was heated to $50^{\circ} \mathrm{C}$ and kept for $12 \mathrm{~h}$. The mixture was poured onto ice $(50 \mathrm{~g})$ and the $\mathrm{pH}$ was carefully adjusted to $12-13$ with $5 \mathrm{M} \mathrm{NaOH}$. The precipitate was collected by filtration and purified by flash column chromatography on silica gel. The 6-(dimethylamino)quinolin-2-ol $(\mathbf{Q 2}, 365 \mathrm{mg}$, Yield $=39 \%)$ was got as yellow solid. ${ }^{1} \mathrm{H}$ NMR (400 MHz, $\left.\mathrm{CDCl}_{3}\right) \delta=12.54$ (br s, $\left.1 \mathrm{H}, \mathrm{ArOH}\right), 7.73$ (d, $\left.J=9.4 \mathrm{~Hz}, 1 \mathrm{H}, \mathrm{ArH}\right), 7.36$ (d, $J=$ $9.0 \mathrm{~Hz}, 1 \mathrm{H}, \mathrm{ArH}), 7.08(\mathrm{dd}, J=9.0,2.8 \mathrm{~Hz}, 1 \mathrm{H}, \mathrm{ArH}), 6.78(\mathrm{~d}, J=2.7 \mathrm{~Hz}, 1 \mathrm{H}, \mathrm{ArH}), 6.69$ (d, $J=$ $9.4 \mathrm{~Hz}, 1 \mathrm{H}, \mathrm{ArH}), 2.96\left(\mathrm{~s}, 6 \mathrm{H}, \mathrm{NCH}_{3}\right)$.

Q2 (339 mg, $1.8 \mathrm{mmol}$ ) was suspended in $\mathrm{POCl}_{3}(5 \mathrm{~mL})$ and heated to reflux for $3 \mathrm{~h}$. After cooling down to room temperature, the mixture was poured onto ice $(30 \mathrm{~g})$. Aqueous $\mathrm{Na}_{2} \mathrm{CO}_{3}(10 \%$, w/w) was added to adjust $\mathrm{pH}$ to $8-9$. The precipitate was collected by filtration and purified by flash column chromatography on silica gel. The 2-chloro- $N, N$-dimethylquinolin-6-amine $(\mathbf{Q 3}, 210 \mathrm{mg}$, yield $=56 \%)$ was obtained as yellow solid. ${ }^{1} \mathrm{H} \mathrm{NMR}\left(400 \mathrm{MHz}, \mathrm{CDCl}_{3}\right) \delta=7.89(\mathrm{~d}, J=8.6 \mathrm{~Hz}, 1 \mathrm{H}$, ArH), 7.86 (d, $J=9.4 \mathrm{~Hz}, 1 \mathrm{H}, \mathrm{ArH}), 7.35(\mathrm{dd}, J=9.4,2.9 \mathrm{~Hz}, 1 \mathrm{H}, \mathrm{ArH}), 7.24(\mathrm{~d}, J=8.6 \mathrm{~Hz}, 1 \mathrm{H}$, $\mathrm{ArH}), 6.78(\mathrm{~d}, J=2.9 \mathrm{~Hz}, 1 \mathrm{H}, \mathrm{ArH}), 3.07\left(\mathrm{~s}, 6 \mathrm{H}, \mathrm{NCH}_{3}\right)$.

Imidazole (272 mg, $4 \mathrm{mmol}), \mathbf{Q 3}(207 \mathrm{mg}, 1 \mathrm{mmol}), \mathrm{K}_{2} \mathrm{CO}_{3}(207 \mathrm{mg}, 1.5 \mathrm{mmol})$ and a catalytic amount of $\mathrm{CuSO}_{4} \cdot 5 \mathrm{H}_{2} \mathrm{O}(5 \mathrm{mg})$ were stirred in a sealed tube at $195^{\circ} \mathrm{C}$ for $14 \mathrm{~h}$. After cooling to room temperature, the crude product was dissolved in water, filtered, and purified by flash column chromatography on silica gel. The 2-(1H-imidazol-1-yl)- $N, N$-dimethylquinolin-6-amine (DMQI, 
$161 \mathrm{mg}$, Yield $=68 \%)$ was achieved as yellow solid. ${ }^{1} \mathrm{H}$ NMR $\left(400 \mathrm{MHz}, \mathrm{CDCl}_{3}\right) \delta=8.40(\mathrm{~s}, 1 \mathrm{H}$, ArH), 8.04 (d, $J=8.8 \mathrm{~Hz}, 1 \mathrm{H}, \mathrm{ArH}), 7.86$ (d, $J=9.3 \mathrm{~Hz}, 1 \mathrm{H}, \operatorname{ArH}), 7.76$ (s, 1H, ArH), 7.37 (dd, $J=$ $9.3 \mathrm{~Hz}, 2.8 \mathrm{~Hz}, 2 \mathrm{H}, \mathrm{ArH}), 7.35$ (d, $J=8.8 \mathrm{~Hz}, 1 \mathrm{H}, \mathrm{ArH}), 7.21(\mathrm{~s}, 1 \mathrm{H}, \mathrm{ArH}), 6.79$ (d, $J=2.8 \mathrm{~Hz}, 1 \mathrm{H}$, $\mathrm{ArH}), 3.07$ (s, $\left.6 \mathrm{H}, \mathrm{NCH}_{3}\right) ;{ }^{13} \mathrm{C} \mathrm{NMR}\left(101 \mathrm{MHz}, \mathrm{CDCl}_{3}\right) \delta=148.7,144.5,140.5,137.5,135.1,130.4$, 129.3, 128.6, 120.4, 116.5, 112.16, 105.0, 40.8; HRMS(ESI+): $m / z$ calcd for $\mathrm{C}_{14} \mathrm{H}_{14} \mathrm{~N}_{4}+\mathrm{H}^{+}$: 239.1297; found: 239.1297 .

\section{Supplementary Tables and Figures}

Supplementary Table 1. Fluorescence quantum yield (QY) of DIB with various contents of 4BBI.

\begin{tabular}{cc}
\hline Contents of 4BBI in DIB & QY \\
\hline $0 \%$ & $16.6 \%$ \\
$0.5 \%$ & $9.7 \%$ \\
$1 \%$ & $9.4 \%$ \\
$2 \%$ & $9.0 \%$ \\
$5 \%$ & $7.0 \%$ \\
$10 \%$ & $4.5 \%$ \\
\hline
\end{tabular}

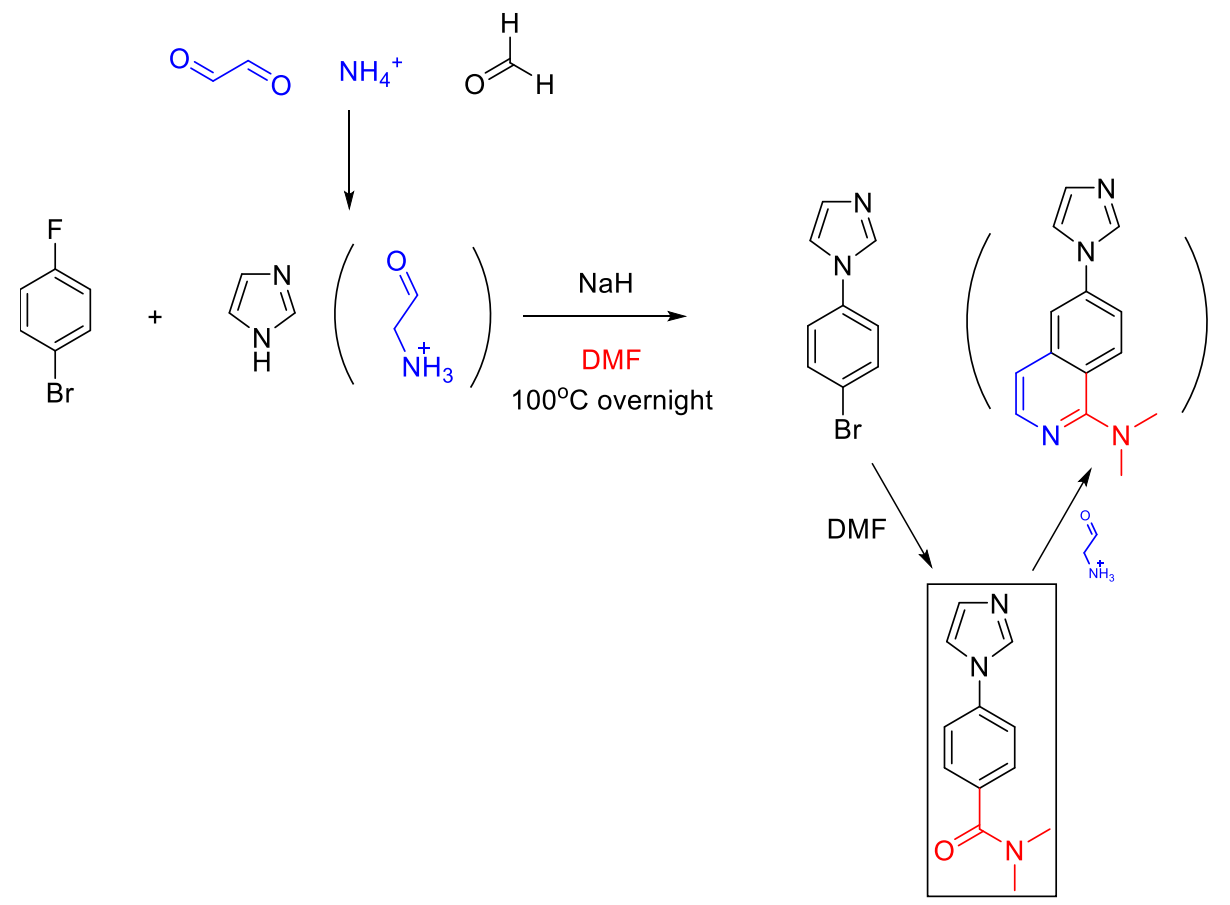

Supplementary Figure 1. Proposed origin of DMIQI. 


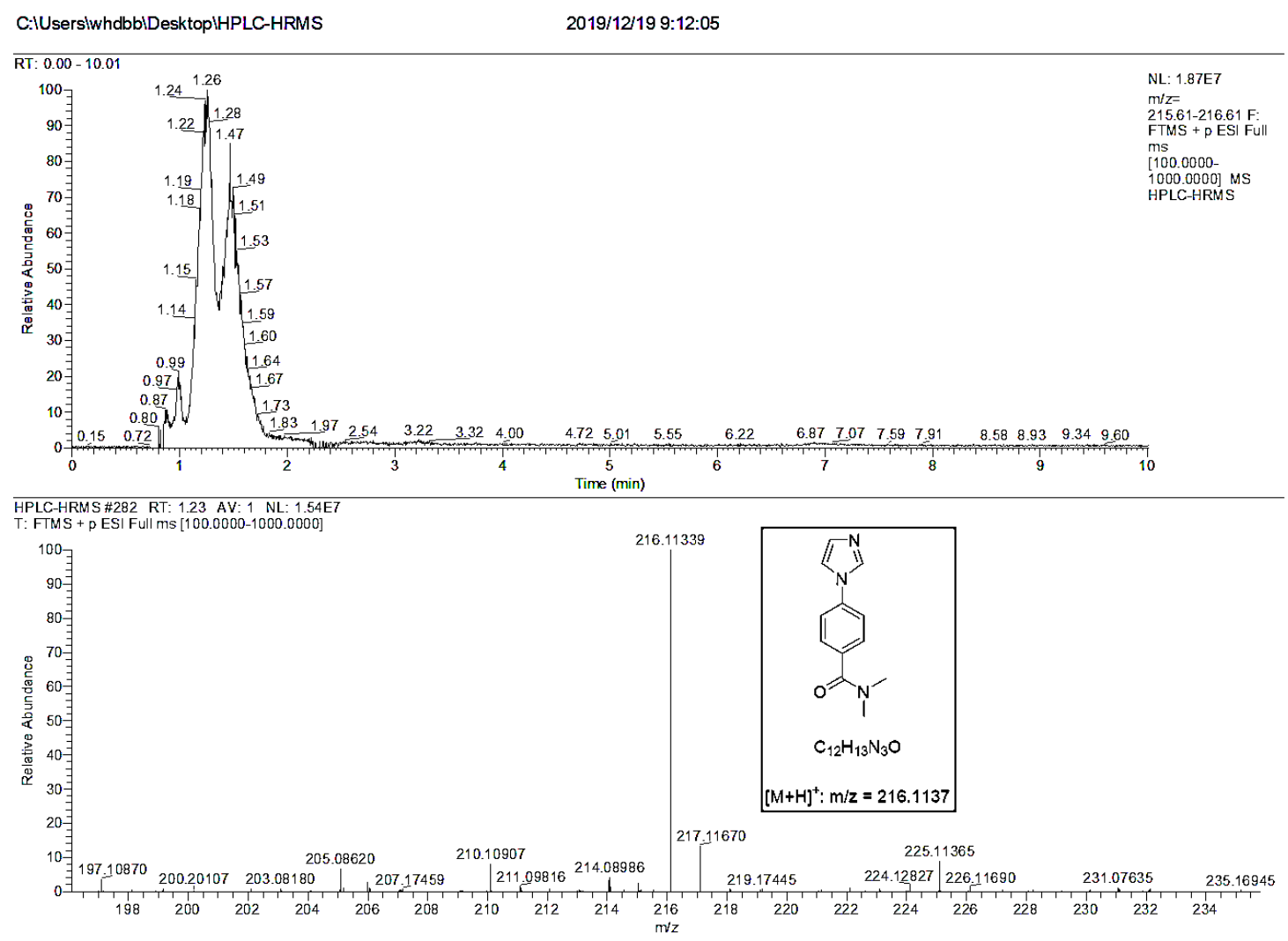

Supplementary Figure 2. HPLC-HRMS analysis of intermediate in synthetic process.

A

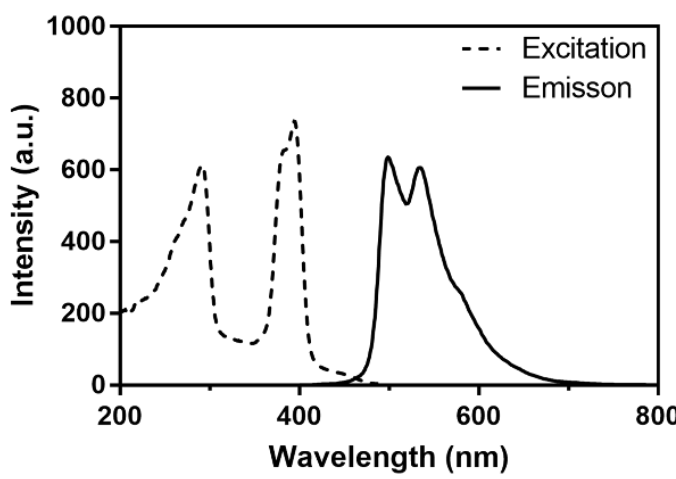

B

RTP lifetime

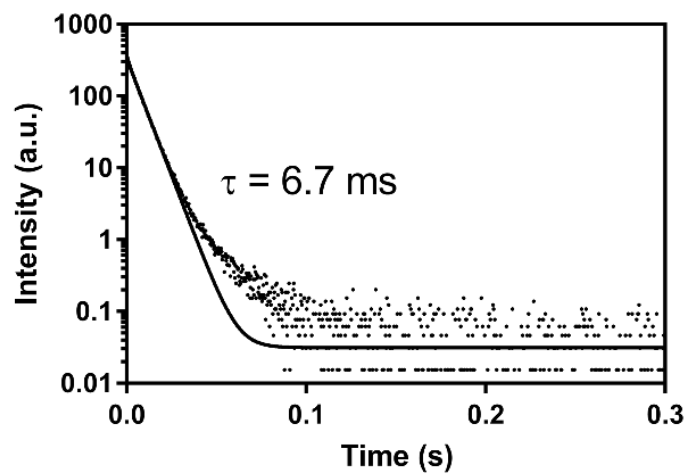

Supplementary Figure 3. (A) RTP emission and excitation spectra and (B) lifetime of crude 1BBI synthesized from 4-bromoaniline. Excitation: $365 \mathrm{~nm}$; Slit width: $10 \mathrm{~nm}$; Voltage: $700 \mathrm{~V}$. 


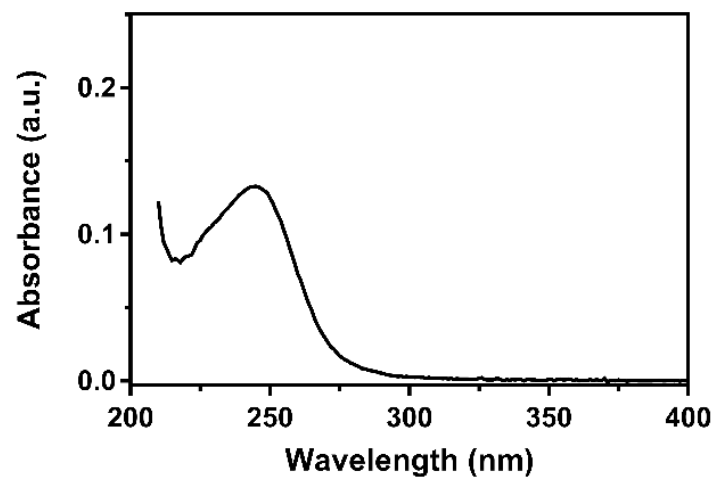

Supplementary Figure 4. Absorption spectra of $\mathbf{1 B B I}$ in $\mathrm{MeOH}$ solution $\left(\mathrm{c}=1 \times 10^{-5} \mathrm{M}\right)$.

A

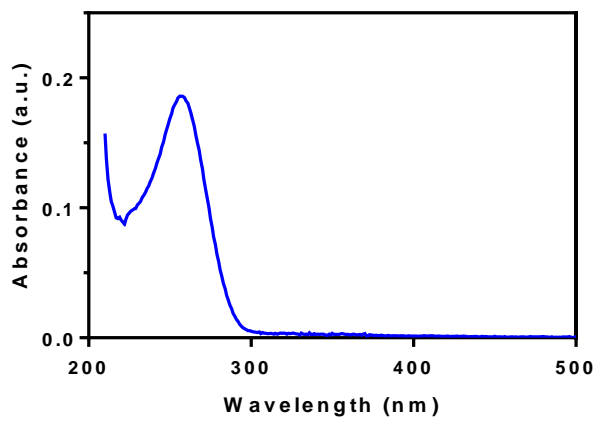

B

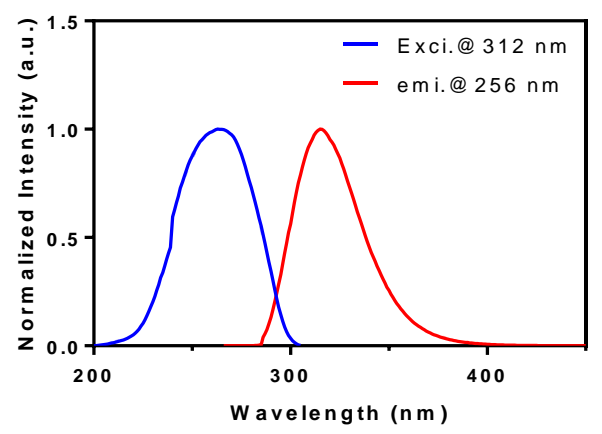

Supplementary Figure 5. (A) Absorption spectra of DIB in MeOH solution ( $\left.\mathrm{c}=1 \times 10^{-5} \mathrm{M}\right)$. (B) Normalized fluorescence emission and excitation spectra of DIB in $\mathrm{MeOH}$ solution $\left(\mathrm{c}=1 \times 10^{-4}\right.$ M).

A

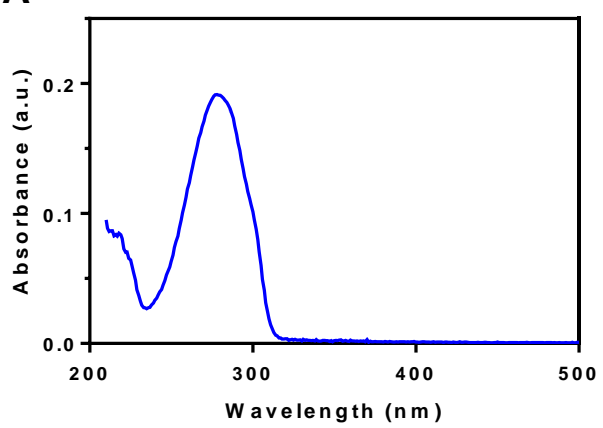

B

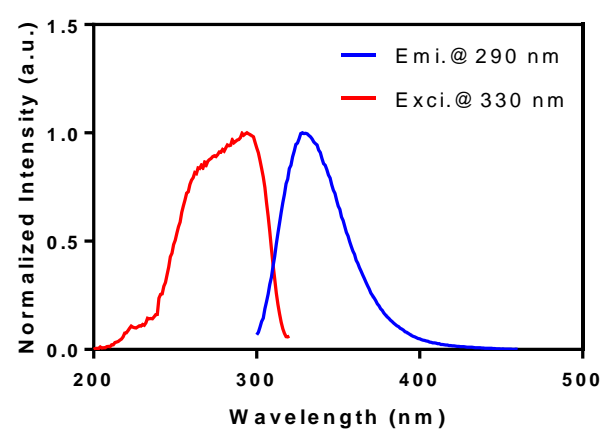

Supplementary Figure 6. (A) Absorption spectra of 2BBI in $\mathrm{MeOH}$ solution $\left(\mathrm{c}=1 \times 10^{-5} \mathrm{M}\right)$. (B) Fluorescence emission and excitation spectra of $\mathbf{2 B B I}$ in $\mathrm{MeOH}$ solution $\left(\mathrm{c}=1 \times 10^{-4} \mathrm{M}\right)$. 
A

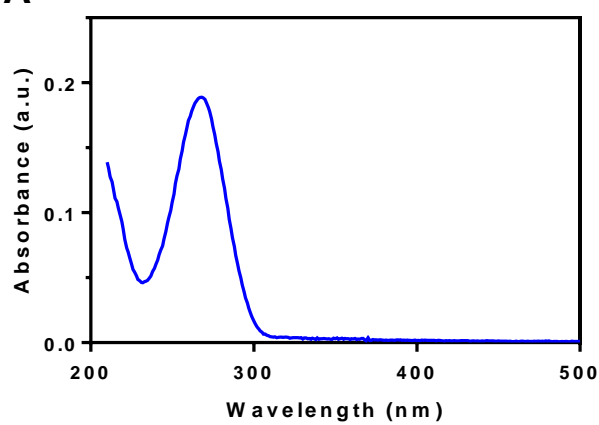

B

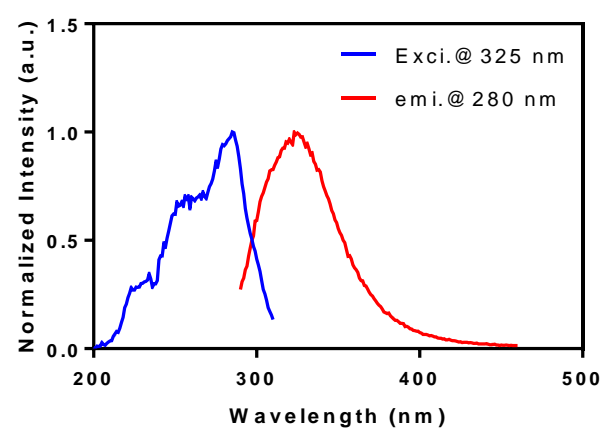

Supplementary Figure 7. (A) Absorption spectra of $4 \mathrm{BBI}$ in $\mathrm{MeOH}$ solution $\left(\mathrm{c}=1 \times 10^{-5} \mathrm{M}\right)$. (B) Fluorescence emission and excitation spectra of $4 \mathrm{BBI}$ in $\mathrm{MeOH}$ solution $\left(\mathrm{c}=1 \times 10^{-4} \mathrm{M}\right)$.

A

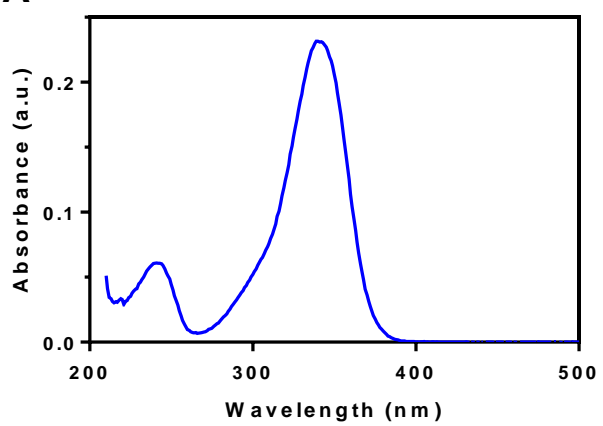

B

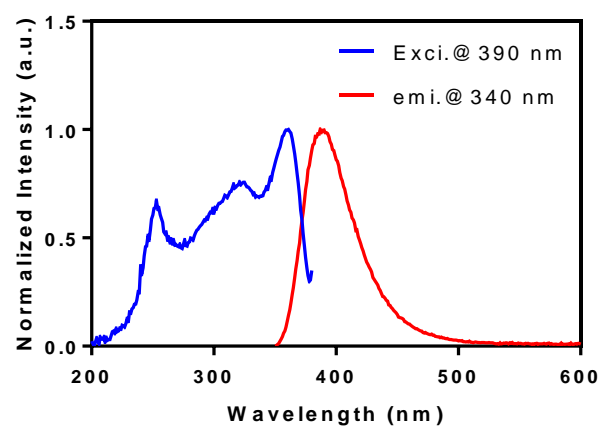

Supplementary Figure 8. (A) Absorption spectra of DMBA in MeOH solution $\left(\mathrm{c}=1 \times 10^{-5} \mathrm{M}\right)$. (B) Fluorescence emission and excitation spectra of DMBA in $\mathrm{MeOH}$ solution $\left(\mathrm{c}=1 \times 10^{-4} \mathrm{M}\right)$.

A

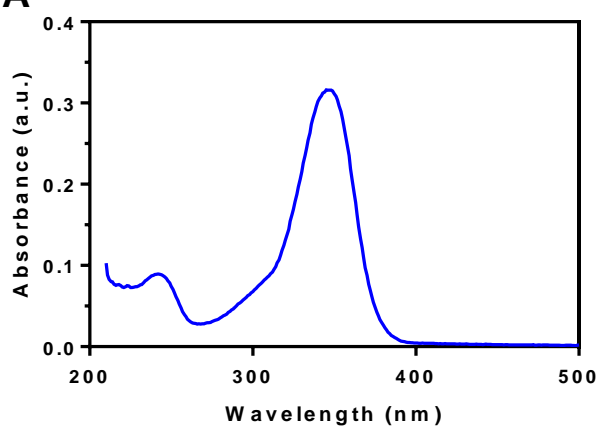

B

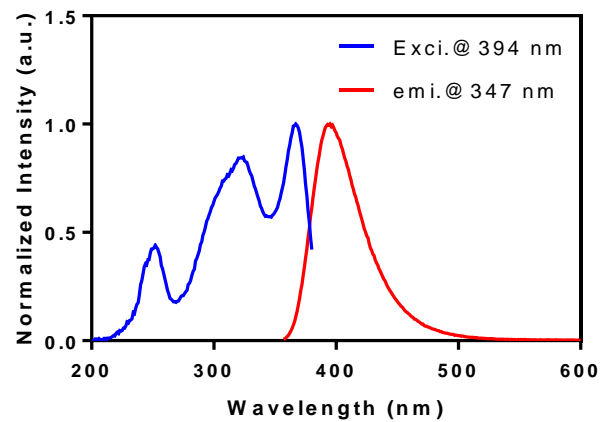

Supplementary Figure 9. (A) Absorption spectra of PBA in $\mathrm{MeOH}$ solution $\left(\mathrm{c}=1 \times 10^{-5} \mathrm{M}\right)$. (B) Fluorescence emission and excitation spectra of PBA in $\mathrm{MeOH}$ solution $\left(\mathrm{c}=1 \times 10^{-4} \mathrm{M}\right)$. 
A

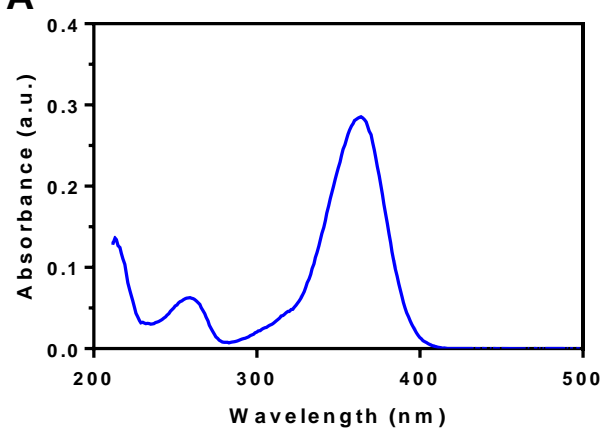

B

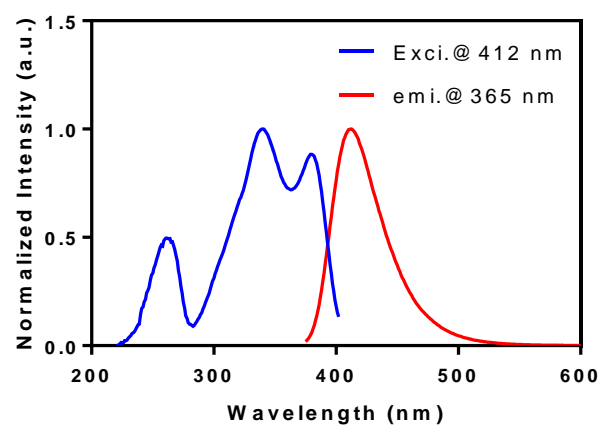

Supplementary Figure 10. (A) Absorption spectra of JCA in MeOH solution $\left(\mathrm{c}=1 \times 10^{-5} \mathrm{M}\right)$. (B) Fluorescence emission and excitation spectra of JCA in $\mathrm{MeOH}$ solution $\left(\mathrm{c}=1 \times 10^{-4} \mathrm{M}\right)$.

A

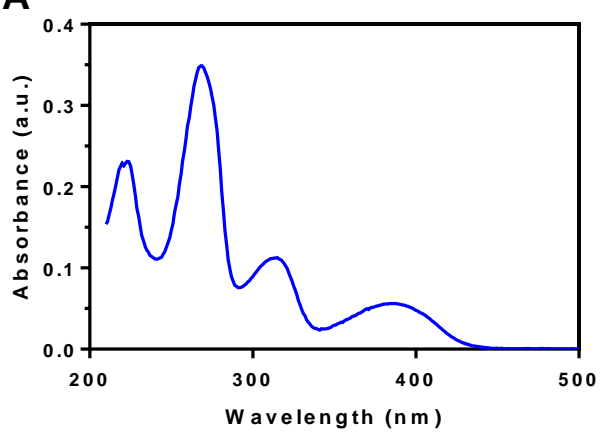

B

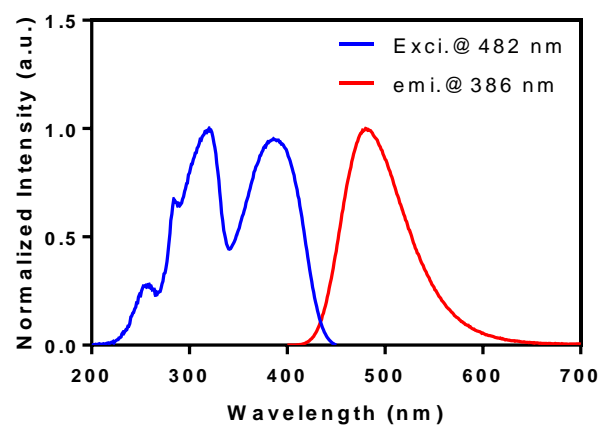

Supplementary Figure 11. (A) Absorption spectra of DMQI in MeOH solution ( $\left.\mathrm{c}=1 \times 10^{-5} \mathrm{M}\right)$. (B) Fluorescence emission and excitation spectra of DMQI in MeOH solution $\left(\mathrm{c}=1 \times 10^{-4} \mathrm{M}\right)$.

A

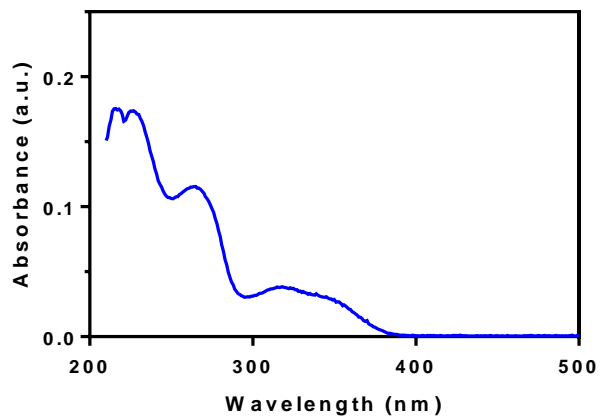

B

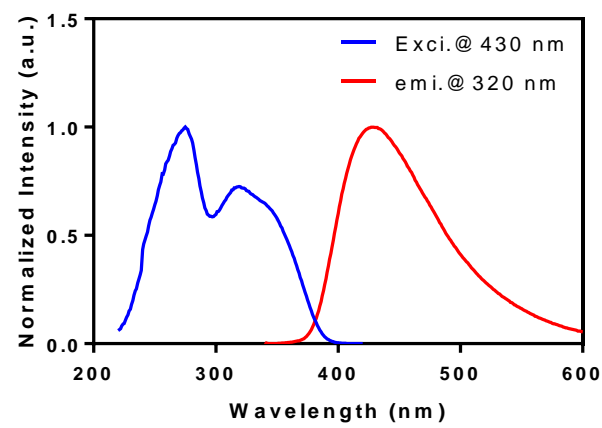

Supplementary Figure 12. (A) Absorption spectra of DMIQI in MeOH solution $\left(\mathrm{c}=1 \times 10^{-5} \mathrm{M}\right)$. (B) Fluorescence emission and excitation spectra of DMIQI in MeOH solution $\left(\mathrm{c}=1 \times 10^{-4} \mathrm{M}\right)$. 
A

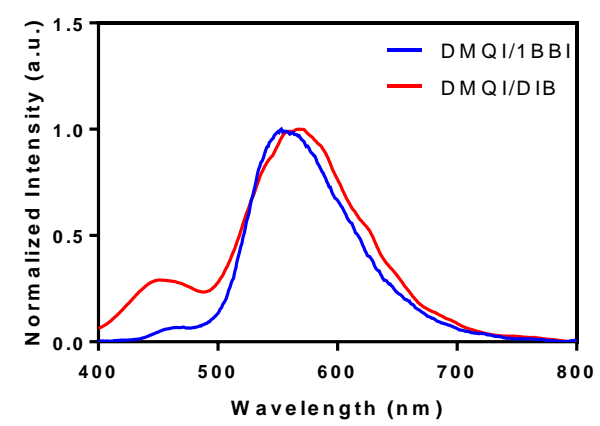

B

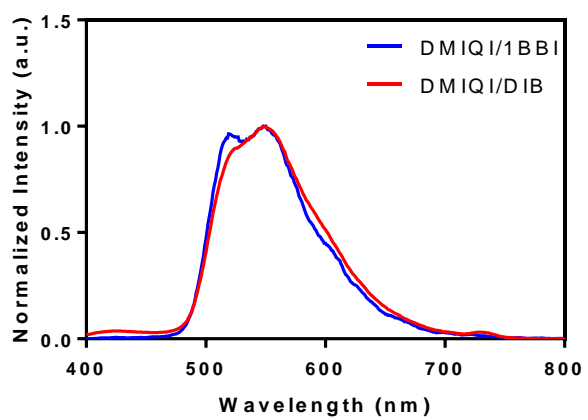

Supplementary Figure 13. (A) Comparative RTP spectra of DMQI/1 BBI with DMQI/DIB. (B) Comparative RTP spectra of DMIQI/1BBI with DMIQI/DIB.
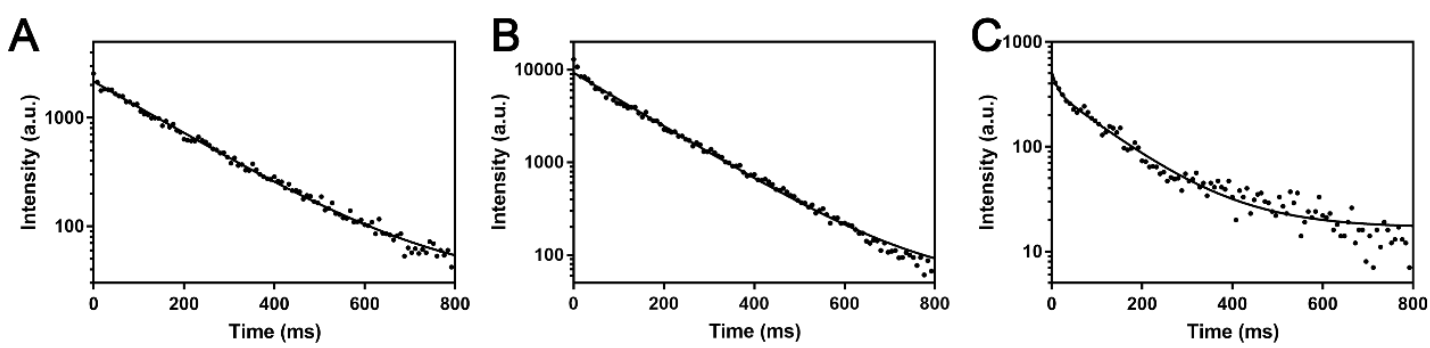

Supplementary Figure 14. Phosphorescence decay curve of A) DMBA/1BBI, B) PBA/1BBI and

C) JCA/1BBI in $\mathrm{MeOH}$ solution at $77 \mathrm{~K}$.
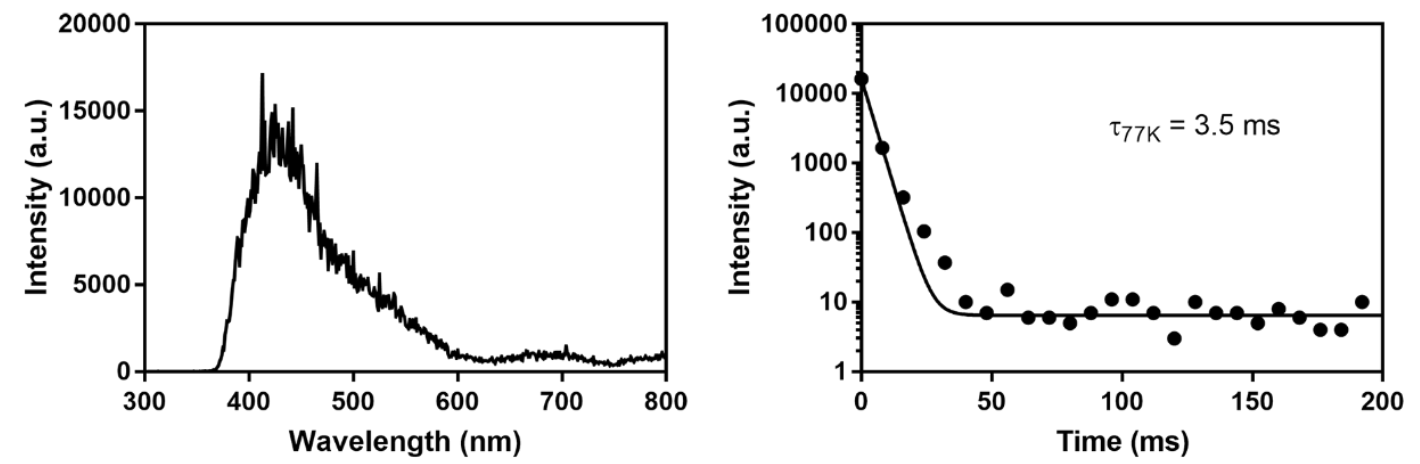

Supplementary Figure 15. Phosphorescence spectra and decay curve of $\mathbf{1 B B I}$ in $\mathrm{MeOH}$ solution at $77 \mathrm{~K}$. 

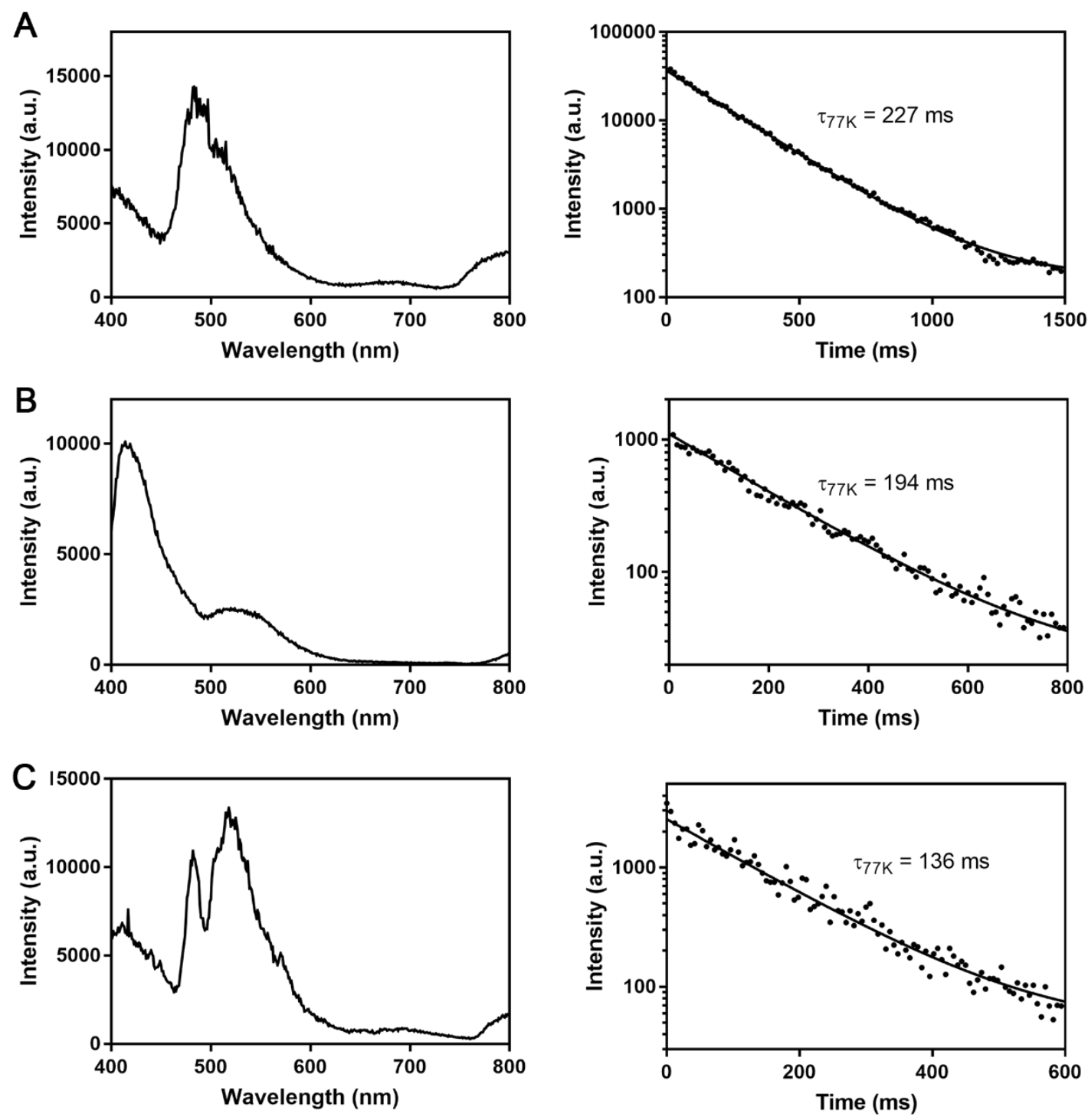

Supplementary Figure 16. Phosphorescence spectra and decay curve of (A) DMBA, (B) PBA and (C) JCA in $\mathrm{MeOH}$ solution at $77 \mathrm{~K}$. 

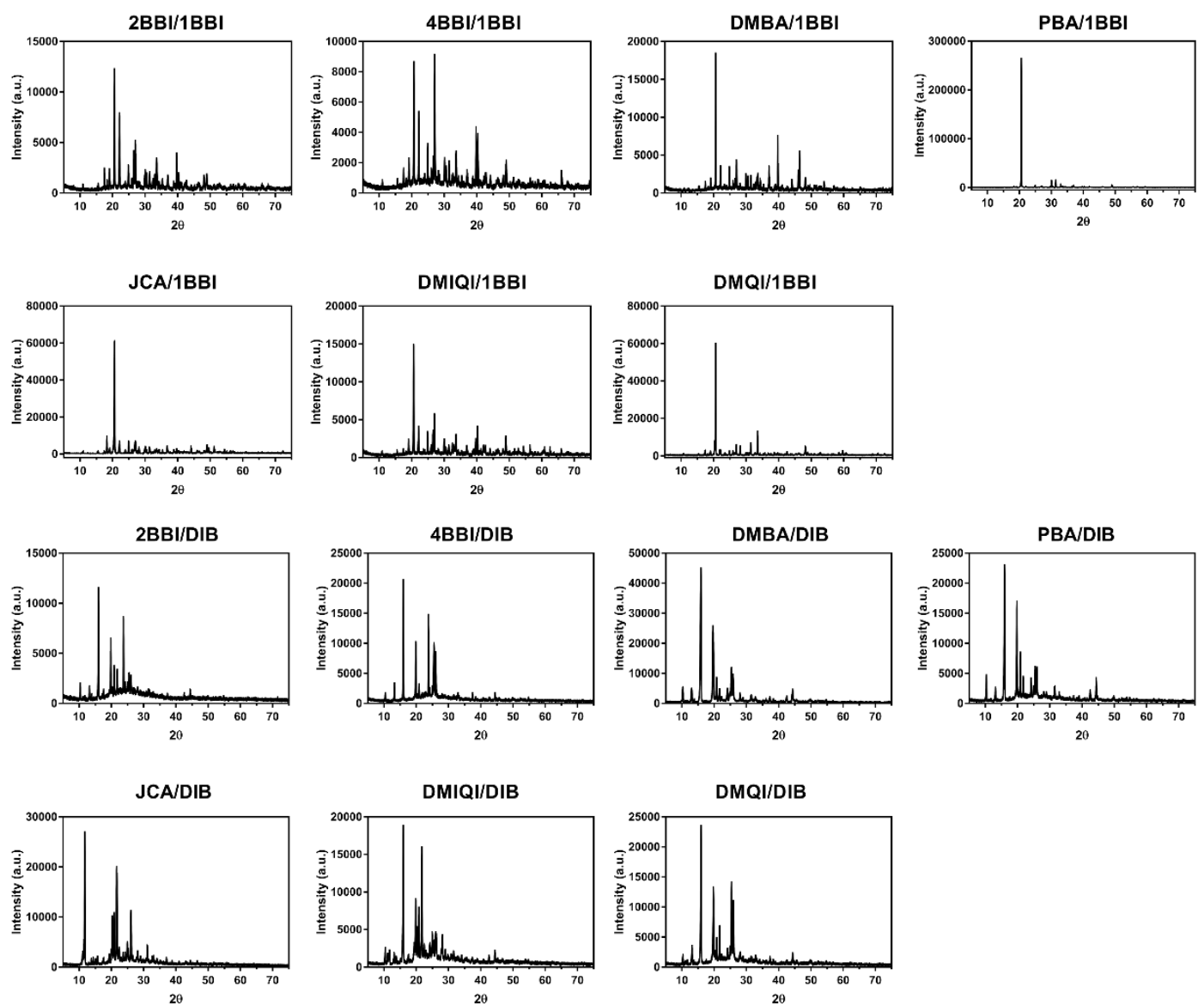

Supplementary Figure 17. XRD pattern of mixed bicomponent system at $1 \mathrm{~mol} \%$ proportion.

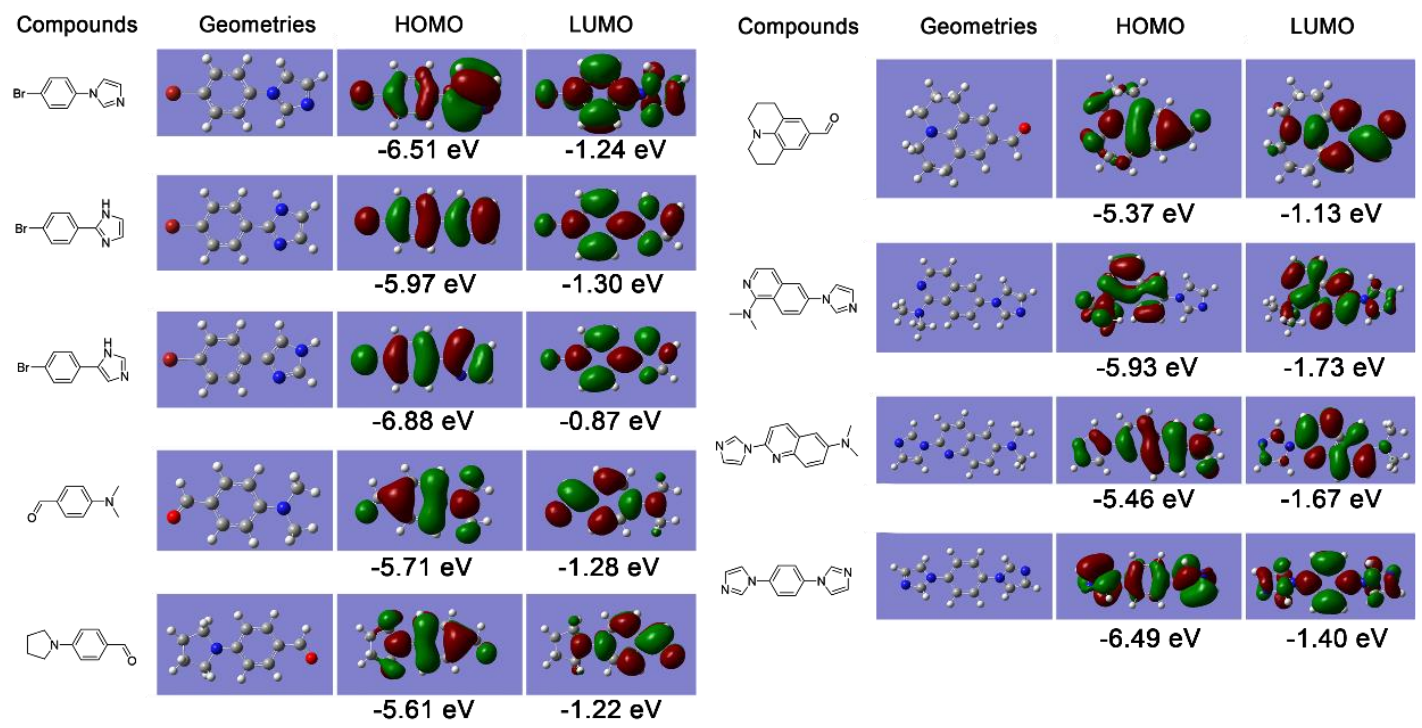

Supplementary Figure 18. The optimized geometries, HOMO and LUMO calculated using Gaussian 09E01 program with B3LYP/6-311g(d) method. 
A

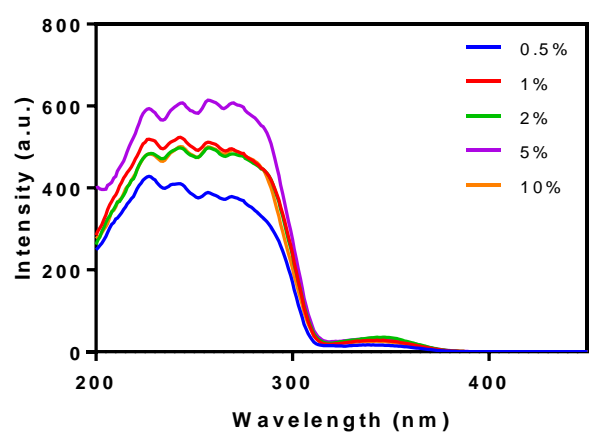

B

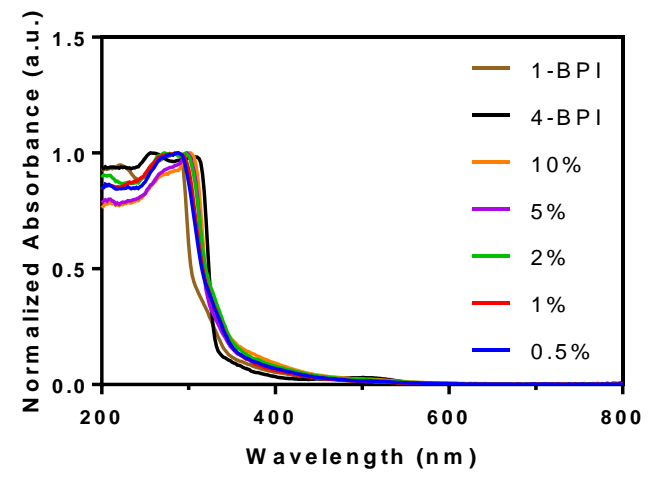

Supplementary Figure 19. A) The excitation spectra and B) solid state absorbance of 4BBI/1BBI at different ratio.

A

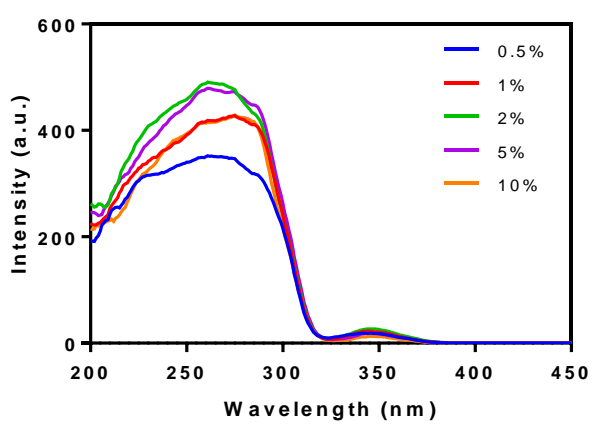

B

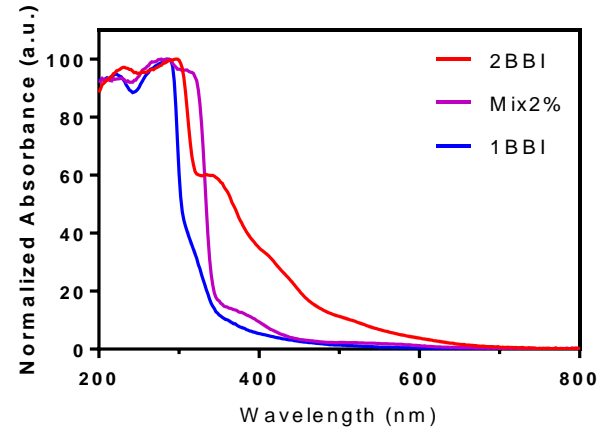

Supplementary Figure 20. A) The excitation spectra and B) solid state absorbance of 2BBI/1BBI at different ratio.

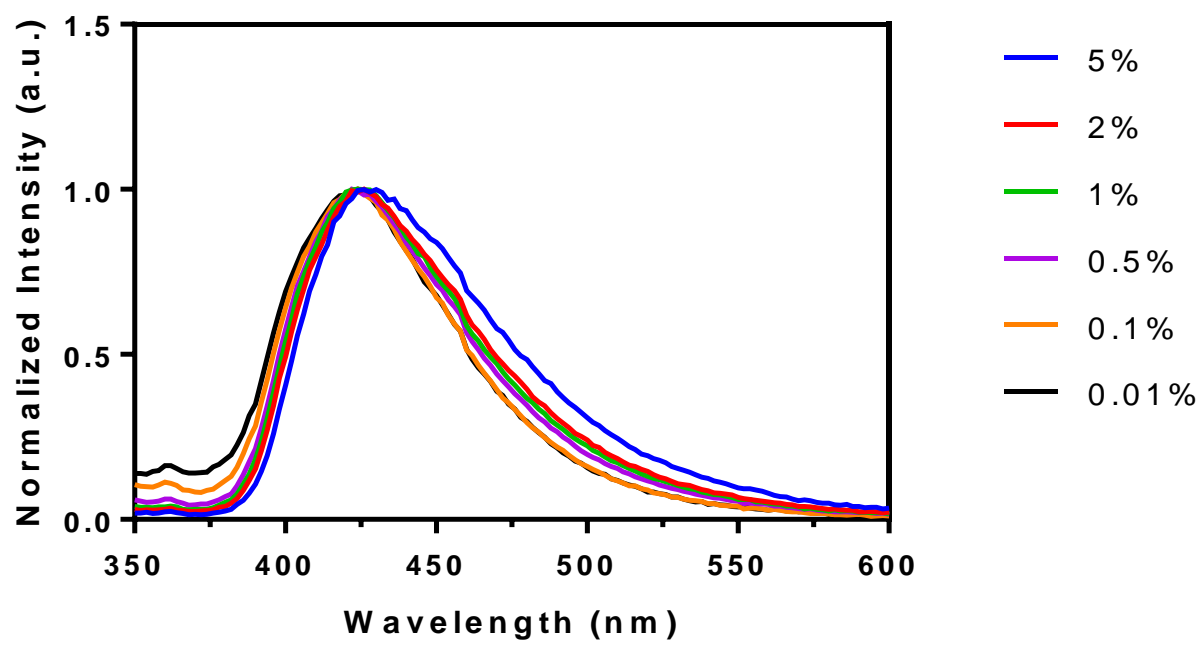

Supplementary Figure 21. The fluorescence of DMIQI/1BBI at different ratio. 


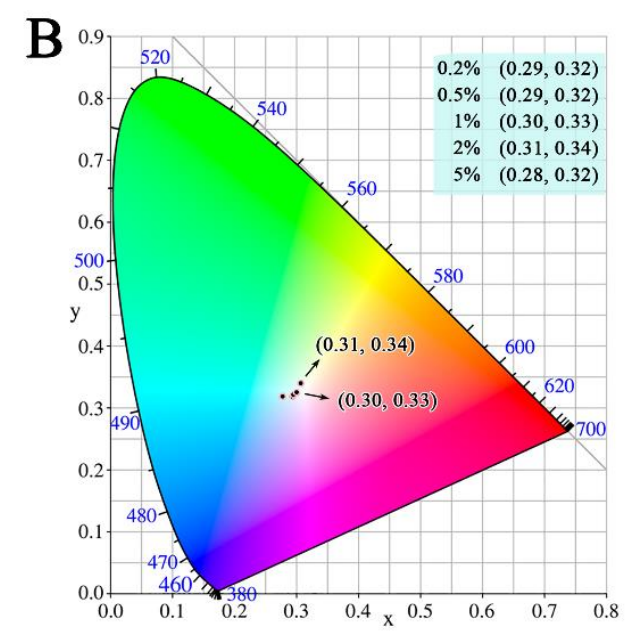

Supplementary Figure 22. (A) Images of DMQI/1BBI solid under different excitation at various proportions. (B) CIE coordinate of DMQI/1BBI luminescence at various proportions under 280 $\mathrm{nm}$ excitation.
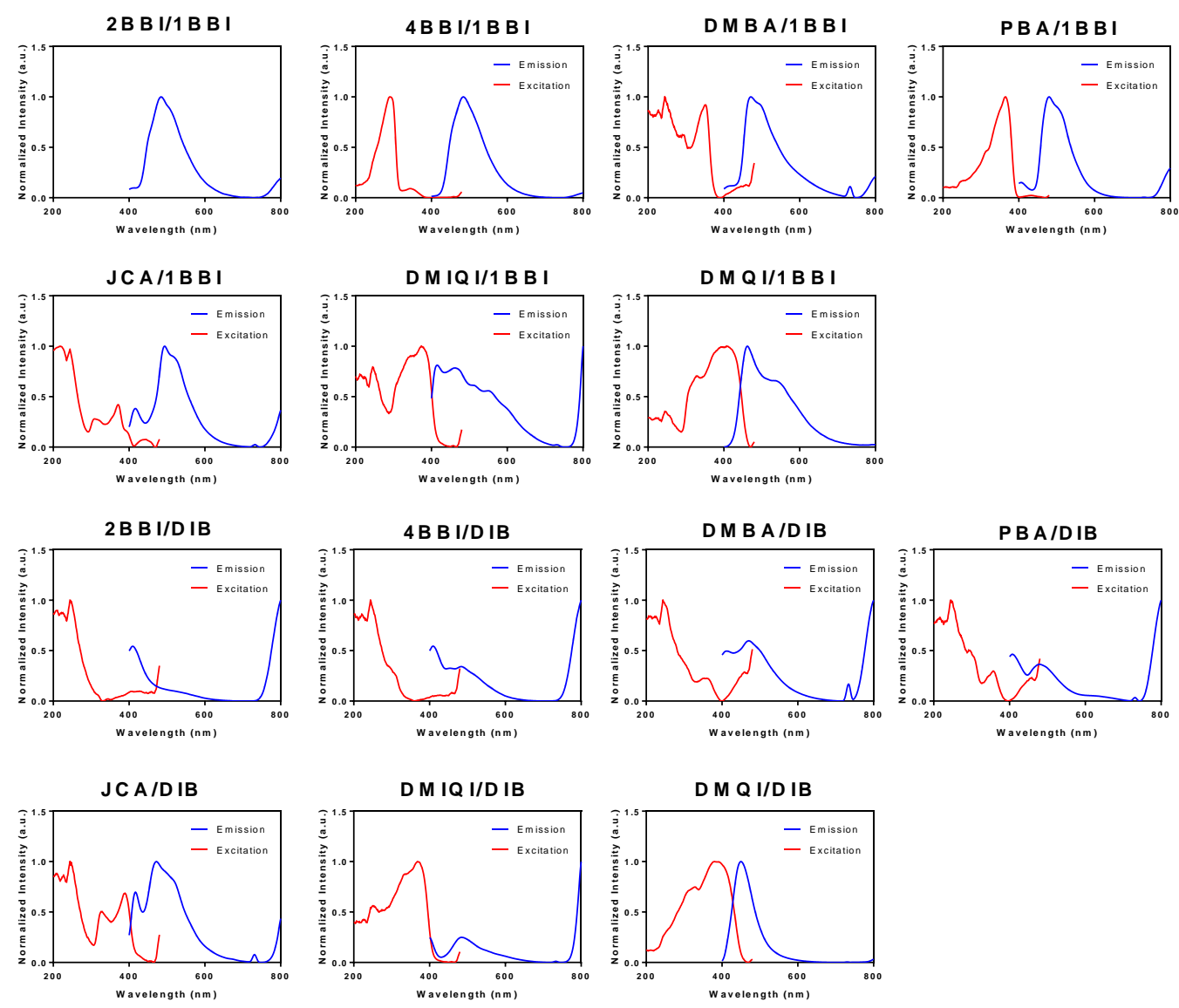

Supplementary Figure 23. Normalized steady state luminescence and excitation spectra of bicomponent systems at $1 \mathrm{~mol} \%$ proportion. 
<smiles>Brc1ccc(-n2cccn2)cc1</smiles><smiles>c1ccc(-n2ccnc2)cc1</smiles><smiles>Fc1ccc(-n2ccnc2)cc1</smiles><smiles>Nc1ccc(-n2ccnc2)cc1</smiles><smiles>CN(C)c1ccc(-n2ccnc2)cc1</smiles><smiles>O=Cc1ccc(Br)cc1</smiles><smiles>CC(=O)c1ccc(N(C)C)cc1</smiles><smiles>CN(C)c1ccc(C=C(C#N)C#N)cc1</smiles><smiles>CN(C)c1ccc(C(=O)c2ccccc2)cc1</smiles><smiles>CN(C)c1ccc(C(=O)c2ccc(N(C)C)cc2)cc1</smiles><smiles>CN(C)c1ccc2cc(C=O)ccc2c1</smiles><smiles>CN(C)c1ccc(-c2ccc(C=O)cc2)cc1</smiles><smiles>CN(C)c1ccc(-n2ccnc2)cn1</smiles><smiles>Brc1ccc(-n2cc[n+](-c3ccc(Br)cc3)c2)cc1</smiles><smiles>O=Cc1ccc(-n2ccnc2)cc1</smiles><smiles>CN(C)c1ccc2cc(-n3ccnc3)ccc2c1</smiles>

Supplementary Figure 24. A list of compounds that could not achieve RTP after mixing with 1BBI. The red marked compound shows RTP with 1BBI when used directly from commercial source but RTP disappears after purification. 
Supplementary Table 2. Singlet and triplet transition configurations and energy gaps.

\begin{tabular}{|c|c|c|c|c|}
\hline Compounds & States & Energy $(\mathrm{eV})$ & $\begin{array}{c}\text { Transition } \\
\text { configuration }(\%)^{\mathrm{a}}\end{array}$ & $\Delta \mathrm{ST}(\mathrm{eV})^{\mathrm{b}}$ \\
\hline \multirow{5}{*}{$1 \mathrm{BBI}$} & $\mathrm{S}_{1}$ & 4.65 & $\mathrm{H} \rightarrow \mathrm{L}+1(87 \%)$ & 0.15 \\
\hline & $\mathrm{T}_{4}$ & 4.50 & $\begin{array}{c}\mathrm{H}-3 \rightarrow \mathrm{L}+1(71 \%) \\
\mathrm{H}-1 \rightarrow \mathrm{L}(20 \%)\end{array}$ & \\
\hline & $\mathrm{T}_{3}$ & 4.16 & $\begin{array}{c}\mathrm{H}-1 \rightarrow \mathrm{L}+1(45 \%) \\
\mathrm{H} \rightarrow \mathrm{L}+1(48 \%)\end{array}$ & \\
\hline & $\mathrm{T}_{2}$ & 3.90 & $\begin{array}{c}\mathrm{H}-1 \rightarrow \mathrm{L}(29 \%) \\
\mathrm{H} \rightarrow \mathrm{L}(35 \%) \\
\mathrm{H} \rightarrow \mathrm{L}+3(24 \%)\end{array}$ & \\
\hline & $\mathrm{T}_{1}$ & 3.51 & $\begin{array}{c}\mathrm{H}-3 \rightarrow \mathrm{L}+1(21 \%) \\
\mathrm{H}-1 \rightarrow \mathrm{L}(33 \%) \\
\mathrm{H} \rightarrow \mathrm{L}(38 \%)\end{array}$ & \\
\hline \multirow{6}{*}{ DIB } & $\mathrm{S}_{1}$ & 4.52 & $\mathrm{H} \rightarrow \mathrm{L}(88 \%)$ & 0.05 \\
\hline & $\mathrm{T}_{5}$ & 4.47 & $\begin{array}{c}\mathrm{H} \rightarrow \mathrm{L}(16 \%) \\
\mathrm{H}-5 \rightarrow \mathrm{L}+1(71 \%)\end{array}$ & \\
\hline & $\mathrm{T}_{4}$ & 4.05 & $\begin{array}{c}\mathrm{H}-2 \rightarrow \mathrm{L}+1(29 \%) \\
\mathrm{H} \rightarrow \mathrm{L}+1(65 \%)\end{array}$ & \\
\hline & $\mathrm{T}_{3}$ & 3.91 & $\begin{array}{c}\mathrm{H}-2 \rightarrow \mathrm{L}(37 \%) \\
\mathrm{H}-1 \rightarrow \mathrm{L}+2(20 \%) \\
\mathrm{H} \rightarrow \mathrm{L}(21 \%)\end{array}$ & \\
\hline & $\mathrm{T}_{2}$ & 3.86 & $\begin{array}{l}\mathrm{H}-1 \rightarrow \mathrm{L}(65 \%) \\
\mathrm{H} \rightarrow \mathrm{L}+2(17 \%)\end{array}$ & \\
\hline & $\mathrm{T}_{1}$ & 3.45 & $\begin{array}{c}\mathrm{H}-5 \rightarrow \mathrm{L}+1(16 \%) \\
\mathrm{H}-2 \rightarrow \mathrm{L}+1(22 \%) \\
\mathrm{H}-2 \rightarrow \mathrm{L}(53 \%)\end{array}$ & \\
\hline \multirow{4}{*}{ 2BBI } & $\mathrm{S}_{1}$ & 4.42 & $\mathrm{H} \rightarrow \mathrm{L}(97 \%)$ & 0.22 \\
\hline & $\mathrm{T}_{3}$ & 4.20 & $\begin{array}{c}\mathrm{H}-2 \rightarrow \mathrm{L}+1(41 \%) \\
\mathrm{H}-1 \rightarrow \mathrm{L}(19 \%) \\
\mathrm{H} \rightarrow \mathrm{L}+4(12 \%)\end{array}$ & \\
\hline & $\mathrm{T}_{2}$ & 3.86 & $\mathrm{H} \rightarrow \mathrm{L}+1(78 \%)$ & \\
\hline & $\mathrm{T}_{1}$ & 3.45 & $\mathrm{H} \rightarrow \mathrm{L}(89 \%)$ & \\
\hline \multirow{4}{*}{$4 \mathrm{BBI}$} & $\mathrm{S}_{1}$ & 4.64 & $\begin{array}{c}\mathrm{H} \rightarrow \mathrm{L}(42 \%) \\
\mathrm{H} \rightarrow \mathrm{L}+1(46 \%)\end{array}$ & 0.05 \\
\hline & $\mathrm{T}_{5}$ & 4.59 & $\mathrm{H} \rightarrow \mathrm{L}+2(87 \%)$ & \\
\hline & $\mathrm{T}_{4}$ & 4.54 & $\begin{array}{c}\mathrm{H}-1 \rightarrow \mathrm{L}+1(40 \%) \\
\mathrm{H} \rightarrow \mathrm{L}+3(31 \%)\end{array}$ & \\
\hline & $\mathrm{T}_{3}$ & 4.25 & $\begin{array}{c}\mathrm{H}-2 \rightarrow \mathrm{L}(21 \%) \\
\mathrm{H}-1 \rightarrow \mathrm{L}+1(23 \%) \\
\mathrm{H} \rightarrow \mathrm{L}+1(14 \%) \\
\mathrm{H} \rightarrow \mathrm{L}+3(19 \%)\end{array}$ & \\
\hline
\end{tabular}




\begin{tabular}{|c|c|c|c|c|}
\hline & $\mathrm{T}_{2}$ & 3.86 & $\mathrm{H} \rightarrow \mathrm{L}+1(76 \%)$ & \\
\hline & $\mathrm{T}_{1}$ & 3.45 & $\mathrm{H} \rightarrow \mathrm{L}(87 \%)$ & \\
\hline \multirow{3}{*}{ DMBA } & $\mathrm{S}_{1}$ & 3.85 & $\mathrm{H}-1 \rightarrow \mathrm{L}(97 \%)$ & 0.52 \\
\hline & $\mathrm{T}_{2}$ & 3.33 & $\mathrm{H}-1 \rightarrow \mathrm{L}(94 \%)$ & \\
\hline & $\mathrm{T}_{1}$ & 2.89 & $\mathrm{H} \rightarrow \mathrm{L}(94 \%)$ & \\
\hline \multirow{4}{*}{ PBA } & $\mathrm{S}_{1}$ & 3.86 & $\mathrm{H}-1 \rightarrow \mathrm{L}(96 \%)$ & 0.02 \\
\hline & $\mathrm{T}_{3}$ & 3.84 & $\mathrm{H} \rightarrow \mathrm{L}+1(98 \%)$ & \\
\hline & $\mathrm{T}_{2}$ & 3.34 & $\mathrm{H}-1 \rightarrow \mathrm{L}(93 \%)$ & \\
\hline & $\mathrm{T}_{1}$ & 2.86 & $\mathrm{H} \rightarrow \mathrm{L}(94 \%)$ & \\
\hline \multirow{4}{*}{ JCA } & $\mathrm{S}_{1}$ & 3.87 & $\mathrm{H}-1 \rightarrow \mathrm{L}(96 \%)$ & 0.16 \\
\hline & $\mathrm{T}_{3}$ & 3.71 & $\mathrm{H} \rightarrow \mathrm{L}+1(98 \%)$ & \\
\hline & $\mathrm{T}_{2}$ & 3.35 & $\mathrm{H}-1 \rightarrow \mathrm{L}(93 \%)$ & \\
\hline & $\mathrm{T}_{1}$ & 2.71 & $\mathrm{H} \rightarrow \mathrm{L}(95 \%)$ & \\
\hline \multirow{4}{*}{ DMIQI } & $\mathrm{S}_{1}$ & 3.68 & $\mathrm{H} \rightarrow \mathrm{L}(95 \%)$ & 0.14 \\
\hline & $\mathrm{T}_{3}$ & 3.54 & $\begin{array}{l}\mathrm{H}-2 \rightarrow \mathrm{L}(11 \%) \\
\mathrm{H}-1 \rightarrow \mathrm{L}(31 \%) \\
\mathrm{H} \rightarrow \mathrm{L}+1(47 \%)\end{array}$ & \\
\hline & $\mathrm{T}_{2}$ & 3.45 & $\begin{array}{c}\mathrm{H}-2 \rightarrow \mathrm{L}(17 \%) \\
\mathrm{H}-1 \rightarrow \mathrm{L}(17 \%) \\
\mathrm{H} \rightarrow \mathrm{L}(11 \%) \\
\mathrm{H} \rightarrow \mathrm{L}+1(38 \%)\end{array}$ & \\
\hline & $\mathrm{T}_{1}$ & 2.62 & $\mathrm{H} \rightarrow \mathrm{L}(83 \%)$ & \\
\hline \multirow{3}{*}{ DMQI } & $\mathrm{S}_{1}$ & 3.30 & $\mathrm{H} \rightarrow \mathrm{L}(96 \%)$ & 0.07 \\
\hline & $\mathrm{T}_{2}$ & 3.23 & $\begin{array}{l}\mathrm{H}-2 \rightarrow \mathrm{L}(50 \%) \\
\mathrm{H}-1 \rightarrow \mathrm{L}(11 \%) \\
\mathrm{H} \rightarrow \mathrm{L}+1(20 \%)\end{array}$ & \\
\hline & $\mathrm{T}_{1}$ & 2.46 & $\mathrm{H} \rightarrow \mathrm{L}(90 \%)$ & \\
\hline
\end{tabular}

${ }^{a}$ The transition configurations that blows $10 \%$ are not recorded. $\mathrm{H}$ represents $\mathrm{HOMO}$ and $\mathrm{L}$ represents LUMO. ${ }^{\mathrm{b}}$ The $\triangle \mathrm{ST}$ value means the difference between the first excited singlet state and the nearest lower triplet state. 

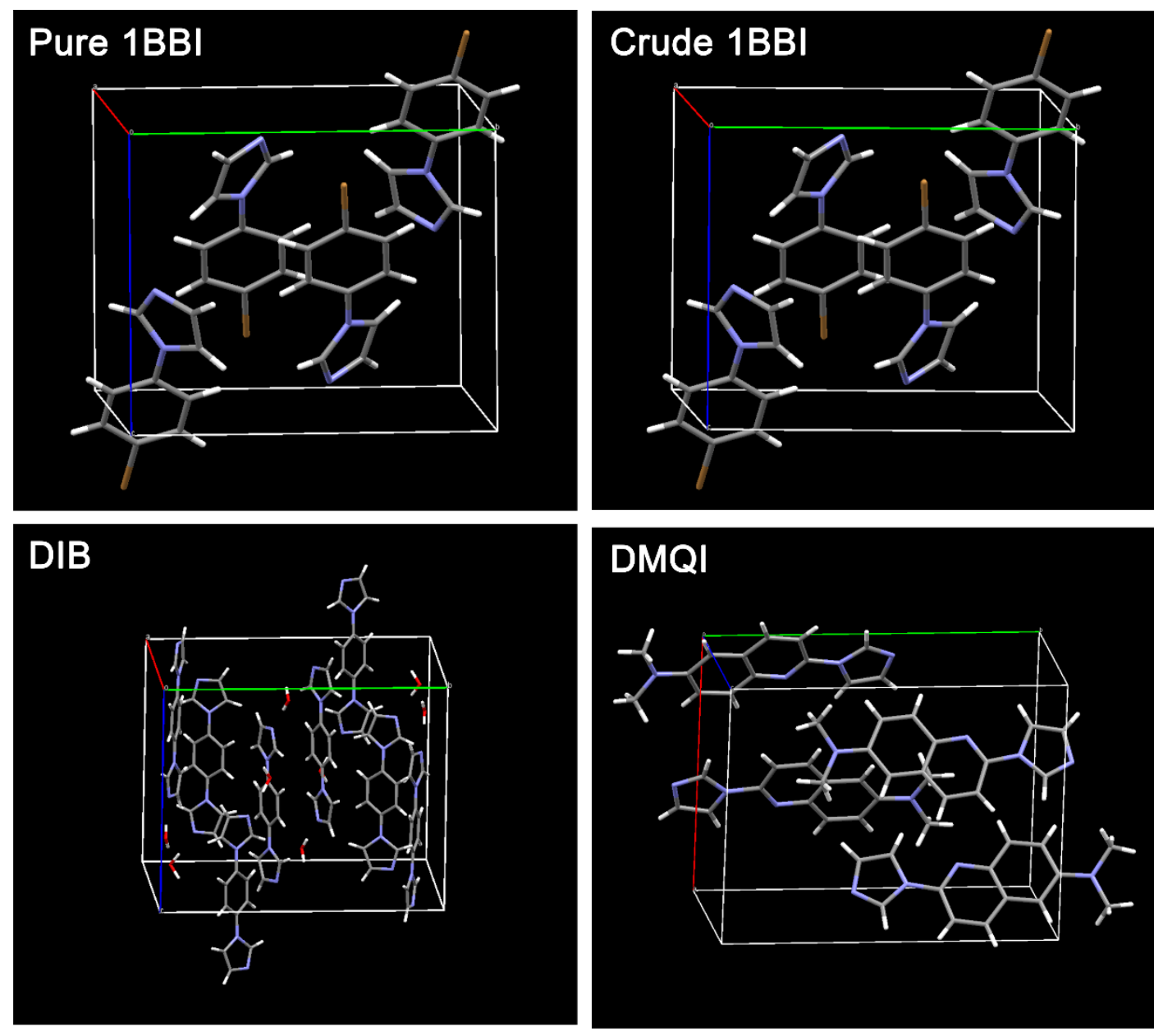

\section{DMQI}
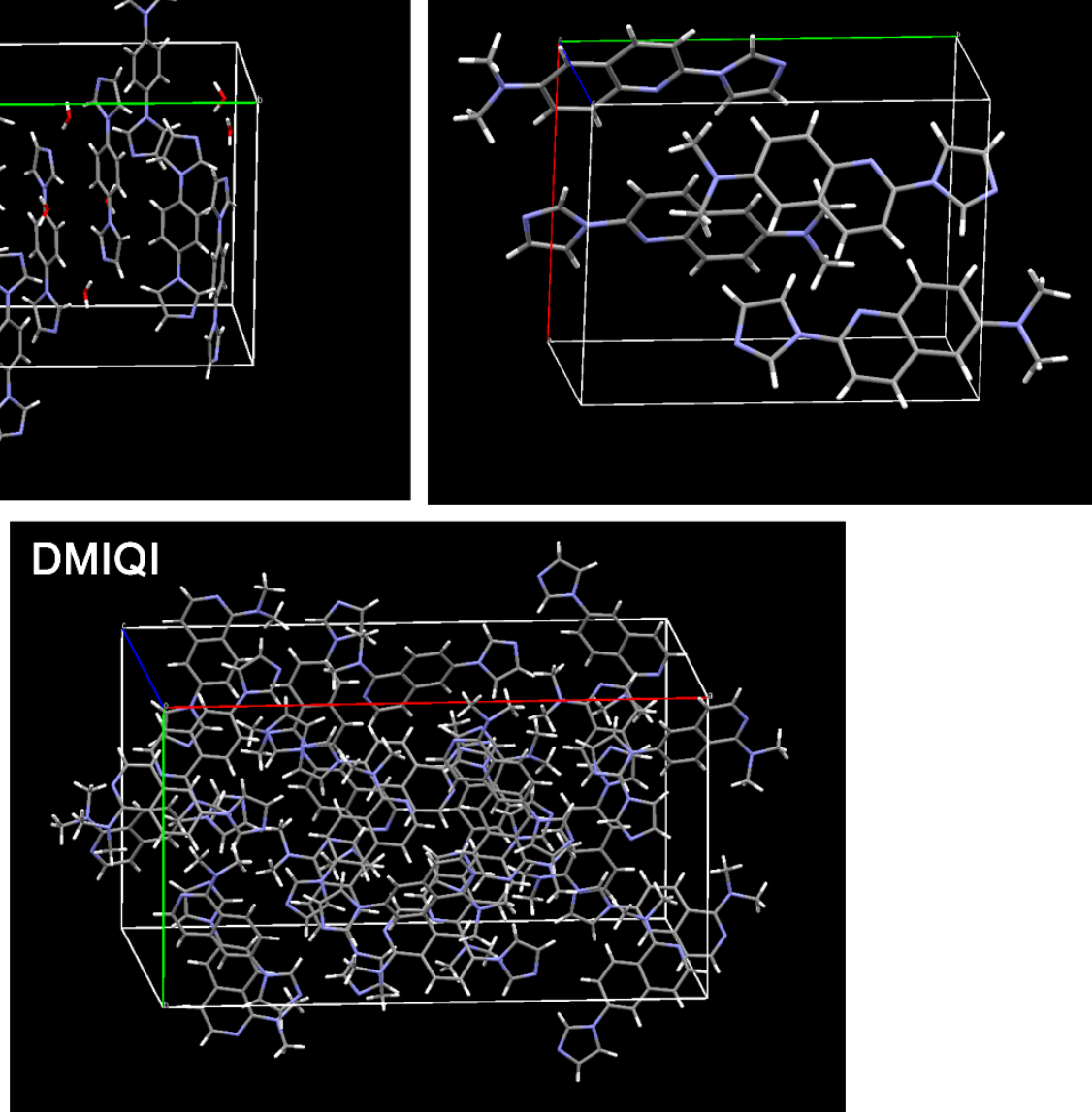

Supplementary Figure 25. Molecular packing of pure 1BBI, crude 1BBI (grow accompanying with DMQI), DIB, DMQI and DMIQI single crystals in the unit cells. 


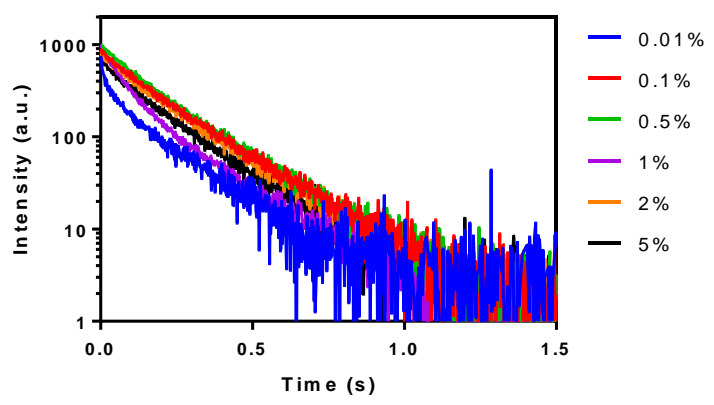

Supplementary Figure 26. RTP intensity decay curve of DMIQI/1BBI system at different mole ratio.

Supplementary Table 3. Crystal data

\begin{tabular}{|l|l|l|l|l|l|}
\hline Compound & ${\text { Pure } 1 \mathrm{BBI}^{\mathrm{a}}}^{\mathrm{C}}$ & $\mathrm{Crude}_{1 \mathrm{BBI}^{\mathrm{b}}}$ & DMQI & DMIQI & DIB \\
\hline CCDC no. & 2034130 & 2034132 & 2034136 & 2034137 & 2034138 \\
\hline Formula & $\mathrm{C}_{9} \mathrm{H}_{7} \mathrm{BrN}_{2}$ & $\mathrm{C}_{9} \mathrm{H}_{7} \mathrm{BrN}_{2}$ & $\mathrm{C}_{14} \mathrm{H}_{14} \mathrm{~N}_{4}$ & $\mathrm{C}_{14} \mathrm{H}_{14} \mathrm{~N}_{4}$ & $\mathrm{C}_{12} \mathrm{H}_{10} \mathrm{~N}_{4}$ \\
\hline Formula Weight & 221.98 & 221.98 & 238.12 & 238.12 & 210.09 \\
\hline Crystal System & monoclinic & monoclinic & orthorhombic & monoclinic & monoclinic \\
\hline Space Group & $\mathrm{P} 2_{1} / \mathrm{c}$ & $\mathrm{P} 2_{1} / \mathrm{c}$ & $\mathrm{P} \mathrm{n}$ a ${ }_{1}$ & $\mathrm{C} \mathrm{c}$ & $\mathrm{P}{ }_{1} / \mathrm{n}$ \\
\hline$a / \AA$ & $8.0296(5)$ & $8.0566(2)$ & $10.9936(4)$ & $29.3318(16)$ & $8.7763(6)$ \\
\hline$b / \AA$ & $11.3296(7)$ & $11.3370(4)$ & $14.0720(4)$ & $16.8695(10)$ & $18.2047(11)$ \\
\hline$c / \AA$ & $9.2491(5)$ & $9.2637(2)$ & $7.5725(2)$ & $14.8762(10)$ & $14.3820(7)$ \\
\hline$\alpha /{ }^{\circ}$ & 90 & 90 & 90 & 90 & 90 \\
\hline$\beta /{ }^{\circ}$ & $97.954(2)$ & $98.1330(10)$ & 90 & $94.751(2)$ & $101.461(2)$ \\
\hline$\gamma /{ }^{\circ}$ & 90 & 90 & 90 & 90 & 90 \\
\hline $\mathrm{V} / \AA^{3}$ & 833.316 & 837.615 & 1171.48 & 7335.64 & 2251.99 \\
\hline $\mathrm{Z}, \mathrm{Z}^{\circ}$ & 4,0 & 4,0 & 4,0 & 24,0 & 8,0 \\
\hline
\end{tabular}

All the single crystal was grown in methanol by solvent evaporation method. ${ }^{\text {a }}$ The single crystal was grown from pure $1 \mathrm{BBI}$ in $\mathrm{MeOH}$. ${ }^{b}$ The crude $1 \mathrm{BBI}$ single crystals were grown in $\mathrm{MeOH}$ containing equal molar mass of DMQI.

\section{NMR and HRMS Spectra}




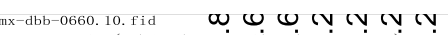

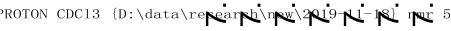

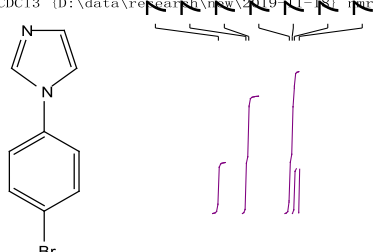

$1 \mathrm{H}$ NMR $(400 \mathrm{MHz}$, Chloroford $\delta 7.83(\mathrm{~s}, 1 \mathrm{H}), 7.61(\mathrm{~d},=8.7 \mathrm{~Hz}, 2 \mathrm{H})$

(d, $=8.8 \mathrm{~Hz}, 2 \mathrm{H}), 7.25(\mathrm{~s}, 1 \mathrm{H}), 7.21(\mathrm{~s}, 1 \mathrm{H})$

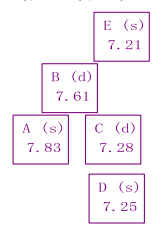

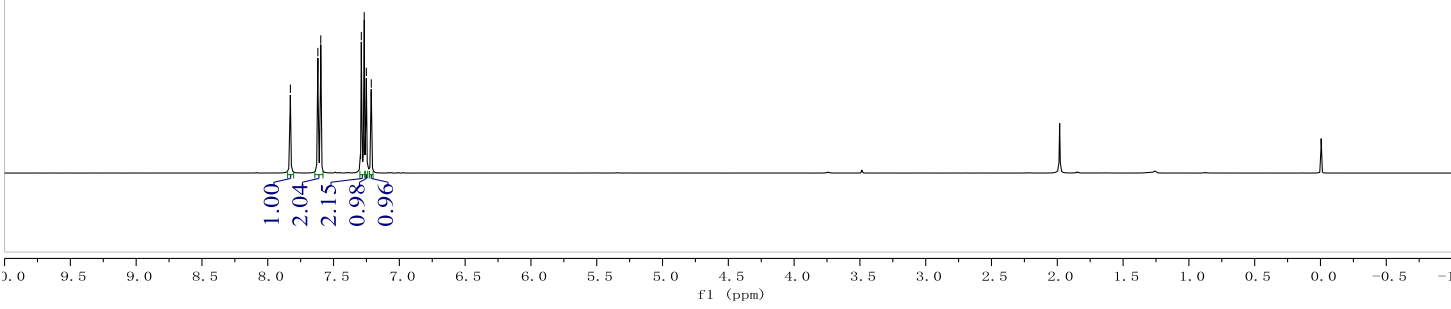

mx-dbb-0780. 10. fid

a (2) (4) (

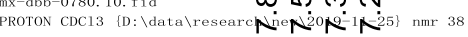

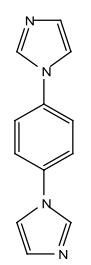

$\backslash>>$,

H NMR (400 MHz, Chloroforat) $-8.88(\mathrm{~s}, 2 \mathrm{H}), 7.52(\mathrm{~s}, 4 \mathrm{H}), 7.31$ (s, 2H), 7.24 (s, $2 \mathrm{H})$

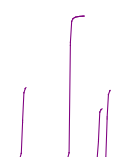

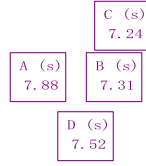

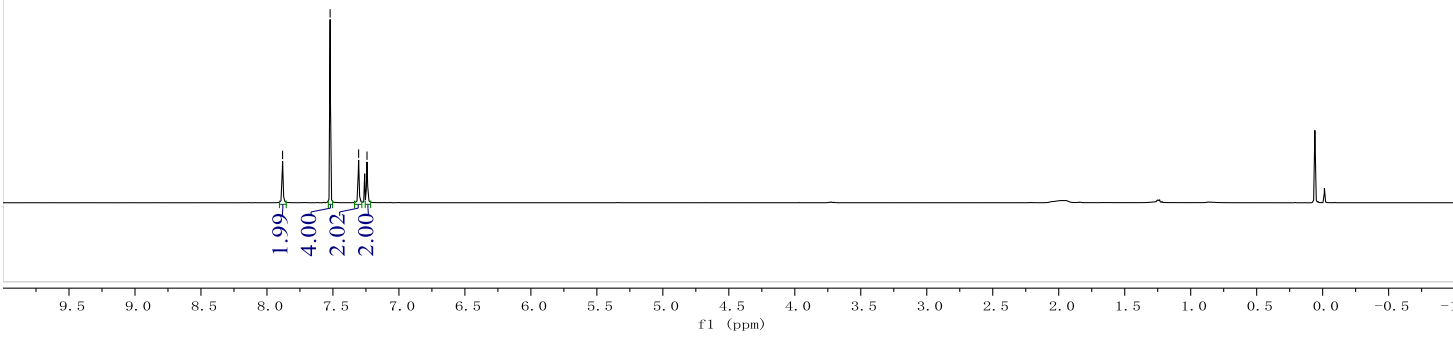




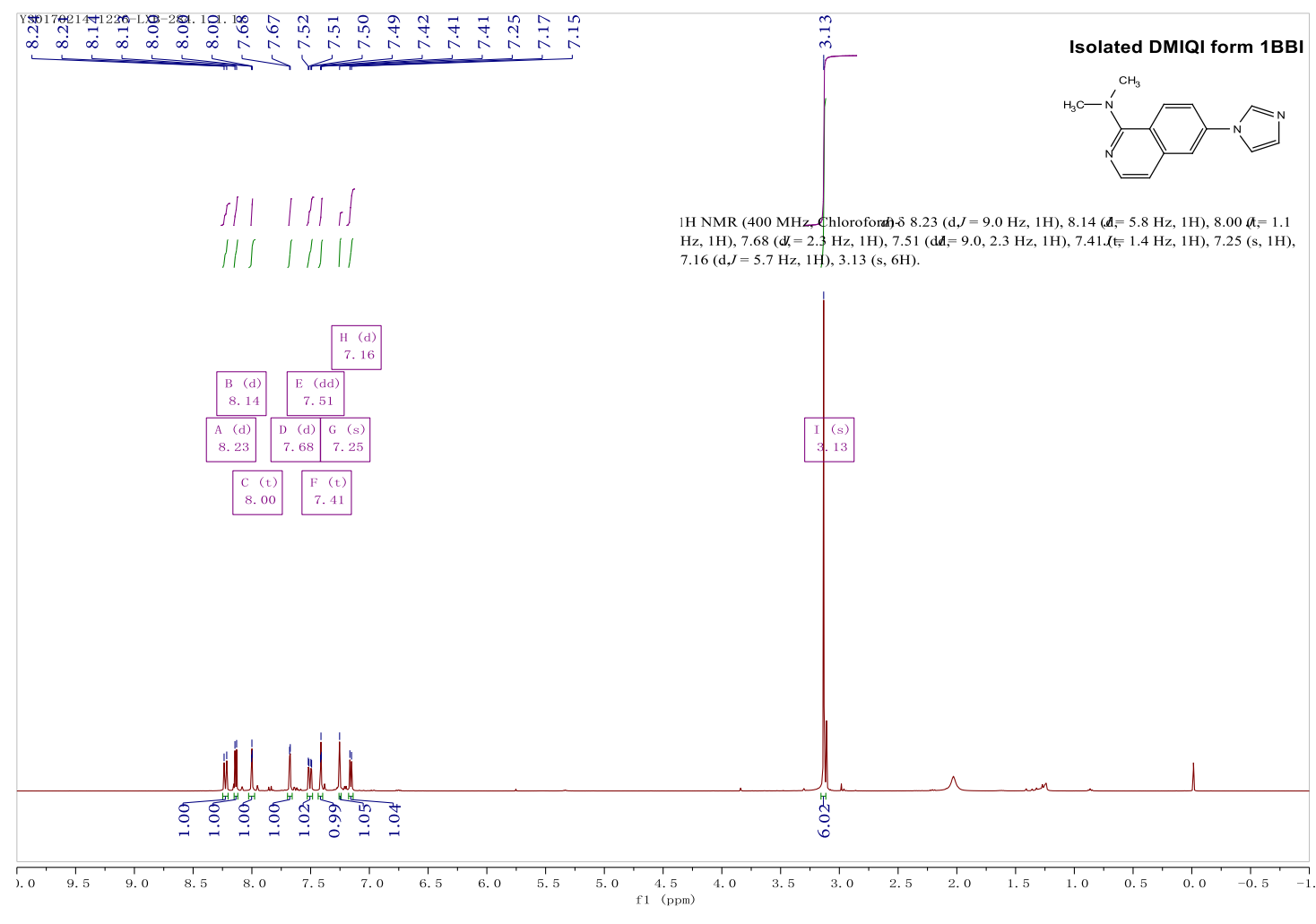

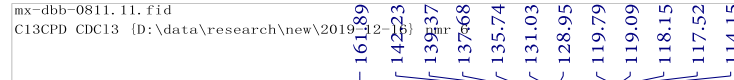

13C NMR (101 MHz, CDC6 161.89, 142.23, 139.37, 137.68, 135.74, 131.03, 128.95, 119.79, 119.09, $118.15,117.52,114.15,43.17$
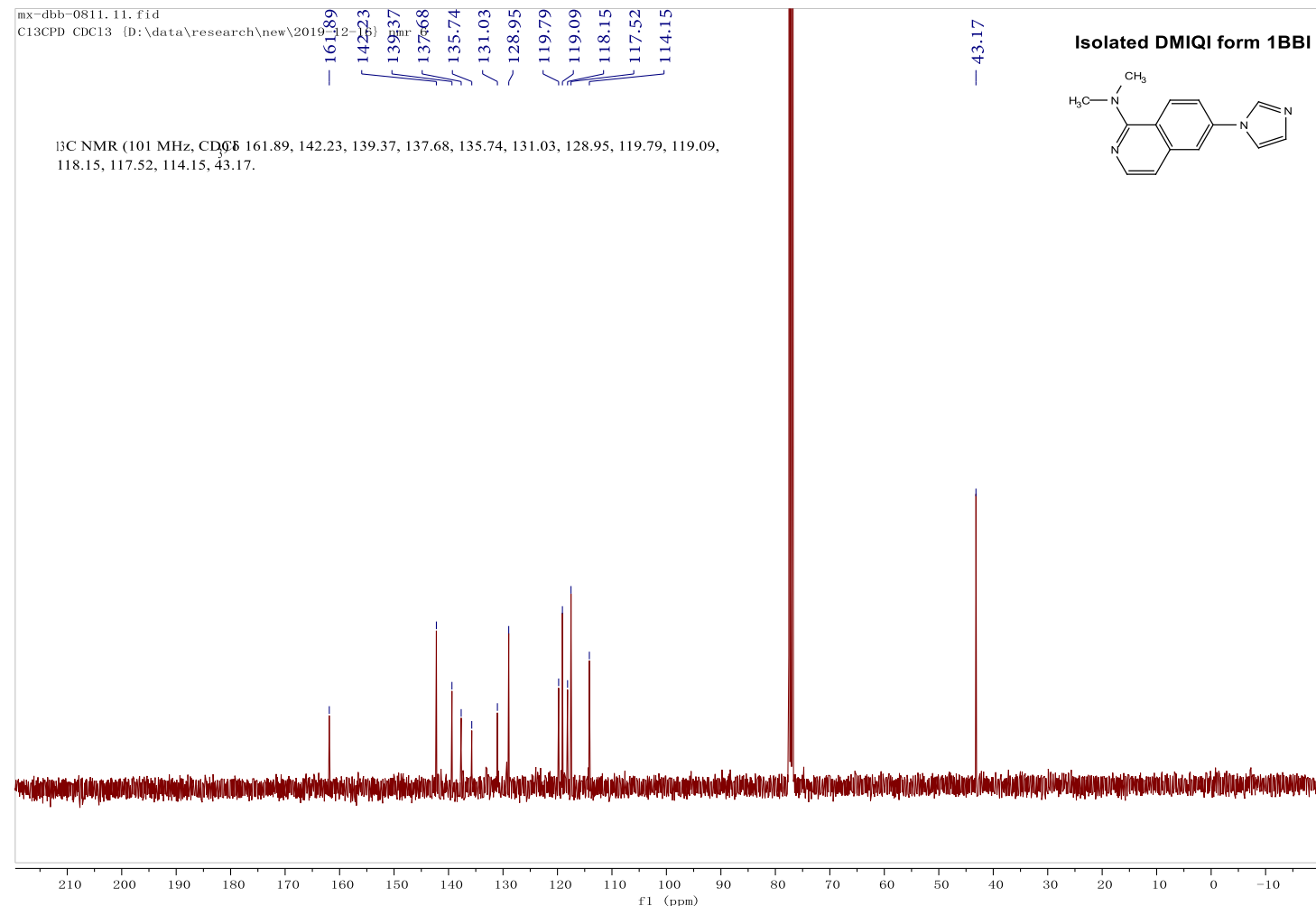

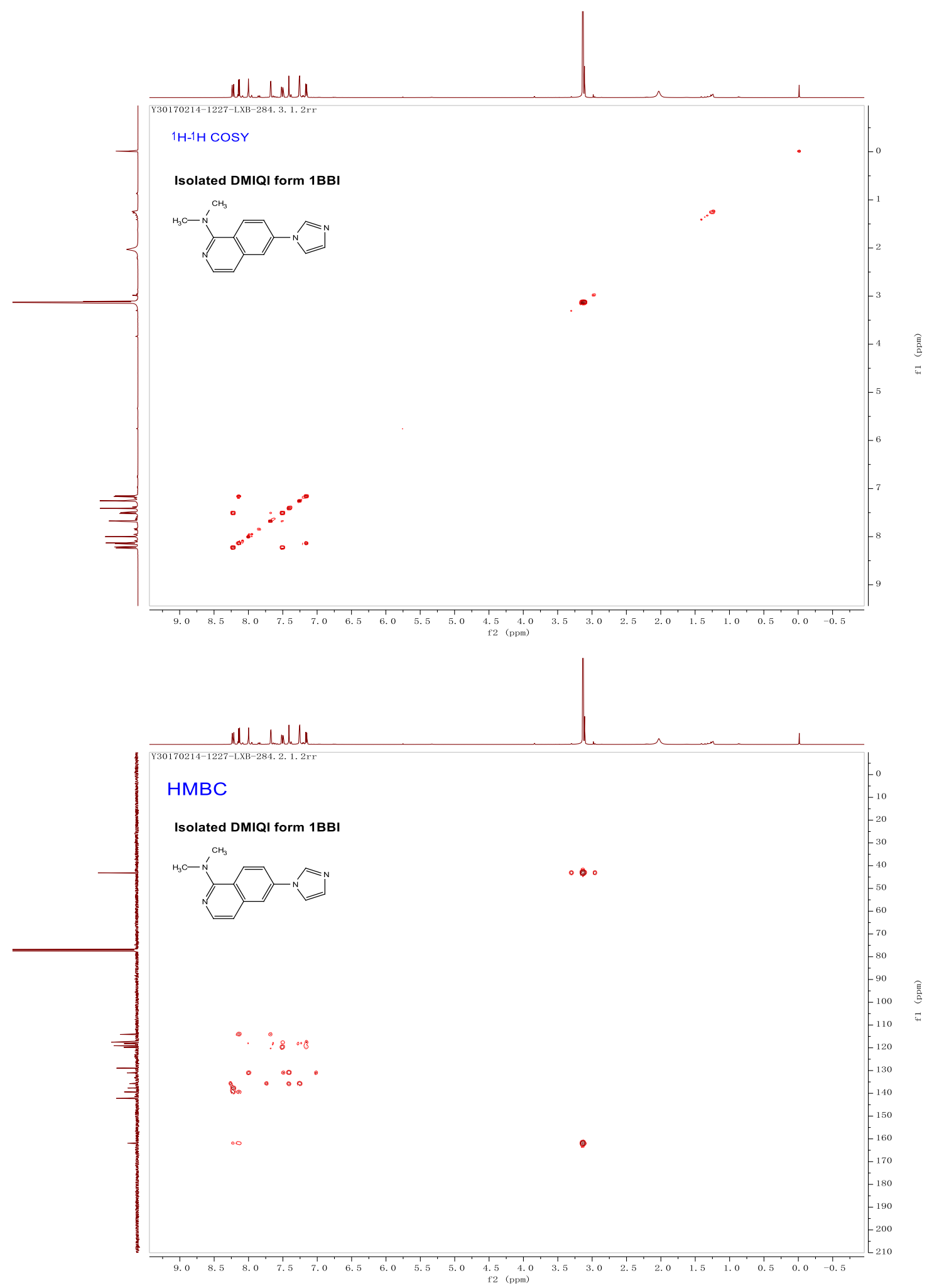


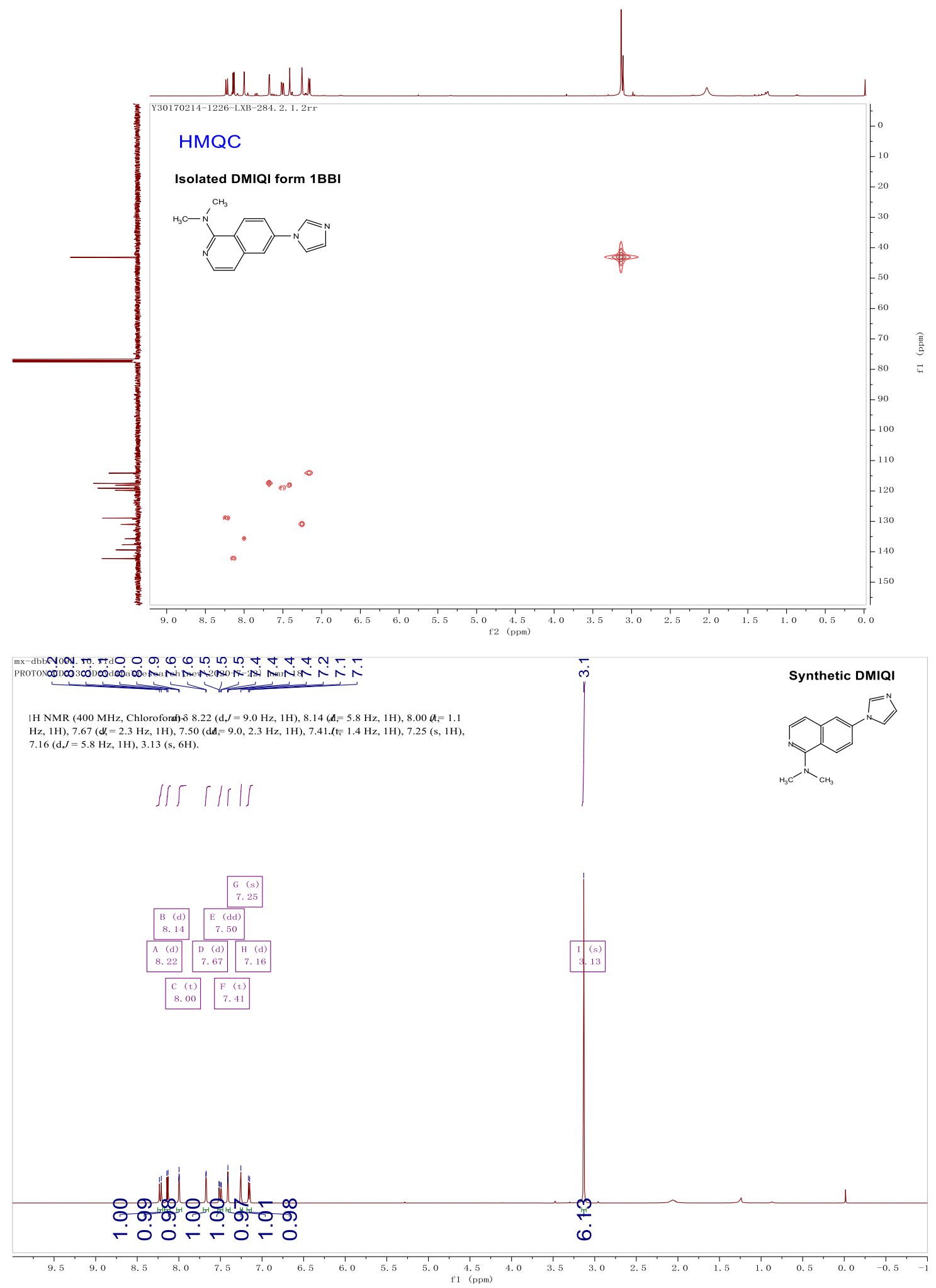




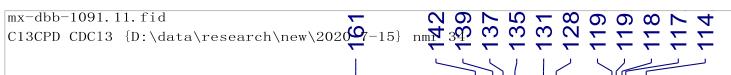

$\stackrel{\dddot{m}}{\dddot{y}}$

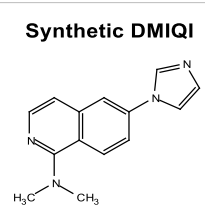

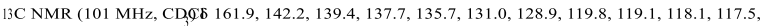
$114.1,43.2$.
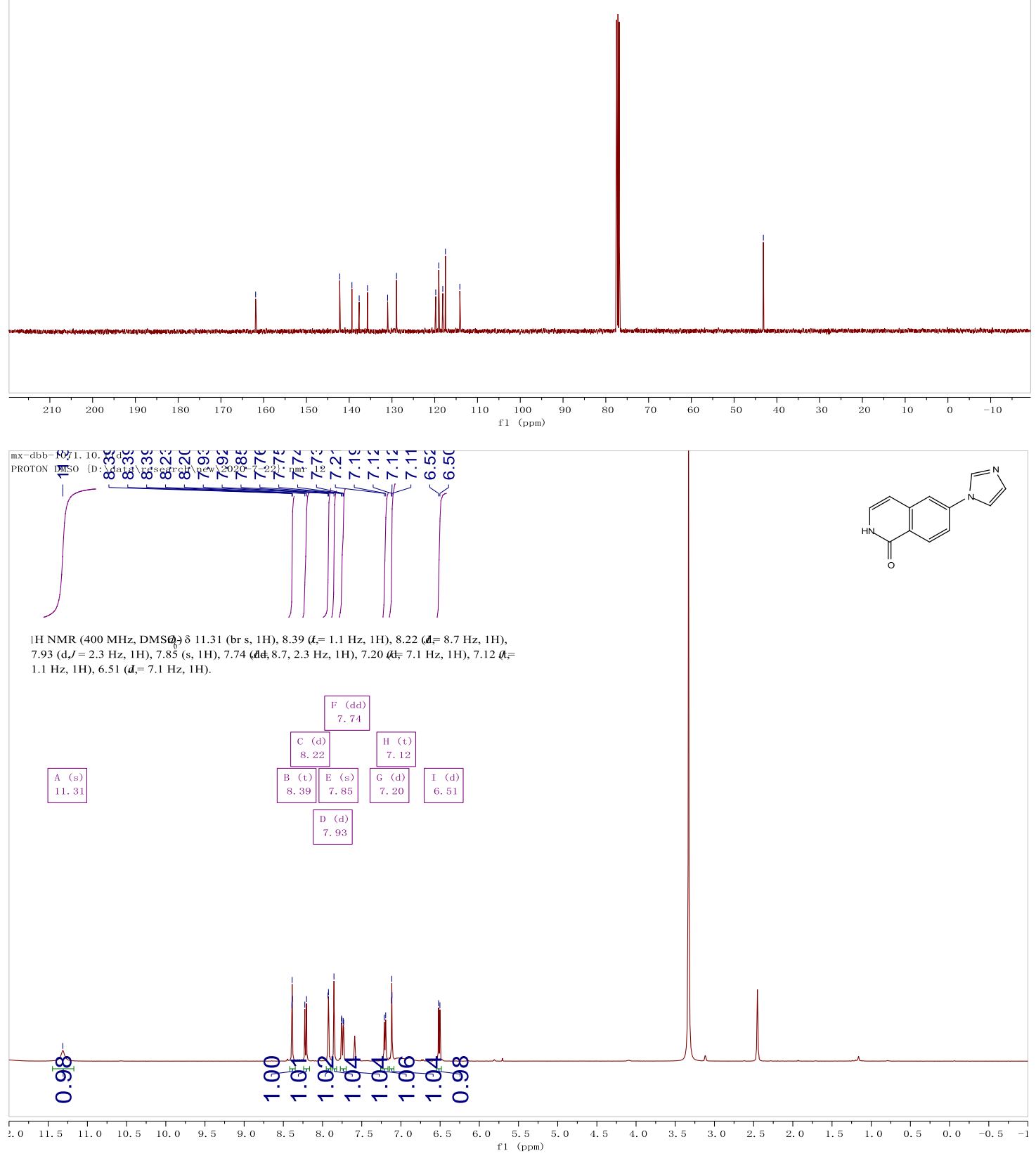

S25 

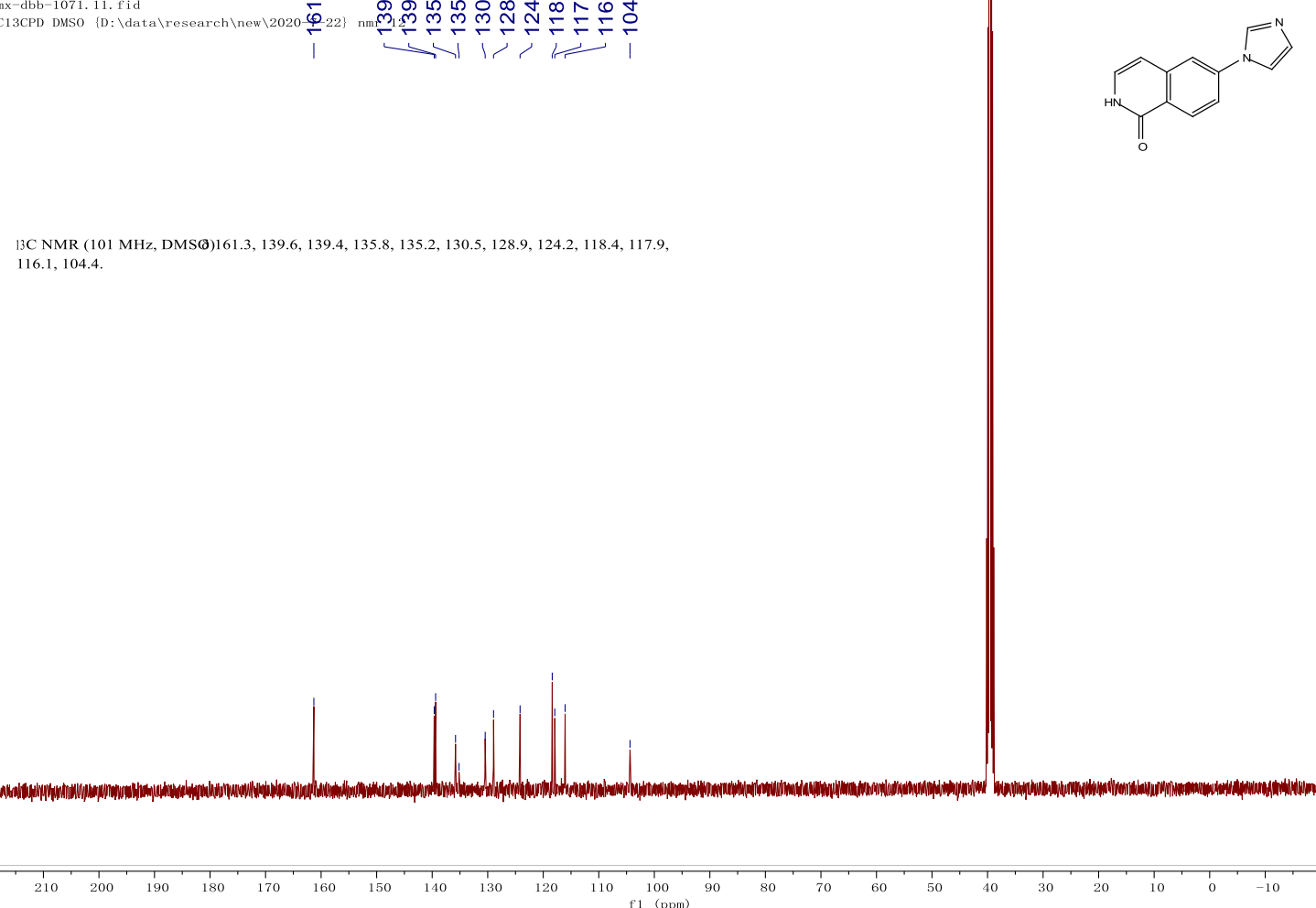

a mom

(1)

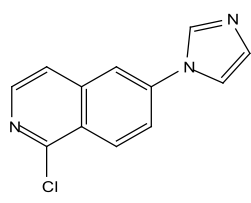

$1 \mathrm{H}$ NMR $(400 \mathrm{MHz}$, Chloroforde $-88.48(\mathrm{~d} J=9.0 \mathrm{~Hz}, 1 \mathrm{H}), 8.34(d=5.7 \mathrm{~Hz}, 1 \mathrm{H}), 8.05(\mathrm{t}=1.1$

$\mathrm{Hz}, 1 \mathrm{H}), 7.83(\mathrm{~d}=2.2 \mathrm{~Hz}, 1 \mathrm{H}), 7.75(\mathrm{~d} d=9.0,2.2 \mathrm{~Hz}, 1 \mathrm{H}), 7.64(\mathrm{dk}=5.7,0.8 \mathrm{~Hz}, 1 \mathrm{H}), 7.45$.

$=1.4 \mathrm{~Hz}, 1 \mathrm{H}), 7.29(\mathrm{t}=1.1 \mathrm{~Hz}, 1 \mathrm{H})$

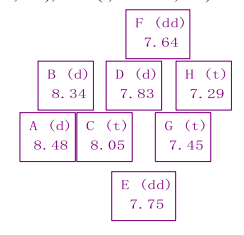

oos o no

$0.0 \% 000$

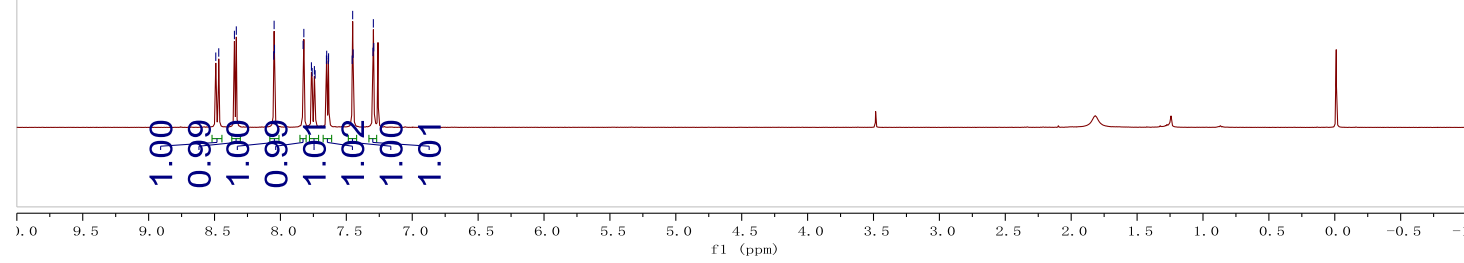



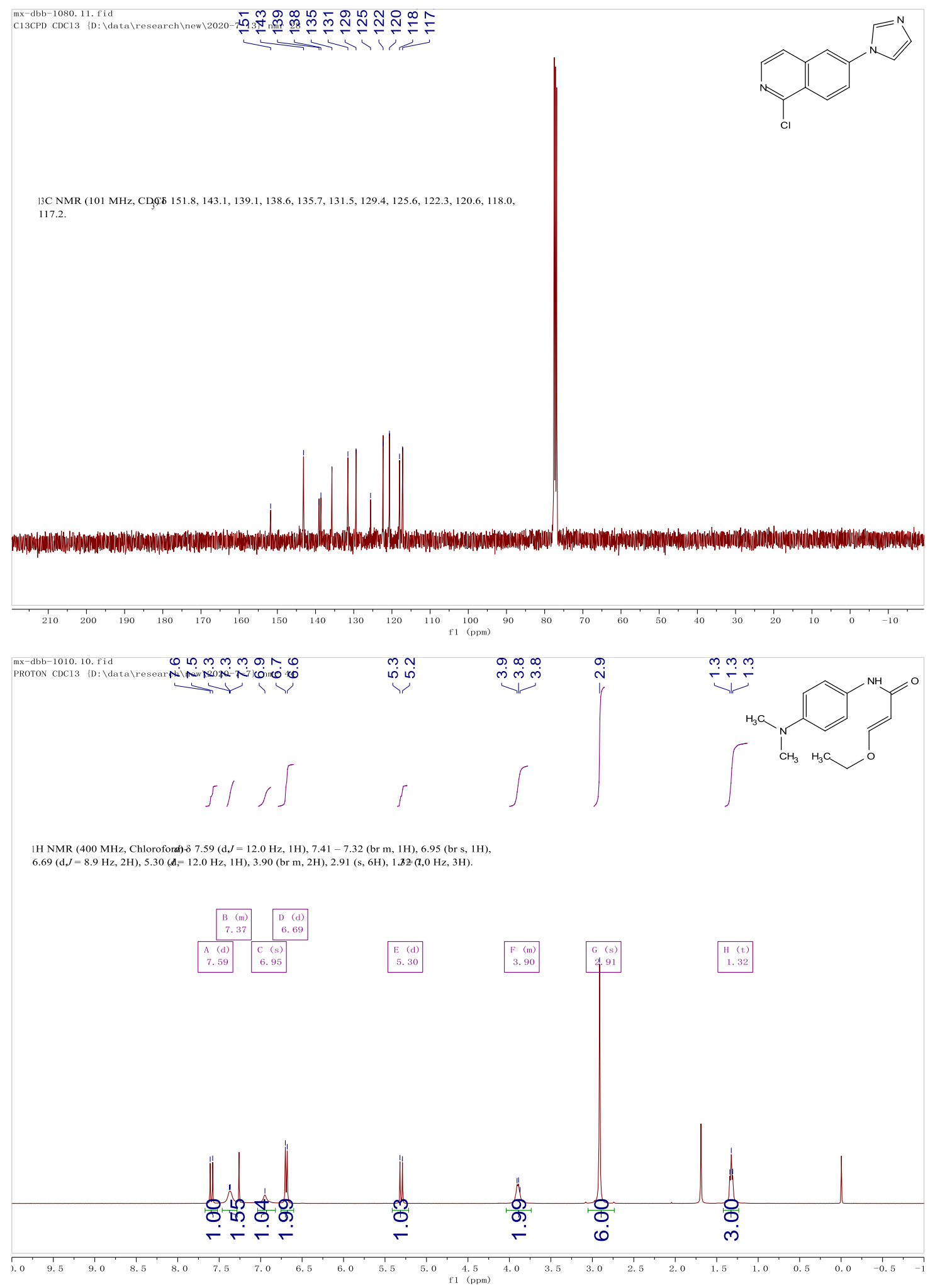


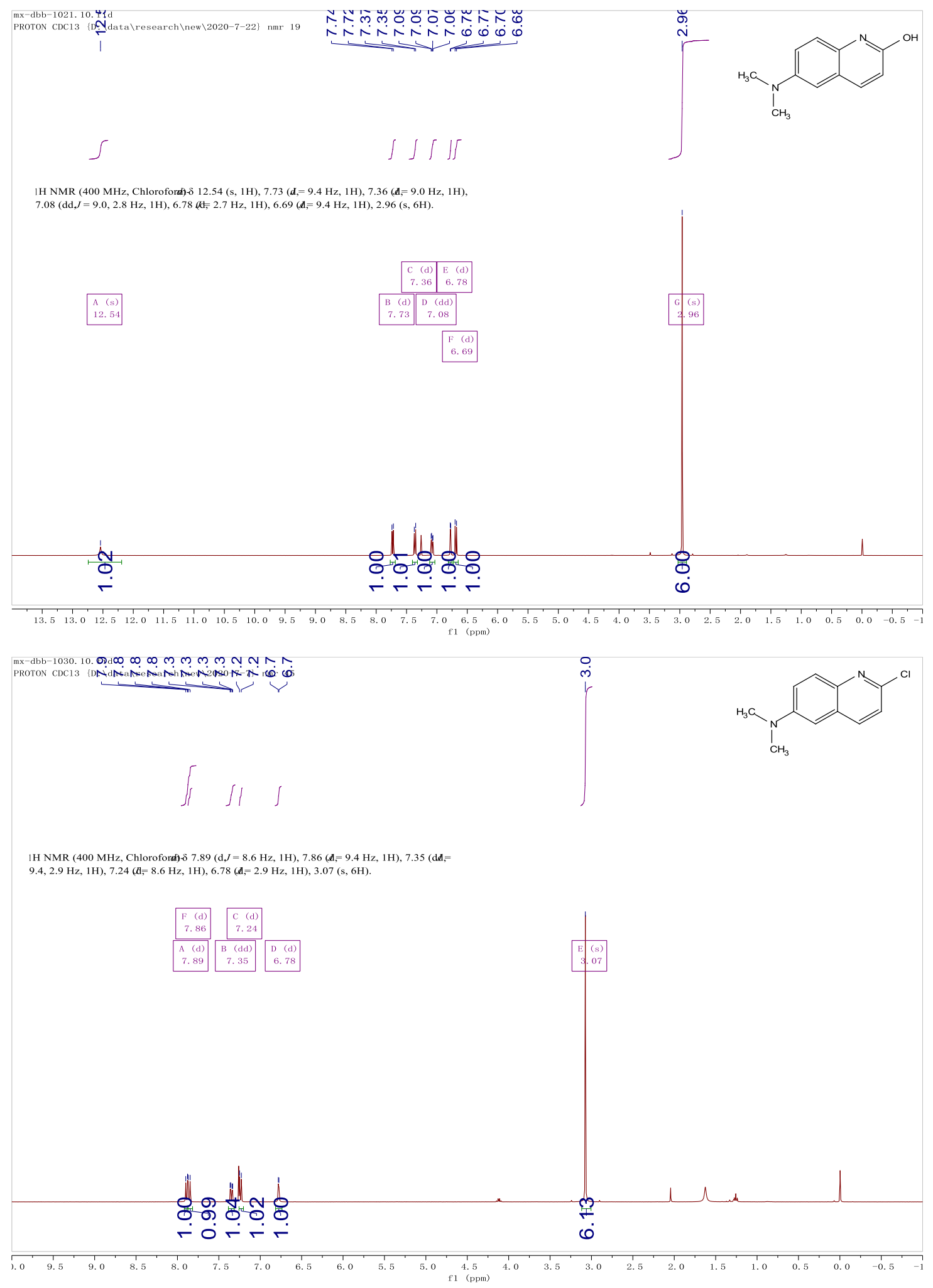




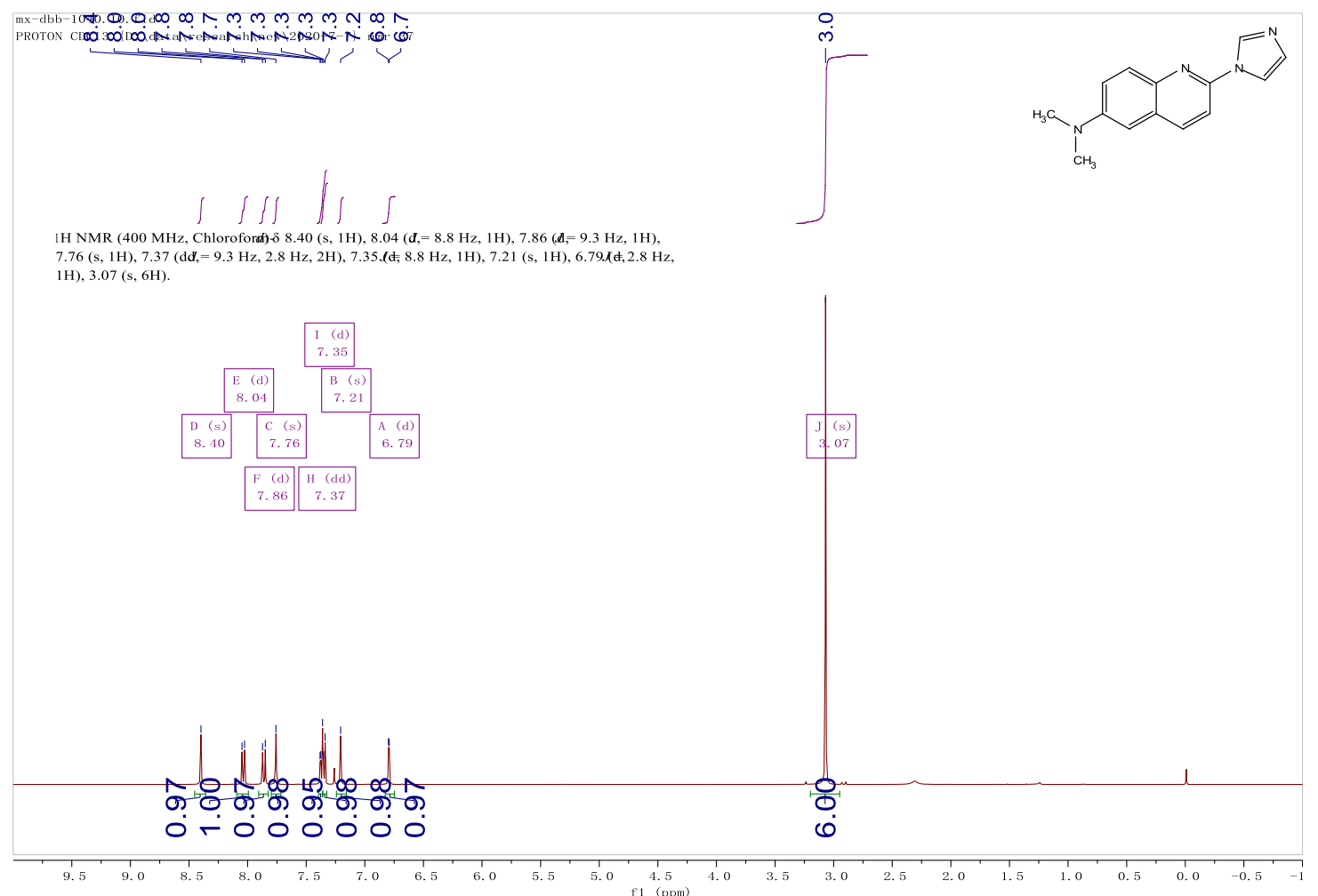

mx-dbb-1040. 11. fid

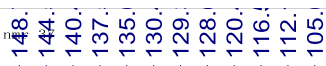

$\stackrel{\substack{r \\ \dot{q} \\ i}}{n}$

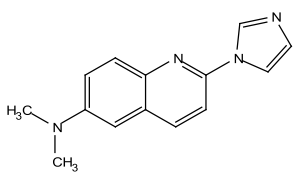

13C NMR (101 MHz, CDQ6 148.7, 144.5, 140.5, 137.5, 135.1, 130.4, 129.3, 128.6, 120.4, 116.5, $112.16,105.0,40.8$.
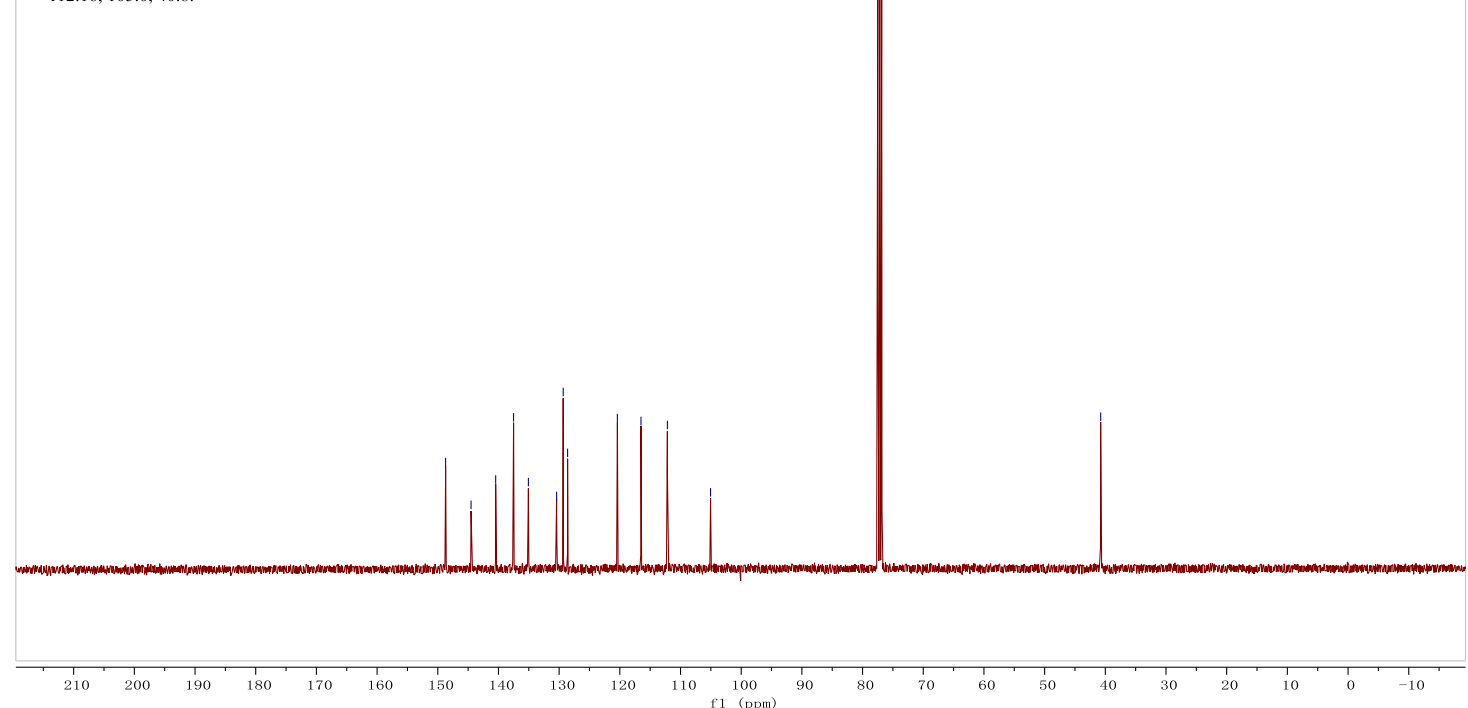


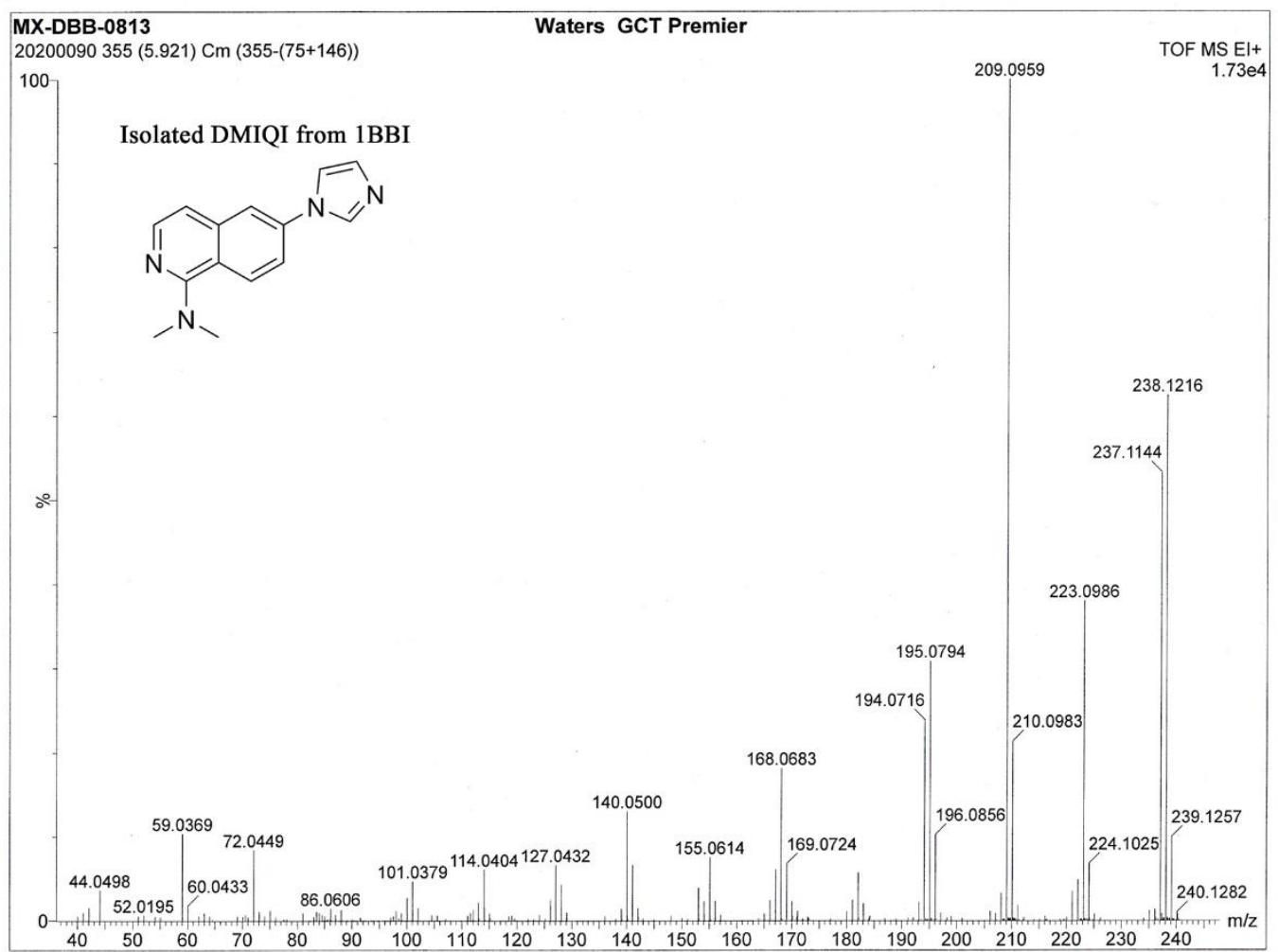

DMIQI

20200946329 (5.483) Cm (329-(32+70))

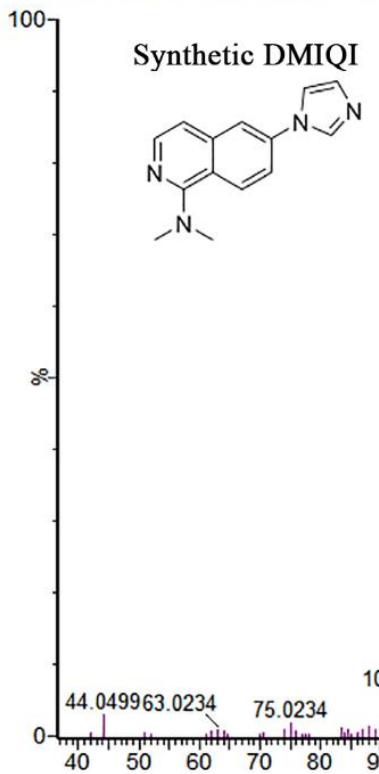

Waters GCTPremier

TOF MS El+ $1.39 \mathrm{e} 4$
239.1251

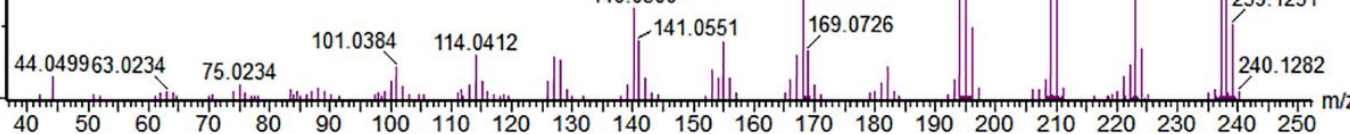




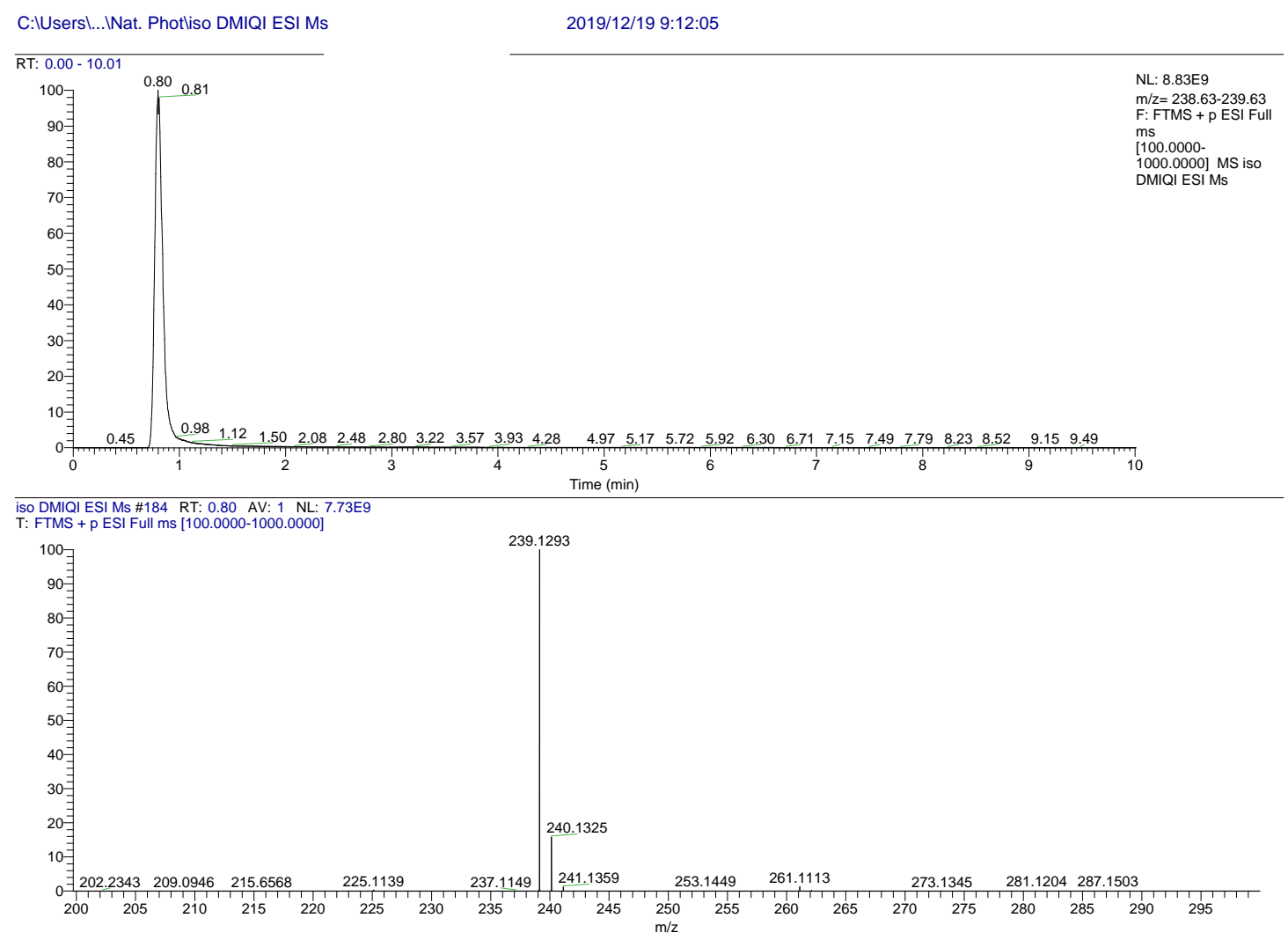

